\author{
UNIVERSIDADE DE SÃO PAULO \\ ESCOLA DE ENGENHARIA DE SÃO CARLOS \\ DEPARTAMENTO DE ENGENHARIA DE MATERIAIS
}

DAIANE BENADUCCI

Nanocompósitos de poliamida 6,6 reciclada reforçados com nanofibras de celulose para aplicação em peças automotivas

São Carlos

2014 



\title{
DAIANE BENADUCCI
}

Nanocompósitos de poliamida 6,6 reciclada reforçados com nanofibras de celulose para aplicação em peças automotivas

\author{
Dissertação apresentada ao Programa de \\ Pós-Graduação em Ciência e Engenharia \\ de Materiais da Universidade de São \\ Paulo para obtenção do título de Mestre \\ em Ciências.
}

Versão Corrigida (original na unidade)

Área de Concentração: Desenvolvimento, Caracterização e Aplicação de Materiais.

Orientadora: Profa. Dra. Márcia Cristina Branciforti.

São Carlos 
AUTORIZO A REPRODUÇÃO TOTAL OU PARCIAL DESTE TRABALHO, POR QUALQUER MEIO CONVENCIONAL OU ELETRO̊NICO, PARA FINS DE ESTUDO E PESQUISA, DESDE QUE CITADA A FONTE.

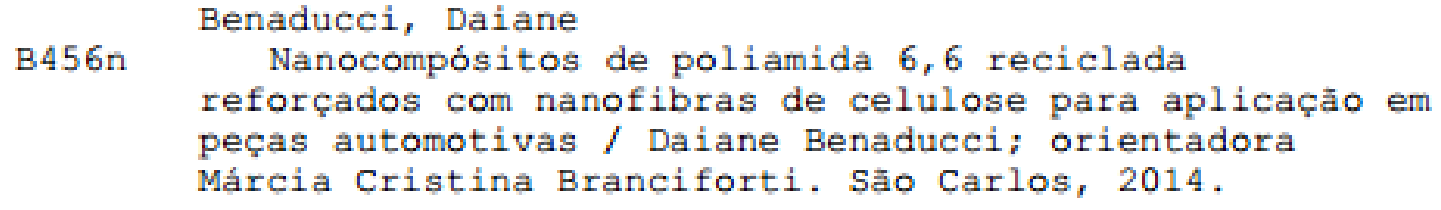

Dissertação (Mestrado) - Programa de Pós-Graduação em Ciências e Engenharia de Materiais e Área de Concentração em -- Escola de Engenharia de São Carlos da Universidade de São Paulo, 2014.

1. Nanocompósitos. 2. Nanofibras de celulose . 3. Poliamida 6,6 reciclada. I. Título. 


\section{FOLHA DE JULGAMENTO}

Candidata: Bacharel DAIANE BENADUCCI.

Título da dissertação: "Nanocompósitos de poliamida 6,6 reciclada reforçados com nanofibras de celulose para aplicação em peças automotivas".

Data da defesa: $15 / 01 / 2014$

Comissão Julgadora:

Prof. Associado Antônio José Félix de Carvalho (Orientador designado)

(Escola de Engenharia de São Carlos/EESC)

\section{Abroweur}

Dra. Ana Carolina Corrêa Bibbo

(Empresa Brasileira de Pesquisa Agropecuária/Embrapa)

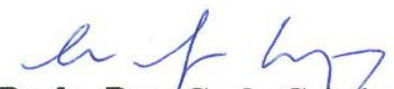

Profa. Dra. Carla Cristina Schmitt Cavalheiro

(Instituto de Química de São Carlos/IQSC)
Resultado:

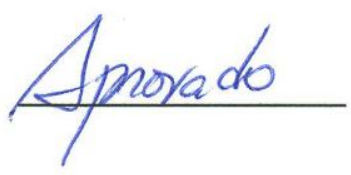

Aprovada

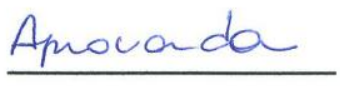

Coordenador do Programa de Pós-Graduação em Ciências e Engenharia de Materias:

Prof. Titular Waldek Wladimir Bose Filho

Presidente da Comissão de Pós-Graduação:

Prof. Titular Denis Vinicius Coury 

Dedico este trabalho a minha FAMÍLIA, por sempre estar presente $e$ ser meu grande alicerce. 



\section{AGRADECIMENTOS}

A Deus, por sempre me dar forças e colocar no meu caminho verdadeiros anjos da guarda.

A Profa. Dra. Márcia Cristina Branciforti pela orientação e oportunidade para realização desse trabalho.

Aos meus pais, Pedro Luiz e Maria Arlene, pela confiança que sempre depositaram em mim, pelo amor incondicional e por me darem uma família linda.

As minhas irmãs, Tatiane e Josiane, por sempre estarem ao meu lado, por todo carinho e por serem o que eu tenho de melhor na vida.

Ao meu colega de grupo, amigo e namorado, José Alexandre. Cada página conquistada desse trabalho foi por ter ao meu lado alguém tão especial. Obrigada por cada lágrima enxugada, por cada sorriso conquistado e por não ter me deixado desistir em momento algum.

Aos meus grandes e sinceros amigos, Thiago e Fernanda, que mesmo longe se fizeram presentes, sempre torcendo por mim e me incentivando.

A todos os amigos que souberam me dar disposição para continuar, àqueles que souberam me dar o conforto do silêncio e um ombro quando precisei e a todos aqueles que proporcionaram momentos simplesmente inesquecíveis de muitas risadas.

Ao aluno de Doutorado e amigo Vitor Brait Carmona pela troca de experiências e contribuições dadas ao trabalho.

Ao CNPq pelo apoio financeiro.

Ao Centro de Biocompósitos e Processamento de Biomateriais da Universidade de Toronto, Canadá, e a empresa Rhodia Poliamida e Especialidades Ltda, Brasil, 
por cederem as nanofibras de celulose e as poliamidas, respectivamente, para realização do trabalho.

Ao Prof. Dr. Antônio José Felix de Carvalho, pelas discussões e todo apoio.

A UNICAMP e ao Grupo de Físico-Química dos Polímeros pelo uso da miniextrusora e da mini- injetora, principalmente as alunas Laura e Rose pelo suporte.

Ao secretário da Pós-Graduação do Departamento de Engenharia de Materiais, Victor Luiz Barioto, por toda atenção e paciência.

Aos demais funcionários do Departamento de Engenharia de Materiais, por toda a ajuda proporcionada durante as análises. 
"Todo dia é uma ocasião especial. Guarde apenas o que tem que ser guardado: lembranças, sorrisos, poemas, cheiros, saudades, momentos." 



\section{RESUMO}

BENADUCCI, D. Nanocompósitos de poliamida 6,6 reciclada reforçados com nanofibras de celulose para aplicação em peças automotivas. 2014. 86p. Dissertação (Mestrado) - Escola de Engenharia de São Carlos, Universidade de São Paulo, São Paulo, 2014.

A busca é cada vez maior por parte das indústrias para encontrar alternativas de uso para seus materiais de descarte. Considerando as vantagens da aplicação da poliamida 6,6 reciclada (PA66Rec), material de descarte da empresa Rhodia Poliamida e Especialidades Ltda, o principal objetivo do trabalho foi a obtenção e caracterização de nanocompósitos a partir desse polímero sintético. Este material possui elevada temperatura de fusão e por esse e outros motivos, como o fato de possuírem mesma polaridade, as nanofibras de celulose (NFC) tornaram-se excelentes candidatas como reforço para essa matriz de poliamida 6,6. As poliamidas 6,6 são amplamente utilizadas na indústria automobilística, porém apesar desse grande interesse tecnológico nas mesmas, poucos estudos de compósitos poliméricos poliamida 6,6/celulose foram publicados. A fim de comparar os resultados obtidos foram preparados também nanocompósitos com matriz de poliamida obtida a partir de resina virgem (PA66) reforçados com NFC. Neste trabalho as NFC foram dispersas em ácido fórmico e a essa suspensão a matriz polimérica foi solubilizada. Foi considerado um branco desse préprocessamento, sem NFC, para comparação. As amostras foram então processadas por extrusão e moldagem por injeção. As propriedades mecânicas, térmicas e morfológicas foram caracterizadas utilizando ensaio de tração, calorimetria exploratória diferencial (DSC), análise termogravimétrica (TG) e microscopia eletrônica de varredura (MEV). Os resultados de TG confirmaram a menor estabilidade térmica das amostras com NFC em relação as sem NFC. Os resultados de DSC das amostras obtidas com a PA66Rec indicaram que o préprocessamento e a adição de 1 e $2 \%$ em massa de NFC não modificaram significativamente as temperaturas de fusão e cristalização. $O$ grau de cristalinidade da amostra com maior teor de NFC diminuiu, entretanto as imagens de MEV mostraram as NFC bem ancoradas na matriz e os resultados de ensaio mecânico revelaram que a adição de 1 e $2 \%$ de NFC levou a um aumento de $10 \%$ do módulo elástico, em média. Para as amostras obtidas com a PA66 a adição de NFC levou a um aumento do grau de cristalinidade de 16 para 23\%, em média, justificando o aumento de $15 \%$ do módulo elástico encontrado no ensaio mecânico de tração. As imagens de MEV para todas as amostras revelaram a boa incorporação da NFC nas matrizes, bem como a boa dispersão das mesmas. Tanto o pré-processamento como a incorporação das NFC não prejudicou o módulo elástico e a resistência máxima à tração, podendo indicar uma alternativa de uso para poliamida 6,6 reciclada, dependendo da aplicação final do material.

Palavras-chave: Nanocompósitos, Nanofibras de celulose, Poliamida 6,6 reciclada. 



\begin{abstract}
BENADUCCI, D. Nanocomposite of recycled polyamide 6,6 reinforced with cellulose nanofibers for application in automotive parts. 2014 . 86p. Dissertação (Mestrado) - Escola de Engenharia de São Carlos, Universidade de São Paulo, São Paulo, 2014.
\end{abstract}

The search by industry to find alternative uses for its materials disposal is increasing. Considering the advantages application of recycled polyamide 6,6 (PA66Rec), disposal material of Rhodia Polyamide and Specialities Ltd company, the main objective of the work was to obtain and characterize nanocomposites from this synthetic polymer. This material has a high melting temperature and for this and other reasons, like the fact that they have the same polarity, the cellulose nanofibers (CNF) have become excellent candidates as reinforcement to the matrix polyamide 6,6 . The polyamides 6,6 are widely used in the automotive industry, but despite this great technological interest in them, few studies of polymer composite polyamide 6,6/cellulose were published. In order to compare the results obtained nanocomposites were also prepared with polyamide matrix obtained from virgin resin (PA66) reinforced with NFC. In this work the CNF were dispersed in formic acid and the polymer matrix was solubilized in this suspension. It was considered a control sample without CNF for this preprocessing for comparison. Then, the samples were processed by extrusion and injection molding. The mechanical, thermal and morphological properties were characterized using tensile test, differential scanning calorimetry (DSC), thermogravimetric analysis (TG) and scanning electron microscopy (SEM). The TG results confirmed the lower thermal stability of the samples with CNF compared with those without CNF. The DSC results obtained from the PA66Rec samples indicated that preprocessing and the addition of 1 and $2 \%$ mass fraction of CNF not significantly changes in melt and crystallization temperatures. The degree of crystallinity of the sample with a higher content of NFC decreased, however the SEM images showed the CNF well anchored in the matrix and the results of mechanical test showed that the addition of 1 and $2 \%$ NFC led to a $10 \%$ increase in the elastic modulus. For the samples obtained with PA66 the addition of CNF led to an increase in the degree of crystallinity of 16 to $23 \%$, on average, justifying the $15 \%$ increase in the elastic modulus found in mechanical tests. The SEM images for all the samples showed good incorporation in the matrix of CNF and the good dispersion thereof. Any preprocessing such as the incorporation of NFC did not impair the elastic modulus and maximum tensile strength, and may indicate an alternative use for recycled polyamide 6,6, depending on the final application of the material.

Key-words: Nanocomposites, Cellulose Nanofibers, Recycled Polyamide 6,6. 



\section{LISTA DE FIGURAS}

Figura 1. Consumo per capita de produtos plásticos no mundo em $\mathrm{Kg} / \mathrm{hab}$ (ABIPLAST, 2012).

Figura 2. Porcentagem de conteúdo plástico em veículos automotivos (VALÊNCIO, 2012).

Figura 3. (a) Suporte do painel de controle dianteiro do novo Golf 7; (b) Suporte do motor de seis cilindros do novo GL Class; (c) Reservatório de óleo do novo motor do Peugeot 508; (d) Tampa do eixo central para motores do Grupo Volkswagen; (e) Tampa do motor do Mercedes Benz Classe A (BLOG DO PLÁSTICO, 2013).....

27

Figura 4. (a) Partes do interior do Mercedes Classe A; (b) Aplicação das fibras naturais em diferentes partes de um veículo automotor (JAWAID; KHALIL, 2011;

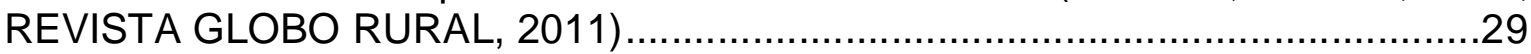

Figura 5. Estrutura da celobiose (FENGEL, 1989)............................................

Figura 6. Obtenção das nanofibras de celulose (NFC) ..........................................34

Figura 7. Esquema da reação de obtenção do Nylon-6,6......................................36

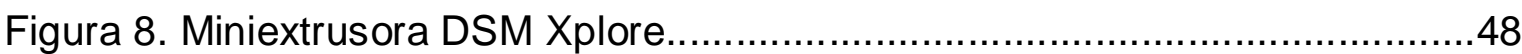

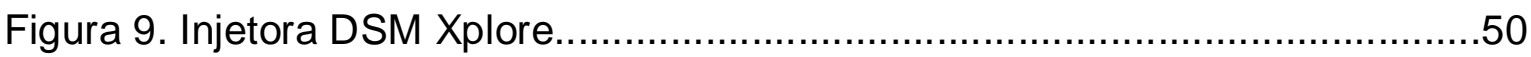

Figura 10. Espectro na região de infravermelho da NFC.....................................53

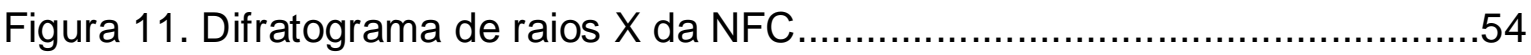

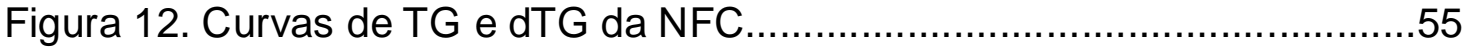

Figura 13. Microscopia eletrônica de transmissão da NFC [gentilmente cedida pelo grupo do Prof. Sain] .............................................................................56

Figura 14. Curvas de TG e dTG da PA66Rec..............................................57

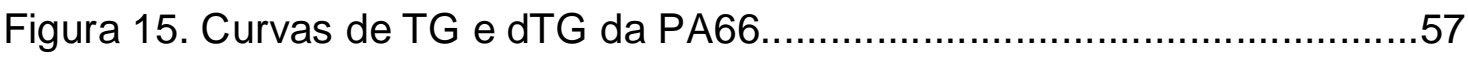

Figura 16. Curva de DSC da PA66 e da PA66Rec...........................................58

Figura 17. Corpos de prova das amostras obtidos após o processamento............59

Figura 18. Curvas de (a) TG e (b) dTG para as amostras com PA66Rec.............60

Figura 19. Curvas de (a) TG e (b) dTG para as amostras com PA66...............61

Figura 20. Curvas DSC para as amostras obtidas com PA66Rec: (a) resfriamento (b) segundo aquecimento. 
Figura 21. Curvas DSC para as amostras obtidas com a PA66: (a) resfriamento

(b) segundo aquecimento 64

Figura 22. Curva tensão-deformação para os corpos de prova obtidos com PA66Rec. 65

Figura 23. (a) Módulo elástico, (b) Resistência à tração e (c) Deformação máxima para os corpos de prova obtidos com a PA66Rec 66

Figura 24. Curva tensão-deformação para os corpos de prova obtidos com PA66.

Figura 25. (a) Módulo elástico, (b) Resistência à tração e (c) Deformação máxima para os corpos de prova obtidos com a PA66. 68

Figura 26. Micrografias das superfícies de fratura dos corpos de prova obtidos com a PA66Rec: (a) PPA66Rec, (b) e (c) NPA66Rec-2F 69

Figura 27. Micrografias das superfícies de fratura dos corpos de prova obtidos com a PA66: (a) PPA66, (b) e (c) NPA66-2F. .70

Figura 1A. Curvas DSC para as amostras obtidas com PA66Rec 83

Figura 2A. Curva do primeiro aquecimento do DSC das amostras obtidas com PA66Rec. .83

Figura 1B. Curvas DSC para as amostras obtidas com PA66 84

Figura 2B. Curva do primeiro aquecimento do DSC das amostras obtidas com PA66Rec. 


\section{LISTA DE TABELAS}

Tabela 1. Nomenclaturas para nanoceluloses a partir da fonte e dos processos de obtenção (KLEMM et al., 2011)

Tabela 2. Composição das NFC (ALEMDAR; SAIN, 2008a; ALEMDAR; SAIN, 2008b) 45

Tabela 3. Propriedades características da PA66 ...........................................45

Tabela 4. Formulação das amostras estudadas. 49

Tabela 5. Parâmetros do processamento de extrusão considerados para as amostras.

Tabela 6. Parâmetros do processamento de moldagem por injeção considerados para as amostras. 49

Tabela 7. Principais bandas observadas no espectro na região do infravermelho da NFC e seus respectivos modos vibracionais [Silverstein, 2007; ALEMDAR; SAIN, 2008a; MORELLI et al., 2012] .53

Tabela 8. Propriedades térmicas obtidas a partir do DSC da PA66 e da PA66Rec. 59

Tabela 9. Parâmetros da curva TG/dTG das as amostras com PA66Rec........60

Tabela 10. Parâmetros da curva TG/dTG das amostras com PA66. 61

Tabela 11. Propriedades térmicas a partir do DSC das amostras obtidas com PA66Rec 63

Tabela 12. Propriedades térmicas a partir do DSC das amostras obtidas com PA66. .65

Tabela 13. Propriedades mecânicas das amostras obtidas com PA66Rec 67

Tabela 14. Propriedades mecânicas das amostras obtidas com PA66. 68 



\section{SUMÁRIO}

1. INTRODUÇÃO

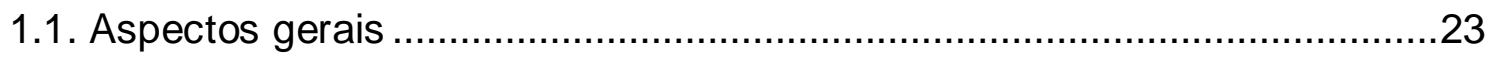

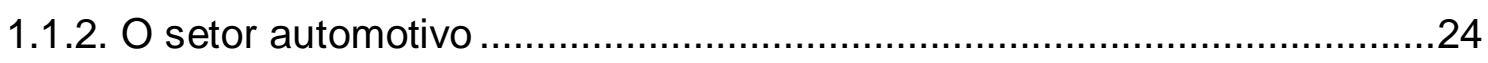

1.2. Compósitos de matriz polimérica................................................................28

1.3. Fibras naturais como agentes de reforço em compósitos de matriz

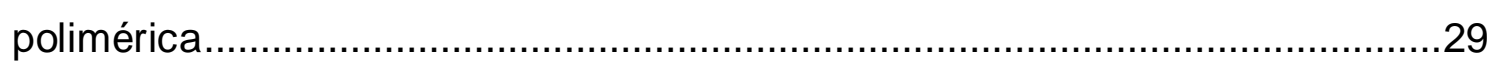

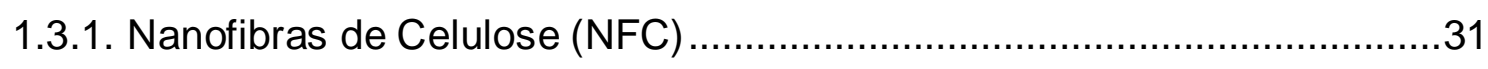

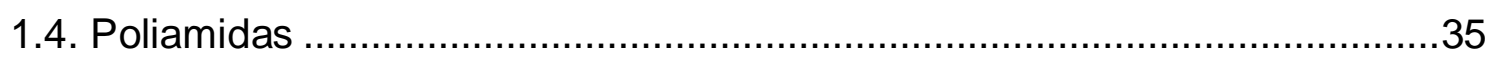

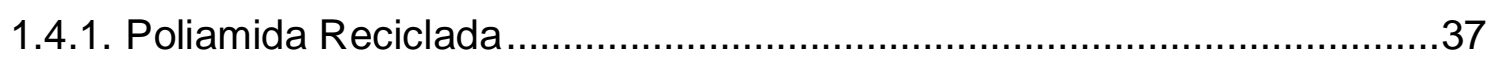

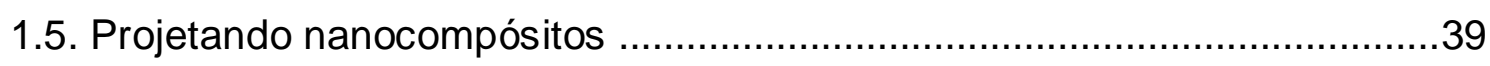

1.6. Caracterização de compósitos reforçados com fibras naturais ...................40

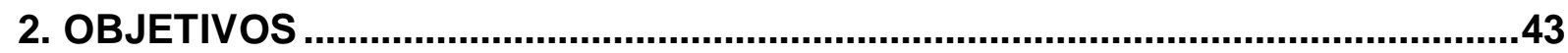

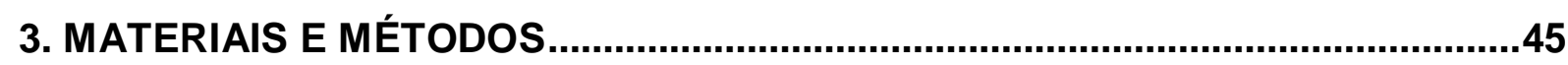

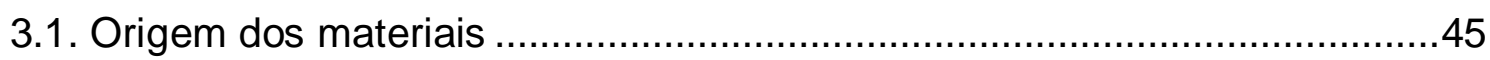

3.2. Caracterização das Nanofibras de Celulose (NFC) e das Poliamidas

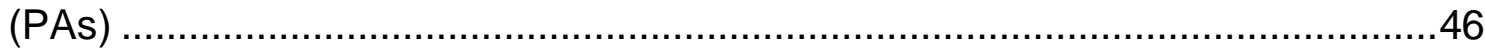

3.2.1. Espectroscopia na região do infravermelho (IV) ....................................46

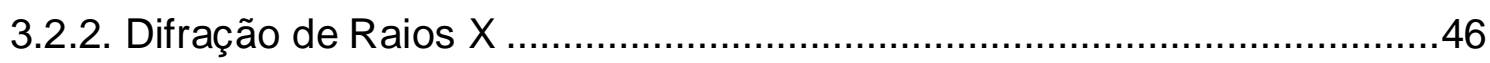

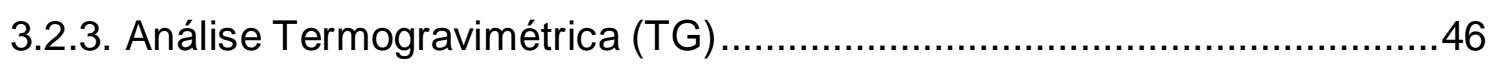

3.2.4. Calorimetria Exploratória Diferencial (DSC) ...........................................47

3.3. Obtenção das amostras processados via extrusão e moldagem por

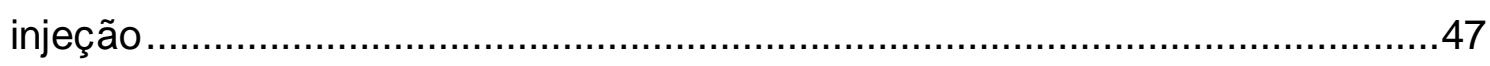

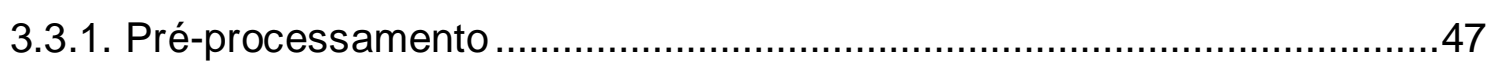

3.3.2. Extrusão e Moldagem por Injeção .........................................................48

3.4. Caracterização das amostras processadas via extrusão e moldagem por

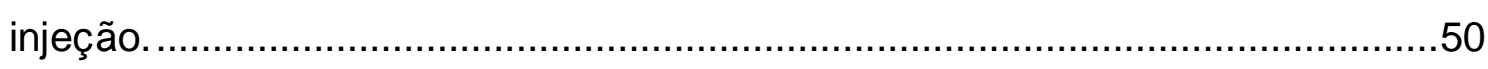

3.4.1. Análise Termogravimétrica (TG) .......................................................50

3.4.2. Calorimetria Exploratória Diferencial (DSC) ........................................50 


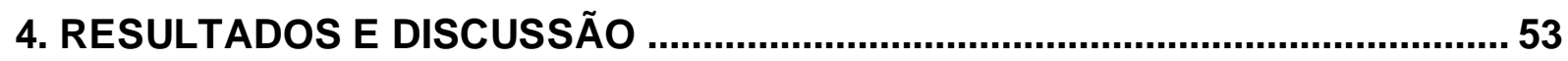

4.1. Caracterização das nanofibras de celulose (NFC) ................................... 53

4.1.1. Espectroscopia na região do infravermelho (IV) .................................. 53

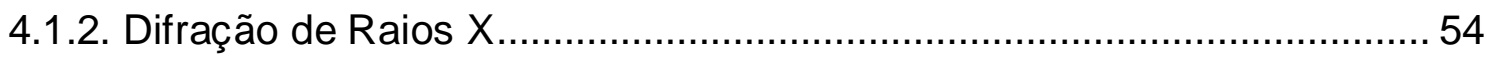

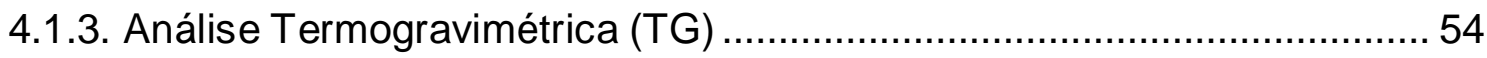

4.1.4. Microscopia Eletrônica de Transmissão (MET) ……………………..... 55

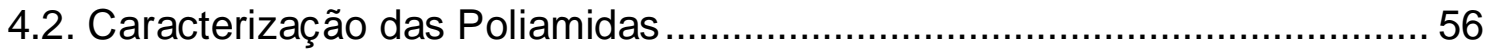

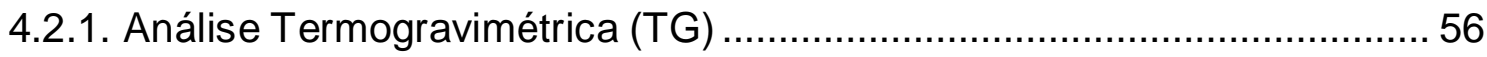

4.2.2. Calorimetria Exploratória Diferencial (DSC) …….................................... 58

4.3. Obtenção e caracterização das amostras estudadas ................................. 59

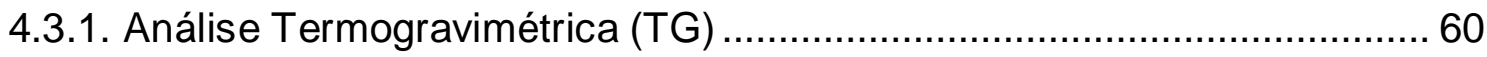

4.3.2. Calorimetria Exploratória Diferencial (DSC) ………………................ 62

4.3.3. Ensaio Mecânico de Tração .................................................................... 65

4.3.4. Microscopia Eletrônica de Varredura (MEV) .......................................... 69

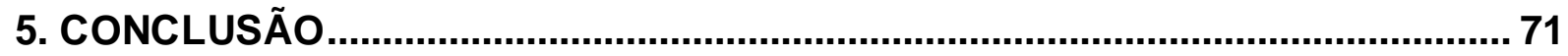

6. SUGESTÕES PARA FUTUROS TRABALHOS ................................................. 73

6. REFERÊNCIAS BIBLIOGRÁFICAS ..........................................................75

APÊNDICE A - CURVAS DSC PARA AS AMOSTRAS OBTIDAS COM

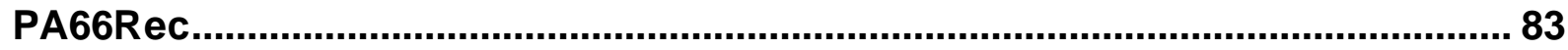

APÊNDICE B - CURVAS DSC PARA AS AMOSTRAS OBTIDAS COM PA66...... 84 




\section{INTRODUÇÃO}

\subsection{Aspectos gerais}

O uso desenfreado de produtos derivados do petróleo traz consequências, como o esgotamento de recursos petrolíferos e a detenção de plásticos na cadeia alimentar e no meio ambiente (JOHN; THOMAS, 2008). A ABIPLAST - Associação Brasileira da Indústria do Plástico - divulgou o consumo per capita de produtos plásticos no mundo em 2005, com uma previsão para 2015 (Figura 1).

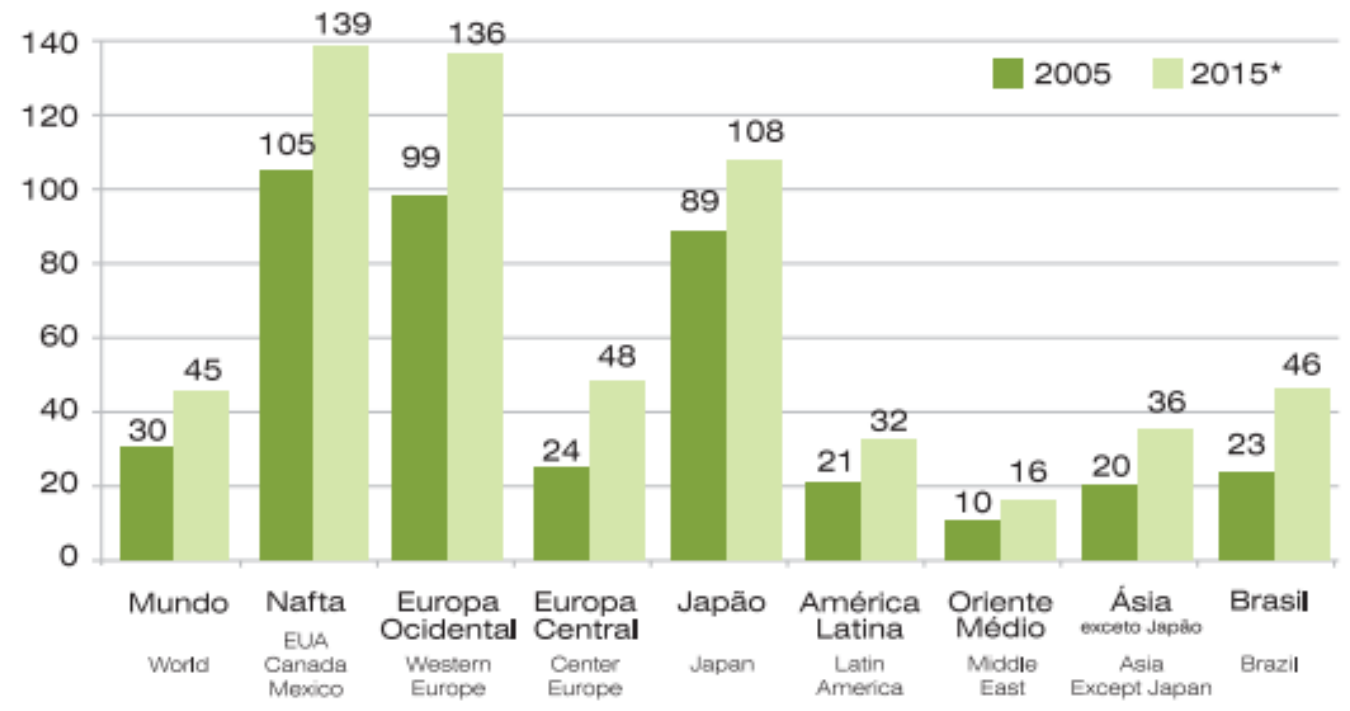

Figura 1. Consumo per capita de produtos plásticos no mundo em $\mathrm{Kg} / \mathrm{hab}$ (ABIPLAST, 2012).

Com regulamentações governamentais cada vez mais rigorosas e uma consciência ambiental crescente em todo o mundo há um interesse simultâneo no desenvolvimento de produtos e tecnologias de processo que sejam inovadores e que possam reduzir a dependência de combustíveis fósseis e gerar materiais compatíveis ao meio ambiente.

Atualmente, uma solução viável tem sido a combinação de recursos petrolíferos e de base biológica para desenvolver um produto rentável com boas aplicações. Um exemplo são os polímeros reforçados com fibras naturais, derivadas a partir de recursos renováveis, como uma boa alternativa para compósitos de fibra de vidro, proporcionando benefícios ambientais positivos (JOHN; THOMAS, 2008; KARNANI; KRISHNAN; NARAYAN, 1997). Compósitos de matriz termoplástica reforçados com fibras naturais tem recebido uma crescente atenção por parte das 
indústrias em um amplo campo de aplicação, tais como automotivo, construção, aeroespacial e de embalagem (ARRAKHIZ et al., 2012).

Os seis primeiros meses de 2012 conferiram a indústria de materiais compósitos um faturamento de $\mathrm{R} \$ 1,502$ bilhão, 5,9\% maior comparado ao registrado entre janeiro e julho passados. Pelas previsões divulgadas, o consumo de compósitos deve atingir neste ano 216 mil toneladas, um acréscimo de 3,8\% sobre 2012 (RETO, 2012a).

Em paralelo a esse cenário, pesquisadores têm focado seus trabalhos no processamento de nanocompósitos, devido aos fortes efeitos de reforço a uma fração de volume baixo (ALI; ELLEITHY, 2011; JOHN; THOMAS, 2008; SIQUEIRA; BRAS; DUFRESNE, 2009). Na nanoescala surgem novos fenômenos que não aparecem na macroescala. Esta alteração de comportamento está relacionada com as forças naturais fundamentais que mudam de importância quando a escala é reduzida (DURÁN; MATTOSO; MORAIS, 2006).

No presente estudo, nanocompósitos de matriz polimérica (termoplástica de engenharia) reforçados com nanofibras de celulose (NFC) foram considerados.

\subsubsection{O setor automotivo}

Os plásticos de engenharia são capazes de oferecer elevada resistência química, mecânica e térmica em setores de alta tecnologia, como o setor de eletroeletrônicos e automotivo, foco do presente trabalho. Esses plásticos são utilizados progressivamente como alternativa aos metais, vidros e outros materiais, resultando em significativa redução no peso do material final e aumento na flexibilidade de design dos mesmos, o que possibilita projetos diferenciados. No caso dos automóveis a redução de peso faz com que a emissão de $\mathrm{CO}_{2}$ seja reduzida, aumentando assim a sustentabilidade.

Uma vantagem adicional para as montadoras no setor automotivo é o aumento na vida útil das peças, sinônimo de prazos de garantia maiores, e ainda pelas melhorias de produtividade, conquistadas com a eliminação de pinturas ou redução de operações secundárias como soldagem, colagem, fixações, entre outras (RETO, 2012b).

A busca pelos benefícios que os plásticos de engenharia promovem e 0 mercado atual encorajam a evolução tecnológica dessas resinas, resultando em 
contínuos desenvolvimentos voltados para o setor. A América do Sul ocupa o quarto lugar no mercado de vendas de veículos e sexto lugar em produção automotiva. $O$ mercado nacional apresenta elevado potencial de crescimento, sendo a relação habitante/automóvel de 8,6, enquanto que nos EUA é de 1,2 (RETO, 2012b). Entre 2012 e 2015, os programas de investimento do setor no Brasil estão na ordem $R \$ 22$ bilhões (MINISTÉRIO DA FAZENDA, 2012).

Um levantamento recente, produzido pela consultoria A.T. Kearney (Figura 2), indica que a porcentagem de conteúdo plástico de qualquer carro pode chegar a 20\% do seu peso até 2020 - um número que está mostrando uma tendência ascendente (VALÊNCIO, 2012). Um exemplo (Figura 3a) é o suporte do painel de controle dianteiro do novo Golf 7 que esta sendo fabricado totalmente com plástico, no caso, uma poliamida altamente reforçada ( $45 \%$ de fibra de vidro). As peças anteriormente feitas de placas de aço conectadas foram eliminadas, reduzindo assim o peso do módulo dianteiro significativamente em comparação ao do modelo anterior. Reduziu-se também o tempo de montagem e, consequentemente, os custos (BAFILE, 2013).

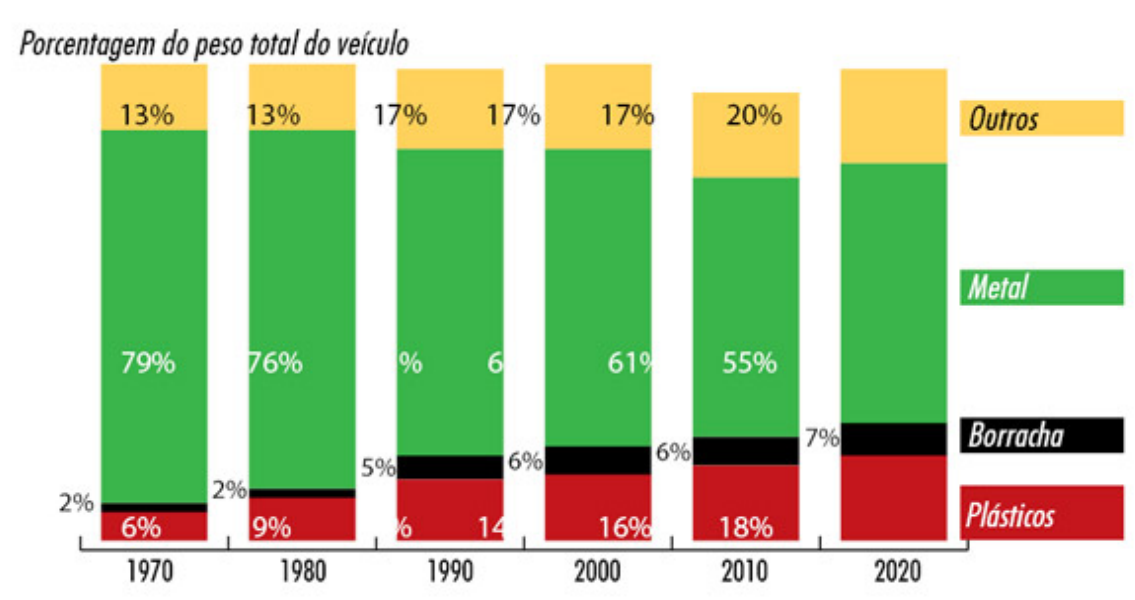

Figura 2. Porcentagem de conteúdo plástico em veículos automotivos (VALÊNCIO, 2012).

O uso de termoplásticos e compósitos não se limita mais aos carros de passeio. Veículos com menor volume de produção de massa, caso dos caminhões, utilitários e ônibus, também estão no alvo das indústrias química e automobilística (VALÊNCIO, 2012). No mercado de maior volume de veículos, mais da metade deles é formada por termoplásticos ou compósitos. Na figura 3 são apresentados alguns 
exemplos de peças do setor automotivo que atualmente utilizam compósitos com matriz de poliamida, considerada no presente trabalho (BLOG DO PLÁSTICO, 2013). A Daimler, empresa automobilística alemã, está instalando o primeiro suporte de plástico do mundo (poliamida 6,6 da BASF reforçada com $50 \%$ de fibra de vidro) no motor a diesel de seis cilindros utilizado no novo GL Class (Figura 3b). Em comparação com o suporte de alumínio anterior, a peça de plástico oferece melhores propriedades acústicas, características superiores de isolamento térmico e uma vantagem positiva de peso. Uma poliamida $6 \mathrm{com} 35 \%$ de fibra de vidro da Royal DSM foi utilizada no reservatório de óleo do novo motor do Peugeot 508 (Figura 3c). A tampa do eixo central para a mais recente geração de motores diesel desenvolvidos pelo Grupo Volkswagen (Figura 3d) e a tampa do motor do Mercedes Benz Classe A (Figura 3e) são fabricados com uma poliamida 4,10 também da Royal DSM, que contem $10 \%$ de fibra de vidro e $20 \%$ de partículas minerais. 


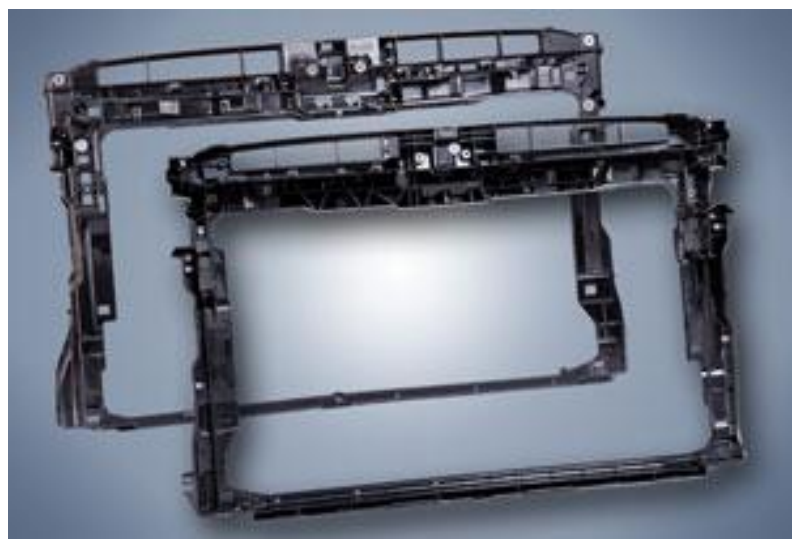

(a)

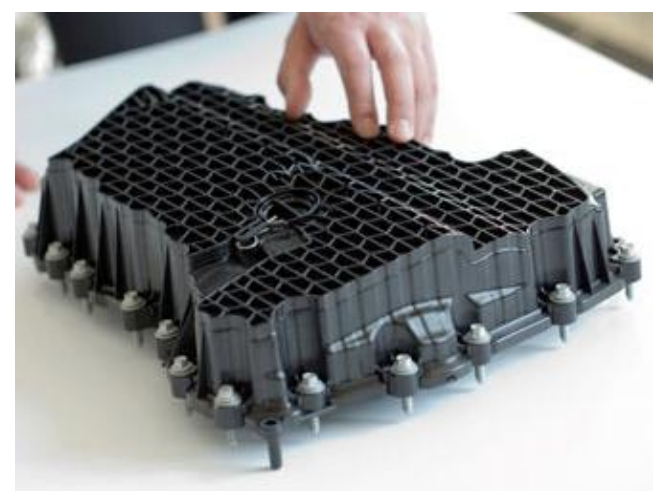

(c)

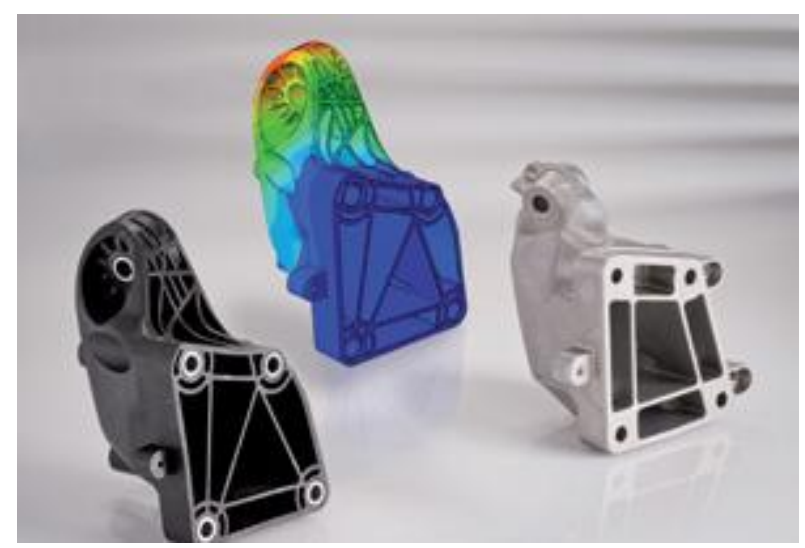

(b)

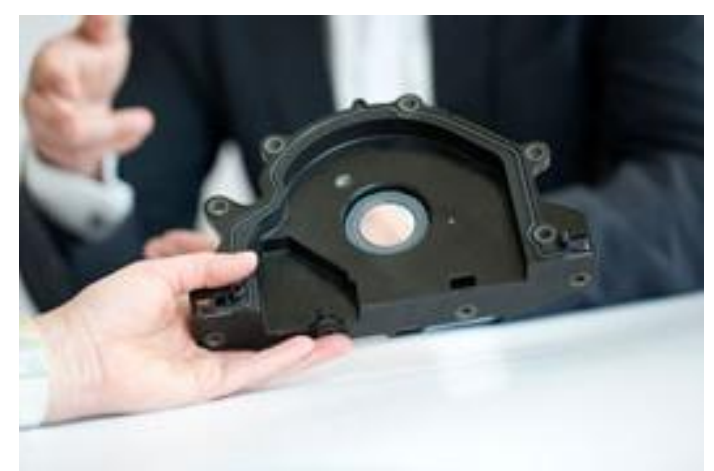

(d)

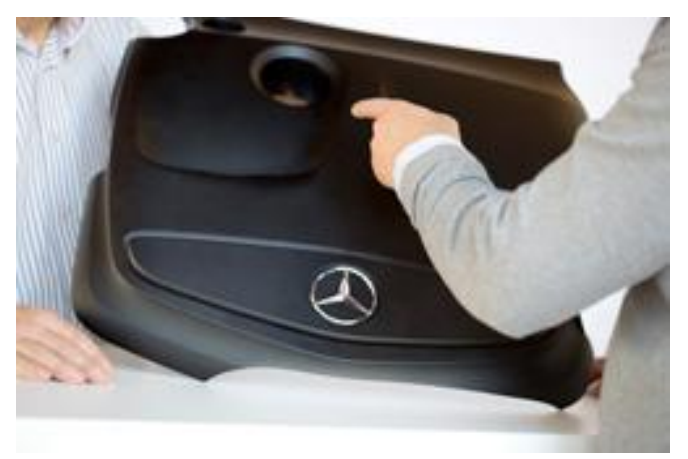

(e)

Figura 3. (a) Suporte do painel de controle dianteiro do novo Golf 7; (b) Suporte do motor de seis cilindros do novo GL Class; (c) Reservatório de óleo do novo motor do Peugeot 508; (d) Tampa do eixo central para motores do Grupo Volkswagen; (e) Tampa do motor do Mercedes Benz Classe A (BLOG DO PLÁSTICO, 2013). 


\subsection{Compósitos de matriz polimérica}

Um compósito pode ser definido como um material combinado formado de duas ou mais fases quimicamente diferentes, um agente de reforço e uma matriz compatível, separadas por uma interface. Essa combinação tem como objetivo maximizar propriedades específicas, que não são alcançadas pelos componentes separadamente.

Os compósitos podem ser classificados com base na forma de seus componentes estruturais: fibroso, laminar e particulado. A matriz pode ser de três tipos: cerâmica, polimérica (termorrígido, termoplástico e elastômero) e metálica. Os componentes, bem como a interface entre eles, podem ser fisicamente identificados, e o comportamento e as propriedades da interface geralmente controlam as propriedades dos compósitos (ROSATO, 1982).

Os compósitos com matrizes poliméricas desenvolveram-se rapidamente e logo foram aceitos para diversas aplicações, desde a indústria automotiva, naval e aeroespacial, passando por aplicações militares, construção civil e mesmo na confecção de materiais esportivos. Isso porque a preparação de um compósito de matriz polimérica não envolve necessariamente altas pressões e temperaturas elevadas. Ainda, os problemas relacionados com a degradação do reforço durante a manufatura são menos significativos para estes compósitos do que para os de outras matrizes (NICOLAI; BOTARO; LINS, 2008).

Durante os últimos anos, a pesquisa em compósitos poliméricos tem sido particularmente focada nas cargas nanométricas, sendo que os primeiros estudos extensos sobre a utilização das mesmas para a produção de compósitos poliméricos com propriedades específicas foram realizados pela Toyota Motor Corporation (Japão), utilizando silicatos lamelares modificados (MANTIA et al., 2013).

Para ser considerado um nanocompósito, em geral, uma das fases deve possuir uma dimensão na escala nanométrica (1-100 nm), no caso do presente trabalho, as nanofibras de celulose (NFC). As vantagens de materiais nanocompósitos, quando comparados com os compósitos convencionais são as suas excelentes propriedades térmicas, mecânicas e de barreira, bem como a sua melhor capacidade de reciclagem, sua transparência e baixo peso (KHALIL; BHAT; YUSRA, 2012; MANTIA et al., 2013; SIQUEIRA; BRAS; DUFRESNE, 2009; SPOLJARIC; GENOVESE; SHANKS, 2009). 
Essas vantagens se devem ao fato das cargas de tamanho nanométrico apresentarem uma área de superfície maior em comparação com enchimentos tradicionais, promovendo maior interação com a matriz e possivelmente uma alteração mais significativa nas propriedades físico-químicas do nanocompósito final. Além do fato de apenas pequenas quantidades serem suficientes.

\subsection{Fibras naturais como agentes de reforço em compósitos de matriz polimérica}

As fibras sintéticas (aramidas, vidro, carbono) são amplamente utilizadas para o reforço de plásticos. No entanto, estes materiais são caros e são provenientes de recursos não renováveis. Por esse motivo, nos últimos anos os compósitos poliméricos com fibras naturais têm recebido uma atenção considerável, tanto na literatura quanto na indústria. Vários pesquisadores exploram a aplicação de compósitos de fibras naturais com base na indústria automobilística (KIZILTAS et al., 2011). A Mercedes-Benz introduziu painéis de porta com fibra de juta nos seus veículos classe A (Figura 4a) há oito anos. Praticamente, todos os grandes fabricantes de automóveis na Alemanha (Daimler Chrysler, Mercedes, Volkswagen, Audi Group, BMW, Ford e Opel) já utilizam compósitos de fibras naturais em várias aplicações (JAWAID; KHALIL, 2011). A figura 4b destaca algumas das diversas partes em um veículo automotor, onde diferentes fibras naturais estão sendo aplicadas, como a fibra de sisal nos bancos e o bagaço da cana no pára-choque (REVISTA GLOBO RURAL, 2011).
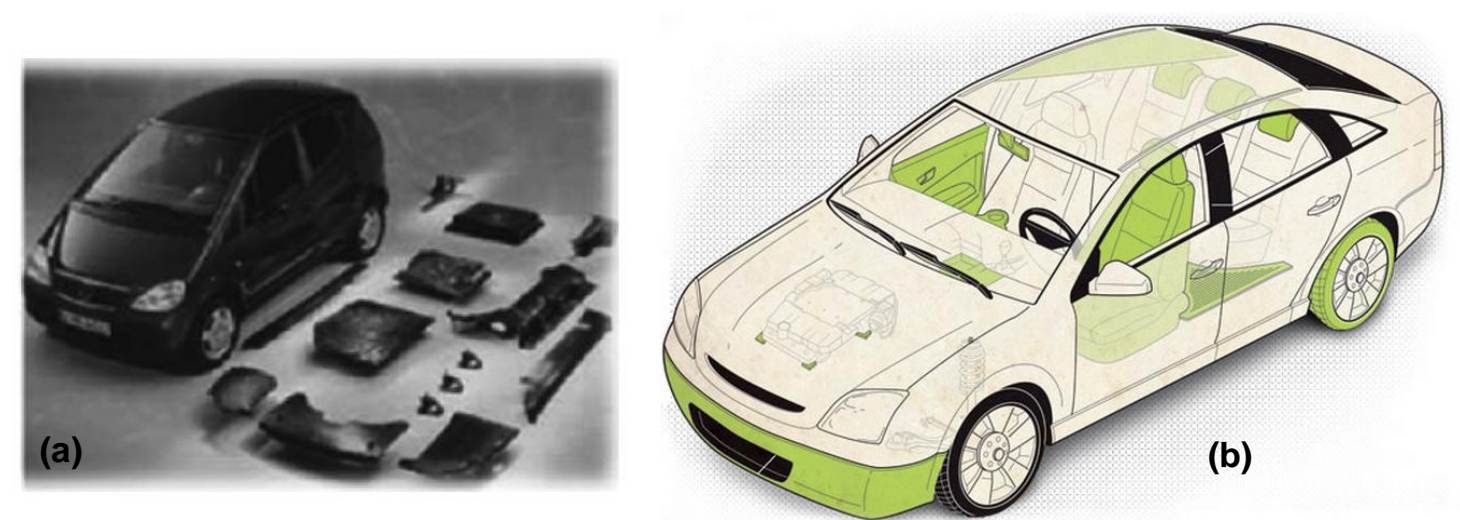

Figura 4. (a) Partes do interior do Mercedes Classe A; (b) Aplicação das fibras naturais em diferentes partes de um veículo automotor (JAWAID; KHALIL, 2011; REVISTA GLOBO RURAL, 2011). 
O interesse nessas fibras como agente de reforço em compósitos poliméricos é principalmente pelo fato delas serem totalmente biodegradáveis, ao contrário dos reforços inorgânicos de enchimento, tais como a nanoargila, sílica, mica e nanofibras de carbono. A maior parte das fibras naturais é constituída de celulose, hemicelulose, e lignina, sendo que as suas propriedades estão fortemente relacionadas com as condições de cultivo e de processamento (HUBER; MÜSSIG, 2008). A presença ou não de lignina na composição das fibras vegetais é o que as diferenciam entre lignocelulósicas e celulósicas, respectivamente. Os materiais lignocelulósicos são basicamente compostos por substâncias macromoleculares, como celulose, hemicelulose, lignina e constituintes de baixa massa molecular, como substâncias minerais. As fibras vegetais celulósicas são compostas majoritariamente por celulose (FENGEL; WEGENER,1989).

A unidade elementar de uma macromolécula de celulose é a $D$-anidroglicose, que contém três grupos hidroxila $(\mathrm{OH})$, o que as torna hidrofílicas. Estes grupos hidroxila formam ligações hidrogênio no interior da própria macromolécula (intramolecular) e entre outras macromoléculas de celulose (intermolecular), definindo a cristalinidade da mesma. As diferenças nas propriedades da celulose são devidas, principalmente, aos diferentes graus de polimerização e de cristalinidade. A figura 5 mostra a unidade repetitiva da celulose, a celobiose (HABIBI et al., 2008; JAWAID; KHALIL, 2011; PANTHAPULAKKAL; SAIN, 2012).

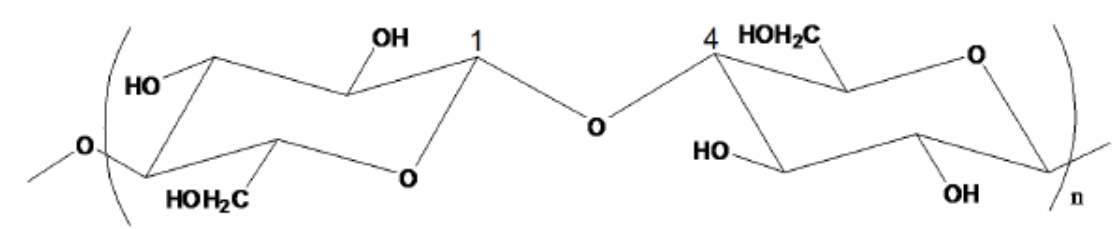

Figura 5. Estrutura da celobiose (FENGEL, 1989).

A celulose é um material polimérico natural e renovável, que representa cerca de $1,5 \times 10^{12}$ toneladas da produção de biomassa total anual, sendo considerada uma fonte quase inesgotável de matéria-prima para a crescente demanda por produtos ecologicamente corretos e biocompatíveis (KHALIL; BHAT; YUSRA, 2012). Possui propriedades especiais, tais como a durabilidade em longo prazo e resistência ao calor extremo em uma ampla faixa de temperatura. A alta rigidez, a baixa densidade 
e o fato de não danificarem o equipamento durante o processamento como o vidro e o carbono, são também propriedades positivas de enchimentos naturais, proporcionando uma alternativa aos enchimentos sintéticos para o reforço de plásticos utilizados na fabricação de peças para automóveis, embalagens e móveis (YANG; GARDNER; NADER, 2011; ARRAKHIZ et al., 2012).

\subsubsection{Nanofibras de Celulose (NFC)}

Um dos problemas relacionados aos materiais lignocelulósicos é a temperatura de processamento dos compósitos ser limitada em torno de $200^{\circ} \mathrm{C}$, devido ao fato da hemicelulose presente nas fibras de madeira começar a degradar próximo de $230^{\circ} \mathrm{C}$. Assim, a temperatura de fusão dos materiais plásticos selecionados não deve ser superior a $200^{\circ} \mathrm{C}$, restringindo a utilização de termoplásticos de engenharia como a poliamida. Entretanto, esses termoplásticos de engenharia, com alta temperatura de fusão como a poliamida 6 e a poliamida 6,6, possuem maiores módulo e temperatura de serviço que os termoplásticos commodities- polietileno (PE), polipropileno (PP), policloreto de vinila (PVC) e poliestireno (PS).

Nesse contexto, pesquisadores buscam soluções em alternativas relacionadas ao método de processamento, uso de aditivos e modificações na estrutura do material celulósico. Estudos de análise termogravimétrica dos componentes poliméricos da madeira mostram que o componente celulósico purificado é termicamente mais estável do que outros componentes poliméricos da madeira. Devido à maior estabilidade térmica em comparação com demais fibras de madeira, essas celuloses purificadas podem ser utilizadas com termoplásticos de engenharia (SAMIR; ALLOIN; DUFRESNE, 2005; KIZILTAS et al., 2011).

Arrakhiz et al. (2012), estudaram diferentes tratamentos químicos nas fibras naturais Alfa a fim de melhorar as propriedades mecânicas de compósitos com matriz de polipropileno. O objetivo nesses tratamentos foi justamente remover os componentes não-celulósicos da fibra. A remoção promoveu não apenas melhora nas propriedades mecânicas como também nas propriedades térmicas.

O estudo das nanofibras de celulose (NFC) como uma fase de reforço em filmes de nanocompósito começou há 20 anos e desde essa época uma grande quantidade da literatura tem se dedicado ao isolamento, caracterização e aplicação 
desses materiais altamente purificados. Várias terminologias aparecem na literatura para esses materiais, porém, genericamente, materiais celulósicos isolados que possuam uma dimensão na escala nanométrica são referidos como nanoceluloses e o interesse dos pesquisadores da área de nanotecnologia é pelo fato delas serem altamente cristalinas, serem abundantes em plantas naturais, terem propriedades únicas e diferentes tamanhos. Estes cientistas acreditam que as nanoceluloses têm um elevado potencial para serem utilizadas como filmes transparentes e extremamente fortes em diversas áreas (KHALIL; BHAT; YUSRA, 2012; KLEMM et al., 2011).

A nomenclatura para nanoceluloses não tem sido utilizada de modo completamente uniforme, entretanto, Klemm et al. (2011) sugeriram a classificação das nanoceluloses em três principais subcategorias, de acordo com suas funções e métodos de preparação, que por sua vez dependem principalmente da fonte de celulose e das condições de processamento (Tabela 1). Todos estes métodos levam a vários tipos de materiais, com diferentes razões de aspecto ( $L / D$, sendo $L O$ comprimento e D o diâmetro) (KHALIL; BHAT; YUSRA, 2012; SAMIR; ALLOIN; DUFRESNE, 2005). 
Tabela 1. Nomenclaturas para nanoceluloses a partir da fonte e dos processos de obtenção (KLEMM et al., 2011).

\begin{tabular}{|c|c|c|c|}
\hline $\begin{array}{c}\text { Tipo de } \\
\text { Nanocelulose }\end{array}$ & Sinônimos & Principais fontes & Obtenção \\
\hline $\begin{array}{c}\text { Celulose } \\
\text { Microfibrilada }\end{array}$ & $\begin{array}{c}\text { Celulose } \\
\text { Nanofibrilada, } \\
\text { Microfibras de } \\
\text { Celulose, } \\
\text { Nanofibras de } \\
\text { celulose. }\end{array}$ & $\begin{array}{l}\text { Madeira, } \\
\text { beterraba, } \\
\text { tubérculos de } \\
\text { batata, cânhamo, } \\
\text { linho. }\end{array}$ & $\begin{array}{c}\text { Delaminação da polpa } \\
\text { de madeira por } \\
\text { pressão mecânica, } \\
\text { antes e/ou depois de } \\
\text { um tratamento químico } \\
\text { ou enzimático. }\end{array}$ \\
\hline $\begin{array}{c}\text { Celulose } \\
\text { Nanocristalina }\end{array}$ & $\begin{array}{c}\text { Nanocristais e } \\
\text { Microcristais de } \\
\text { Celulose, Whiskers }\end{array}$ & $\begin{array}{c}\text { Madeira, } \\
\text { algodão, palha } \\
\text { de trigo, celulose } \\
\text { a partir de algas } \\
\text { e bactérias. }\end{array}$ & $\begin{array}{l}\text { Hidrólise ácida de } \\
\text { celulose a partir de } \\
\text { diversas fontes }\end{array}$ \\
\hline $\begin{array}{c}\text { Nanocelulose } \\
\text { Bacteriana }\end{array}$ & $\begin{array}{l}\text { Celulose } \\
\text { Bacteriana, } \\
\text { Biocelulose, } \\
\text { Celulose } \\
\text { Microbiana }\end{array}$ & $\begin{array}{l}\text { Açúcares de } \\
\text { baixo peso } \\
\text { molecular e } \\
\text { alcoóis. }\end{array}$ & Síntese Bacteriana \\
\hline
\end{tabular}

A figura 6 ilustra como as nanofibras de celulose, consideradas no presente trabalho, são normalmente produzidas. Primeiramente é realizado o processo de polpação, no qual ocorre uma ruptura das ligações presentes na estrutura da madeira, possibilitando a individualização das fibras. Essa quebra de ligações pode ser feita tanto mecanicamente como quimicamente. A segunda etapa é a refinação da celulose, onde a suspensão de fibras diluídas é sujeita a tensões cíclicas repetidas, produzindo a fibrilação externa das mesmas. No processo de homogeneização (última etapa), a mesma suspensão de fibras de celulose é bombeada a uma alta pressão através de um conjunto de válvulas que abrem e fecham de forma rápida e sucessiva, fazendo com que as fibras sofram uma grande queda de pressão, com forças de cisalhamento e impacto. Esta combinação de 
forças promove um elevado grau de microfibrilação das fibras de celulose, resultando nas NFC (KHALIL; BHAT; YUSRA, 2012; KLEMM et al., 2011).

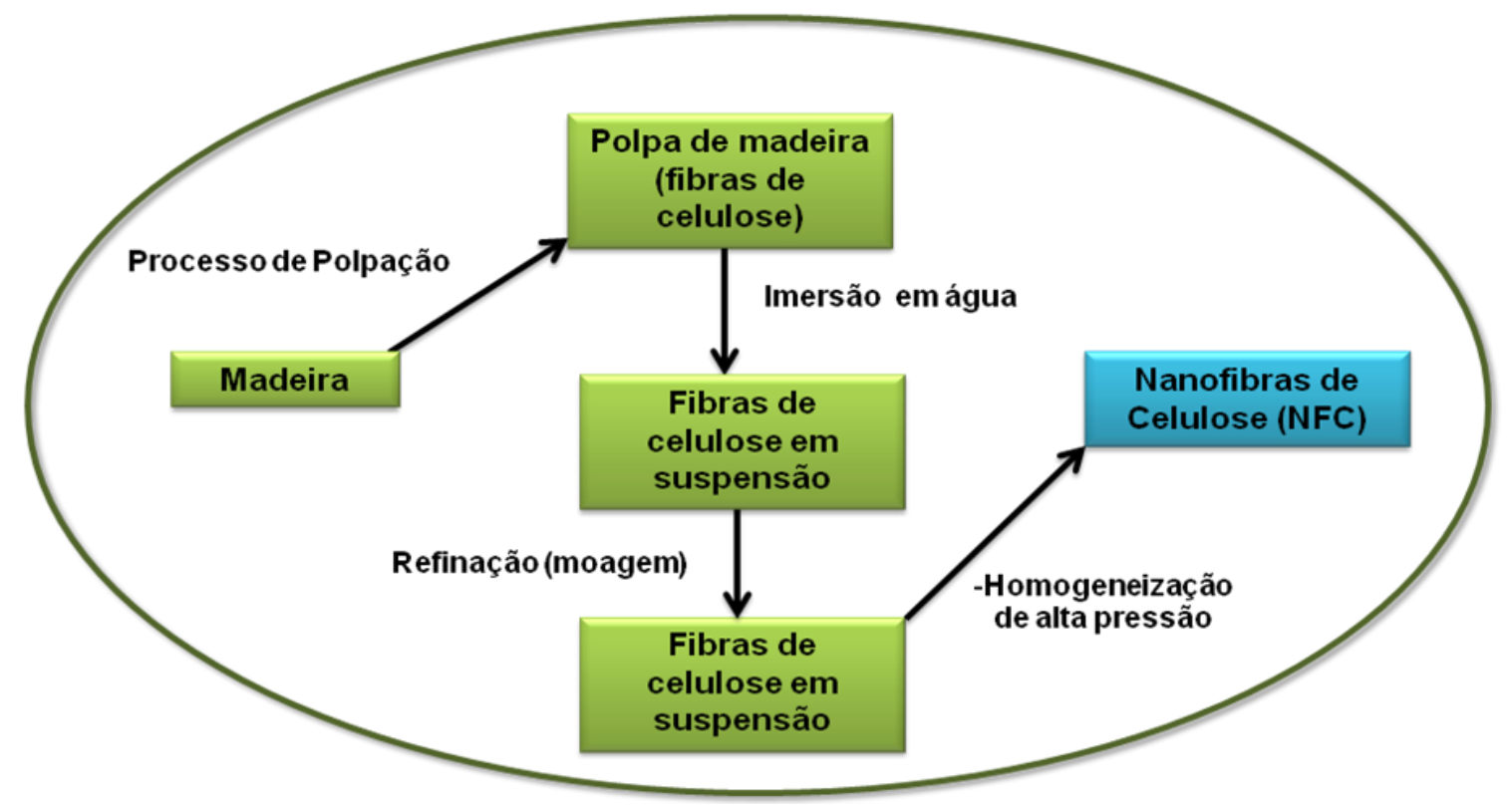

Figura 6. Obtenção das nanofibras de celulose (NFC).

Dois tipos de interações são esperadas na incorporação de cargas aos polímeros. Um tipo são as interações entre a matriz e o reforço, que determinam o desempenho do material, e o outro são as interações entre os reforços (aglomerações), sendo a primeira desejada e a segunda não, porém muito difíceis de evitar. O principal desafio associado à preparação de compósitos com nanocelulose como carga é a sua baixa dispersão na matriz polimérica, devido a essa aglomeração resultante das ligações de hidrogênio no interior das fibrilas de celulose. Com o objetivo de explorar todo o potencial da nanocelulose muitos dos trabalhos relatados utilizam polímeros hidrofílicos para melhorar a dispersão e muitas pesquisas vão nessa direção (KIZILTAS et al., 2011; LU; WANG; DRZAL, 2008; PANTHAPULAKKAL; SAIN, 2012; SOUZA et al., 2010).

Souza et al. (2010), mostraram que a adição de nanocelulose a partir de fibras de curauá em uma matriz de álcool polivinílico (PVA) aumenta a resistência à tração do compósito. Com a adição de 4 e $5 \%$ de nanofibras, um aumento significativo foi observado na tensão máxima de 36 e 44\%, respectivamente, provando o reforço efetivo das fibras na matriz e a boa adesão interfacial devido à compatibilidade com uma matriz hidrofílica. 
Neste trabalho, a matriz polimérica na qual as NFC foram incorporadas foi uma poliamida alifática (poliamida 6,6).

\subsection{Poliamidas}

Apesar das propriedades atraentes dos reforços celulósicos, eles são utilizados de forma limitada na prática industrial, devido às dificuldades associadas à compatibilidade e às interações superficiais. Como mencionado anteriormente, esses reforços possuem natureza polar e hidrofílica enquanto que a maior parte dos polímeros termoplásticos mais comumente utilizados possui características nãopolares, prejudicando a obtenção de níveis aceitáveis de dispersão (SAMIR; ALLOIN; DUFRESNE, 2005; RODIANOVA; LENES, 2011). Por isso a importância na escolha de materiais, dos métodos de fabricação, dos parâmetros de processamento e do tratamento da superfície das fibras ou do uso de aditivos. Essas escolhas podem afetar também a adesão na interface fibra/matriz.

A intensidade da interação na interface é fundamental para as propriedades mecânicas de um compósito. Uma boa aderência entre a matriz e o reforço pode evitar, por exemplo, a desvantagem dos reforços celulósicos em absorver umidade, que gera um inchaço das fibras e alterações nas dimensões e propriedades finais do compósito. Isso pode ser evitado se o material de enchimento hidrofílico estiver completamente encapsulado numa matriz de polímero hidrofóbico ou se ambos possuírem a mesma natureza polar, garantindo uma forte interação. No entanto, se o nível de adesão entre o material de enchimento e a matriz não é suficiente, uma via de difusão pode pré-existir ou pode ser criada sob solicitação mecânica (SAMIR; ALLOIN; DUFRESNE, 2005).

Nesse contexto, as poliamidas se tornam boas candidatas como uma matriz compatível para as NFC. As poliamidas alifáticas são muito conhecidas na indústria de plásticos de engenharia e podem ser produzidas comercialmente por condensação de diaminas com os ácidos dibásicos, pela auto-condensação de um aminoácido ou pela polimerização com abertura de anel de uma caprolactana (CHANDA; ROY, 2009).

Nylon é o nome comercial dado às poliamidas não substituídas, obtidas a partir de monômeros não ramificados alifáticos. O Nylon é fabricado a partir de uma diamina e de um ácido dibásico, e é designado por dois números, em que o primeiro 
representa o número de átomos de carbono na cadeia da diamina e o segundo 0 número de carbonos no ácido (CHANDA; ROY, 2009). Um exemplo é o Nylon-6,6, ou poliamida 6,6, considerado no presente trabalho, obtido a partir de hexametilenodiamina e do ácido adípico (Figura 7).

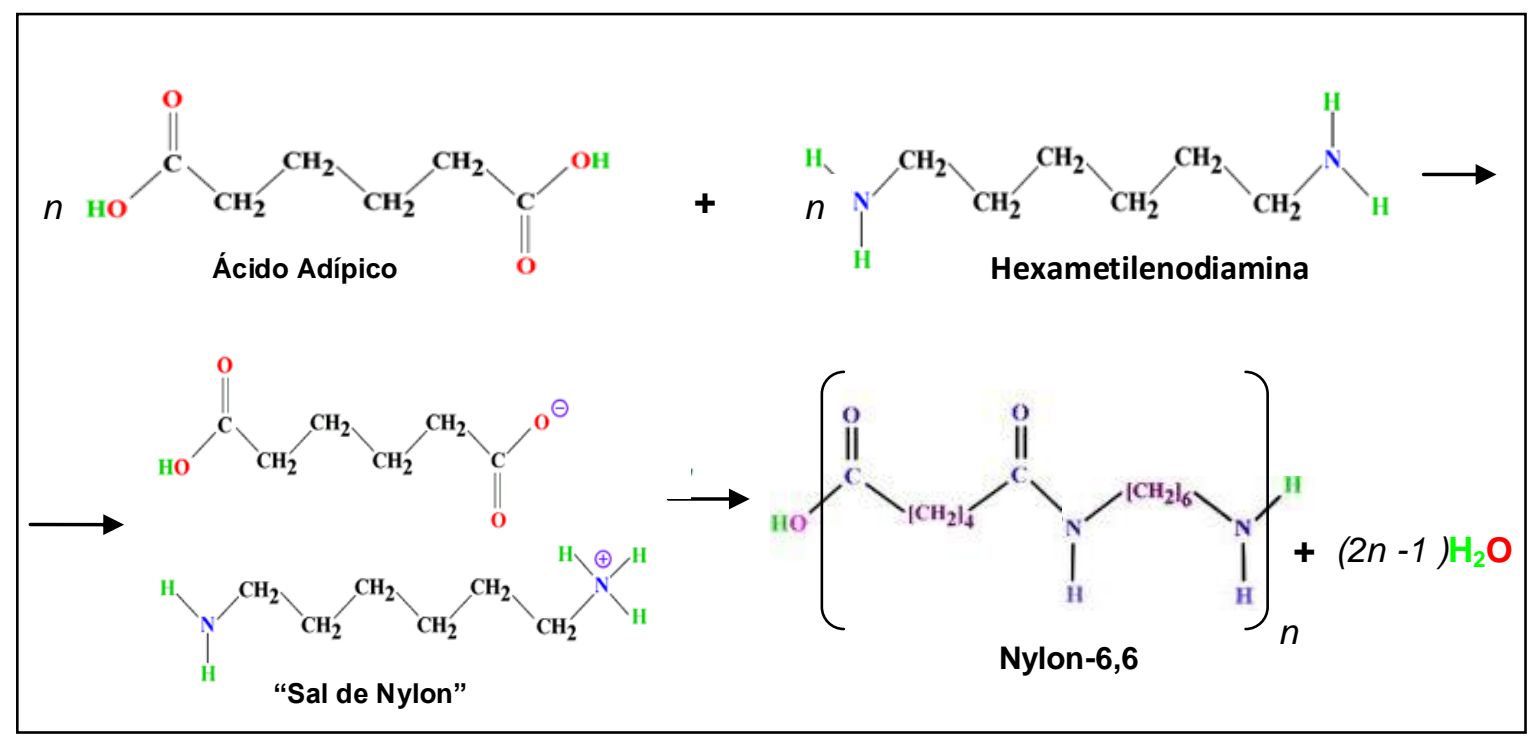

Figura 7. Esquema da reação de obtenção do Nylon-6,6.

As poliamidas alifáticas são polímeros lineares que contêm grupos polares de amidas (-CONH-) espaçados a intervalos regulares por segmentos de cadeia alifática. A principal diferença estrutural entre os diferentes tipos de poliamida é o comprimento desses segmentos alifáticos que separam os grupos amida adjacentes. Os grupos polares são responsáveis pela elevada atração intercadeias nas zonas cristalinas e os segmentos alifáticos por conferir grau de flexibilidade da cadeia nas zonas amorfas. Esta combinação de propriedades produz polímeros altamente tenazes acima das suas temperaturas de transição vítrea, com elevada resistência ao impacto e com boa resistência à abrasão. As propriedades mecânicas das poliamidas são afetadas significativamente pela quantidade de cristalização na peça de teste, pela temperatura e pela umidade, sendo importante um controle desses fatores durante todo o processamento (CHANDA; ROY, 2009; BESCO et al, 2011).

A aplicação mais importante das poliamidas é como fibras, representando quase $90 \%$ da produção mundial de todas as poliamidas. Empresas da área têxtil usam termoplásticos de engenharia, como a poliamida 6 e a poliamida 6,6, também como fibras. Praticamente todo o restante é utilizado em aplicações plásticas. Devido ao 
seu custo elevado, as poliamidas não se tornaram materiais de uso geral, como os materiais de polietileno e poliestireno, entretanto aplicações cada vez maiores, como em materiais plásticos para fins especiais, onde a combinação de dureza, rigidez, resistência à abrasão e resistência ao calor razoável é importante. Portanto, sua ampla área de utilização vai desde a indústria têxtil, passando pelo mercado de construção, até o setor automobilístico (CHANDA; ROY, 2009; KIZILTAS et al., 2011).

O mercado latino-americano de poliamidas, região que consome por volta de 200 mil toneladas anuais do material, gera um movimento financeiro na casa de US\$ 1 bilhão (MORAES, 2012). Melhores propriedades em termos de força, temperatura de deflexão térmica, estabilidade dimensional, barreira de gás, retardante de chama e condutividade elétrica podem ser alcançadas com nanocompósitos de poliamida (BOUSSIA; VOUYIOUKA; PAPASPYRIDES, 2012).

Apesar do grande interesse tecnológico nas poliamidas, apenas alguns estudos de compósitos poliméricos de poliamida 6,6/celulose foram publicados e em menor quantidade estudos de poliamida 6,6/nanofibras de celulose, considerados no presente trabalho (KIZILTAS et al., 2011).

\subsubsection{Poliamida Reciclada}

Desde a primeira produção em escala industrial de polímeros sintéticos a taxa de produção, consumo e geração de desperdício de resíduos sólidos de plástico aumentaram consideravelmente. Dentre os principais métodos utilizados para disposição final desses resíduos demonstrou-se que a deposição em aterro e a incineração são cada vez mais insatisfatórias e inseguras. A incineração é ambientalmente não viável e a deposição em aterro relativamente cara, além da diminuição de espaço para o mesmo, forçando assim a busca por alternativas. Agências governamentais, ambientalistas e técnicos estão em total acordo que a reciclagem é a opção mais viável para operar de forma fácil e conveniente a eliminação dos resíduos plásticos (DORIGATO; FAMBRI, 2011; SUKRI et al., 2012).

Normalmente, o preço do plástico reciclado é $40 \%$ menor do que o da resina virgem, fazendo com que a substituição da resina virgem pela reciclada traga benefícios de redução de custo e aumento da competitividade, além de auxiliar na preservação ambiental. É prática comum, por exemplo, na indústria de fabricação de 
conectores automotivos, a utilização de uma porcentagem de até $20 \%$ de material reciclado misturado ao virgem. Este limite de reciclado é permitido pelos compradores sob a alegação que não há interferência da reciclagem nas propriedades mecânicas exigidas em normas técnicas específicas adotadas pelas empresas (FERNANDES; SANTO, 2009).

As propriedades físicas de misturas da poliamida 6,6 pura e reciclada foram analisadas por Fernandes e Santo (2009). Os resultados obtidos revelaram que a poliamida utilizada com as proporções de reciclagem mantém suas propriedades acima dos valores recomendados pela normalização técnica e especificação da matéria-prima.

Uma Análise do Ciclo de Vida (ACV) conduzida pela empresa Rhodia Poliamida e Especialidades Ltda, Valeo e PSA Peugeot Citroën confirmou os benefícios ambientais obtidos com o uso de poliamida reciclada em aplicações automotivas. As três empresas realizaram uma análise multicritérios de todo o ciclo de vida do conjunto de hélice e defletor do radiador, um componente importante da refrigeração do motor do novo Peugeot 208, lançado mundialmente em 2012 pela PSA. A Valeo fabrica esta autopeça a partir da poliamida Technyl ${ }^{\circledR}$ reciclada da Rhodia (RHODIA SOLVAY GROUP, 2012).

O estudo, que foi revisado por uma consultoria independente (BIO Intelligence Service), comparou o impacto ambiental no uso da poliamida Technyl ${ }^{\circledR}$ reciclada em relação à poliamida Technyl ${ }^{\circledR}$ produzida com resina virgem. Os resultados mostraram que se utilizando a poliamida Technyl ${ }^{\circledR}$ reciclada o impacto ambiental do componente é significativamente reduzido ao longo de todo o seu ciclo de vida. Essa iniciativa de colaboração entre as três empresas tem o potencial de confirmar cientificamente o aumento do uso de plásticos reciclados para responder aos desafios ambientais enfrentados pela indústria automotiva mundial (RHODIA SOLVAY GROUP, 2012).

No presente trabalho, foi utilizada a poliamida 6,6 reciclada produzida pela Rhodia Poliamida e Especialidades Ltda, bem como a resina virgem de poliamida 6,6 , como comparativo. A reciclagem pela qual a poliamida passa é uma reciclagem química a partir de refugo da produção de fios de têxteis da poliamida 6,6 da própria empresa. Normalmente esse refugo seria incinerado ou vendido para uma reciclagem mecânica, onde é apenas fundindo novamente. Porém, como na reciclagem química ocorre a despolimerização e posterior polimerização da 
poliamida, ela preserva mais as propriedades da mesma, permitindo o uso em aplicações que não seriam possíveis com a reciclagem apenas mecânica. Além da questão sustentável em se reutilizar o material, consumindo menos polímero virgem, e do retorno financeiro em se aproveitar os resíduos.

\subsection{Projetando nanocompósitos}

As técnicas de processamento de qualquer compósito têm uma grande importância sobre as propriedades finais do mesmo. Essas técnicas são condicionadas por ambas as propriedades intrínsecas do reforço, da matriz polimérica (solubilidade, dispersibilidade e degradação) e das propriedades finais desejadas, como a forma geométrica (SAMIR; ALLOIN; DUFRESNE, 2005).

Um desafio quando se utiliza NFC esta relacionado à sua superfície polar, que dificulta uma dispersão uniforme em um meio não-polar (JONOOBI et al., 2010; KHALIL; BHAT; YUSRA, 2012; PANTHAPULAKKAL; SAIN, 2012).

desenvolvimento de técnicas de processamento mais flexíveis e que sejam industrialmente viáveis é necessária para promover a comercialização destes materiais. Assim, vários métodos interessantes foram recentemente relatados para estes materiais. Um dos métodos de processamento desenvolvido tem sido a fusão dos componentes (IWATAKE; NOGI; YANO, 2008; JONOOBI et al., 2010; OKSMAN et al., 2006; SURYANEGARA; NAKAGAITO; YANO, 2009).

A extrusão é um dos processos mais utilizados industrialmente para a mistura/dispersão de componentes. Esse processo consiste na moldagem de um termoplástico viscoso, sob pressão, através de uma matriz com extremidade aberta. Uma rosca transportadora ou parafuso sem fim transporta o material peletizado através de uma câmara, onde ele é sucessivamente compactado, fundido e conformado como uma carga contínua de um fluido viscoso. A extrusão ocorre conforme essa massa fundida é forçada através de um orifício na matriz (CALLISTER JR., 2012; MANRICH, 2013).

A moldagem por injeção é uma técnica amplamente utilizada para a fabricação de materiais termoplásticos. Nela uma quantidade do material peletizado é alimentada a partir de uma moega de carregamento para o interior de um cilindro, através do movimento de um embolo ou pistão. Essa carga é empurrada para o interior de uma câmara de aquecimento, onde ela é forçada ao redor de um 
espalhador, proporcionando um melhor contato com a parede aquecida. Como resultado o material se funde para formar um liquido viscoso. O plástico fundido é impelido através de um bico injetor para interior da cavidade fechado do molde e a pressão é mantida até a solidificação do material moldado. Finalmente, o molde é aberto, a peça é ejetada, o molde fechado e todo o ciclo repetido (CALLISTER JR., 2012; SIMIELLI; SANTOS, 2010).

A fusão dos componentes de nanocompósitos de celulose apresenta vários desafios. A principal dificuldade é para alimentar as nanofibras de celulose na extrusora e conseguir a boa dispersão, pelo fato delas possuírem uma área de superfície muito elevada e terem a tendência em se agregar quando estão secas como discutido anteriormente. Isso pode ser evitado misturando-as primeiramente em um meio adequado, ou em um líquido, que é então introduzido na extrusora, ou primeiramente seco e em seguida extrudado (IWATAKE; NOGl; YANO, 2008; JONOOBI et al., 2010; OKSMAN et al., 2006; SURYANEGARA; NAKAGAITO; YANO, 2009).

Jonoobi et al., prepararam nanocompósitos de poliácido lático com NFC (PLA/NFC) usando um processo de duas etapas: preparação de um composto com alta concentração de reforço em uma mistura de solventes, seguido por um processo de extrusão e moldagem por injeção. O efeito do teor de nanofibras (1, 3, $5 \%$ em peso) sobre as propriedades mecânicas e estabilidade térmica dos nanocompósitos foi avaliada. Os resultados mostraram uma boa dispersão para o nanocompósitos reforçados com 1 e $3 \%$ de NFC e um aumento da resistência à tração e o módulo de elasticidade com o aumento do teor de nanofibras.

No presente trabalho os nanocompósitos de poliamida $6,6 / \mathrm{NFC}$ foram obtidos em duas etapas, sendo a primeira um pré-processamento, no qual NFC e polímero foram dispersos em um solvente, e a segunda o processo via extrusão e moldagem por injeção.

\subsection{Caracterização de compósitos reforçados com fibras naturais}

As propriedades mecânicas dos polímeros são caracterizadas pelo modo com que esses materiais respondem as solicitações mecânicas aplicadas. A natureza dessa resposta depende da estrutura química, temperatura, tempo e das condições de processamento do polímero. Algumas propriedades mecânicas são a resistência, 
a dureza, a ductibilidade e a rigidez (CALLISTER JR., 2012; CANEVAROLO JR., 2002). Uma das principais razões em adicionar partículas em polímeros é para elevar as propriedades mecânicas, por isso à importância dos ensaios.

As propriedades mecânicas dos materiais são verificadas pela realização de experimentos laboratoriais, projetados cuidadosamente. Esses experimentos têm a função de reproduzir o mais fielmente possível os esforços que os materiais vão sofrer nas condições reais de uso, chegando a limites extremos de solicitação. Como são alvo da atenção de diversos grupos que possuem diferentes interesses é importante que exista uma consistência segundo a qual são conduzidos os ensaios e na interpretação dos resultados. Essa consistência é obtida com o emprego de técnicas padronizadas. A organização mais ativa é a Sociedade Americana para Ensaios e Materiais (ASTM - American Society for Testing and Materials) (CALLISTER JR., 2012).

Outra propriedade importante a ser analisada no caso de compósitos poliméricos reforçados com materiais celulósicos é a propriedade térmica. Tanto os polímeros naturais como os sintéticos são expostos a reações de degradação térmica sob o efeito do aumento da temperatura. Devido às elevadas temperaturas de processamento de termoplásticos de engenharia, a celulose pode ser degradada e as suas propriedades mecânicas reduzidas durante o processamento por fusão. Por isso, é extremamente relevante ter informação sobre o impacto das temperaturas de processamento durante a obtenção de materiais compósitos de matrizes termoplásticas de engenharia reforçadas com celulose (KIZILTAS et al., 2011).

Por propriedade térmica entende-se a resposta de um material à aplicação de calor. Conforme um sólido absorve energia na forma de calor, a sua temperatura e as sua dimensões aumentam. A energia pode ser transportada para as regiões mais frias da amostra se existir gradientes de temperatura e, por fim, a amostra pode fundir (CALLISTER JR., 2012). A mobilidade de uma cadeia polimérica determina as características físicas do produto, seja este um plástico duro e frágil, borrachoso e tenaz, ou um fluido viscoso. A mobilidade é função da agitação dos átomos nas moléculas, sendo esta diretamente proporcional à temperatura (CANEVAROLO JR., 2002).

Informações essenciais em relação às temperaturas de processamento e de estabilidade térmica dos polímeros naturais e sintéticos são obtidas a partir de técnicas de análise térmica como a análise 
térmica mecânica dinâmica (DMTA), calorimetria exploratória diferencial (DSC) e análise termogravimétrica (TG) (KIZILTAS et al., 2011).

A microscopia eletrônica de varredura (MEV) é a técnica mais utilizada para a avaliação da superfície de fratura de compósitos contendo fibras. O comportamento da fratura em compósitos é afetado por muitas variáveis, como a interação fibramatriz, a orientação das fibras, a quantidade de vazios na matriz, entre outras. 


\section{OBJETIVOS}

Considerando as vantagens da aplicação do polímero sintético poliamida 6,6 e a suscetibilidade de utilização das NFC como reforço nesse termoplástico de elevada temperatura de fusão, o presente trabalho teve como objetivos a caracterização das propriedades térmicas, mecânicas e morfológicas das poliamidas 6,6, reciclada e virgem, bem como a de seus nanocompósitos reforçados com as NFC. Buscou-se ainda uma solução alternativa relacionada ao método de processamento, o pré-processamento, visando a possibilidade de processamento a altas temperaturas e a produção de nanocompósitos com boa dispersão da NFC nas matrizes. 


\section{MATERIAIS E MÉTODOS}

\subsection{Origem dos materiais}

As nanofibras de celulose (NFC) utilizadas como reforço na preparação dos nanocompósitos foram gentilmente cedidas pelo Centro de Biocompósitos e Processamento de Biomateriais da Universidade de Toronto, Canadá. Estas foram obtidas a partir de uma mistura de polpas de madeira macia branqueada e desfibriladas pela passagem em um moedor comercial da empresa Masuko Corp., Japão (ALEMDAR; SAIN, 2008a; ALEMDAR; SAIN, 2008b). A composição das NFC recebida é apresentada na tabela 2.

Tabela 2. Composição das NFC (ALEMDAR; SAIN, 2008a; ALEMDAR; SAIN, 2008b).

\begin{tabular}{c|c|c}
\hline$\alpha$-celulose (\%) & Hemicelulose (\%) & Lignina (\%) \\
\hline $84,6 \pm 4,4$ & $6,0 \pm 1,1$ & $9,4 \pm 0,8$ \\
\hline
\end{tabular}

As matrizes consideradas, a poliamida reciclada (PA66Rec) e a resina virgem de poliamida (PA66), foram cedidas pela empresa Rhodia Poliamida e Especialidades Ltda do Brasil. Na tabela 3 são apresentadas as propriedades características da PA66, fornecidas pela empresa.

Tabela 3. Propriedades características da PA66.

\begin{tabular}{c|c}
\hline Propriedades & Valor \\
\hline Densidade $\left(\mathrm{g} / \mathrm{cm}^{3}\right)$ & 1,14 \\
\hline Temperatura de fusão cristalina $\mathrm{T}_{\mathrm{m}}\left({ }^{\circ} \mathrm{C}\right)$ & $255-265$ \\
\hline Temperatura de transição vítrea, $\mathrm{T}_{\mathrm{g}}\left({ }^{\circ} \mathrm{C}\right)$ & $55-65$ \\
\hline Grau de cristalinidade, $\mathrm{X}_{\mathrm{c}}(\%)$ & $20-40$ \\
\hline Massa molar média, $\mathrm{M}_{\mathrm{w}}(\mathrm{g} / \mathrm{mol})$ & 20.000 \\
\hline
\end{tabular}

O ácido fórmico da Synth (85\%) foi utilizado como solvente na etapa de dissolução das poliamidas 6,6. Resultados preliminares de obtenção de nanofibras 
eletrofiadas de poliamida e reforçadas com argila montmorilonita organicamente modificada evidenciaram a boa dissolução da poliamida e a boa dispersão da carga na matriz polimérica, resultando em materiais com melhores propriedades mecânicas (GUERRINI et al., 2009; BEATRICE et al., 2012; SANTOS et al., 2011).

\subsection{Caracterização das Nanofibras de Celulose (NFC) e das Poliamidas (PAs)}

\subsubsection{Espectroscopia na região do infravermelho (IV)}

A composição das NFC foi caracterizada usando-se um equipamento da marca PerkinElmer Spectrum 100, na região de 650 a $4000 \mathrm{~cm}^{-1}$ e com resolução de $4 \mathrm{~cm}^{-1}$. O ensaio foi realizado direto com uma pequena quantidade da amostra prensada e seca por refletância atenuada (ATR).

\subsubsection{Difração de Raios $X$}

O grau de cristalinidade $(\mathrm{Xc})$ da NFC foi avaliado por Difração de Raios X. O grau de cristalinidade informa sobre a proporção de regiões cristalinas com relação às não cristalinas, presentes na amostra. $O$ índice de cristalinidade foi calculado utilizando-se a Equação 1 (PANTHAPULAKKAL; SAIN, 2012).

$$
X_{C}=I_{2}-I_{1} / I_{2}
$$

Equação (1)

Sendo, $l_{1}=$ intensidade do mínimo de difração $\left(2 \theta\right.$ em torno de $\left.18^{\circ}\right)$

$\mathrm{I}_{2}=$ intensidade do máximo de difração $\left(2 \theta\right.$ em torno de $\left.22^{\circ}\right)$.

As análises foram feitas em um difratômetro Rigaku Rotaflex modelo RU200B com anodo de cobre. As medidas foram realizadas no intervalo de ângulo de difração $2 \theta$ de $3^{\circ}$ a $40^{\circ}$, com potência de $80 \mathrm{~mA}$ e $40 \mathrm{kV}$ através do método de refração.

\subsubsection{Análise Termogravimétrica (TG)}

As análises termogravimétricas da NFC e das PAs consideradas foram realizadas com o equipamento da PerkinElmer Pyris 1TG. Utilizaram-se amostras 
com massa de aproximadamente $7 \mathrm{mg}$, colocadas em porta-amostra de platina. As corridas foram realizadas no intervalo de $25-600^{\circ} \mathrm{C}$, com razão de aquecimento de $30^{\circ} \mathrm{C} / \mathrm{min}$, em atmosfera de nitrogênio $\left(\mathrm{N}_{2}\right)$ com fluxo de $20 \mathrm{~mL} / \mathrm{min}$.

A temperatura inicial de decomposição $\left(T_{i}\right)$ foi atribuída ao início da maior perda de massa da amostra e a temperatura final de decomposição $\left(T_{f}\right)$ foi considerada quando a massa se tornou praticamente constante. Nesse ponto, 0 valor de massa restante foi tomado como a porcentagem de resíduos da amostra. $\mathrm{Na}$ curva de dTG (derivada) a temperatura de degradação máxima ( $T_{\text {deg.máx.) foi }}$ atribuída a perda máxima de massa.

\subsubsection{Calorimetria Exploratória Diferencial (DSC)}

A análise de DSC das PAs foi realizada com o equipamento da PerkinElmer DSC 8000. Foi utilizada amostra com massa de aproximadamente 8,0 mg, colocadas em portas-amostra de alumínio, realizando-se corridas no intervalo de 25 - $350^{\circ} \mathrm{C}$, com razão de aquecimento e resfriamento de $10^{\circ} \mathrm{C} / \mathrm{min}$, em atmosfera de nitrogênio, com fluxo de $20 \mathrm{~mL} / \mathrm{min}$.

\subsection{Obtenção das amostras processados via extrusão e moldagem por injeção}

Foram consideradas 4 amostras diferentes de cada polímero, sendo uma delas apenas o polímero puro na forma de pellets (amostras PPA66Rec e PPA66). As demais amostras passaram por um pré-processamento antes da etapa de extrusão e moldagem por injeção.

\subsubsection{Pré-processamento}

Nessa etapa $10 \mathrm{~g}$ do polímero foram dissolvidos em $35 \mathrm{ml}$ do solvente ácido fórmico (solução 24\% em massa de polímero) para a obtenção das amostras sem NFC tomadas como branco desse processo (amostras BPA66Rec e BPA66). Para as amostras com NFC, estas foram dispersas no ácido fórmico e a suspensão obtida foi adicionada o polímero, mantendo as concentrações de 2 e 5\% em massa, obtendo duas composições diferentes de nanocompósitos para cada poliamida (Tabela 3). 
No pré-processamento das amostras usou-se agitação constante e temperatura de $45^{\circ} \mathrm{C}$ para facilitar a dissolução do polímero. Em seguida as soluções foram adicionadas à um não-solvente, água deionizada, em excesso e o material foi assim precipitado. Posteriormente, o material precipitado foi seco em estufa a vácuo à $100^{\circ} \mathrm{C}$ por $48 \mathrm{~h}$. Finalmente, as amostras foram picadas para facilitar a alimentação durante o processo de extrusão.

\subsubsection{Extrusão e Moldagem por Injeção}

A limitação da quantidade de material de reforço disponível (NFC) fez com que as amostras fossem processadas em equipamentos com capacidade para pequenas massas e que simulam as condições de equipamentos utilizados em larga escala. Todas as amostras foram previamente secas em estufa à $100^{\circ} \mathrm{C}$ por 12 horas antes de serem processadas. Foi utilizada uma miniextrusora de bancada da DSM Xplore, dupla-rosca co-rotantes e cônicas, com 3 zonas de aquecimento (Figura 8). Durante o processamento das amostras que passaram pelo préprocessamento foi observada a necessidade da alimentação concomitante das mesmas com os pellets puros, a fim de gerar o torque na região da alimentação. A tabela 4 apresenta as formulações finais das amostras estudadas e na tabela 5 encontram-se as condições de processamento para extrusão.

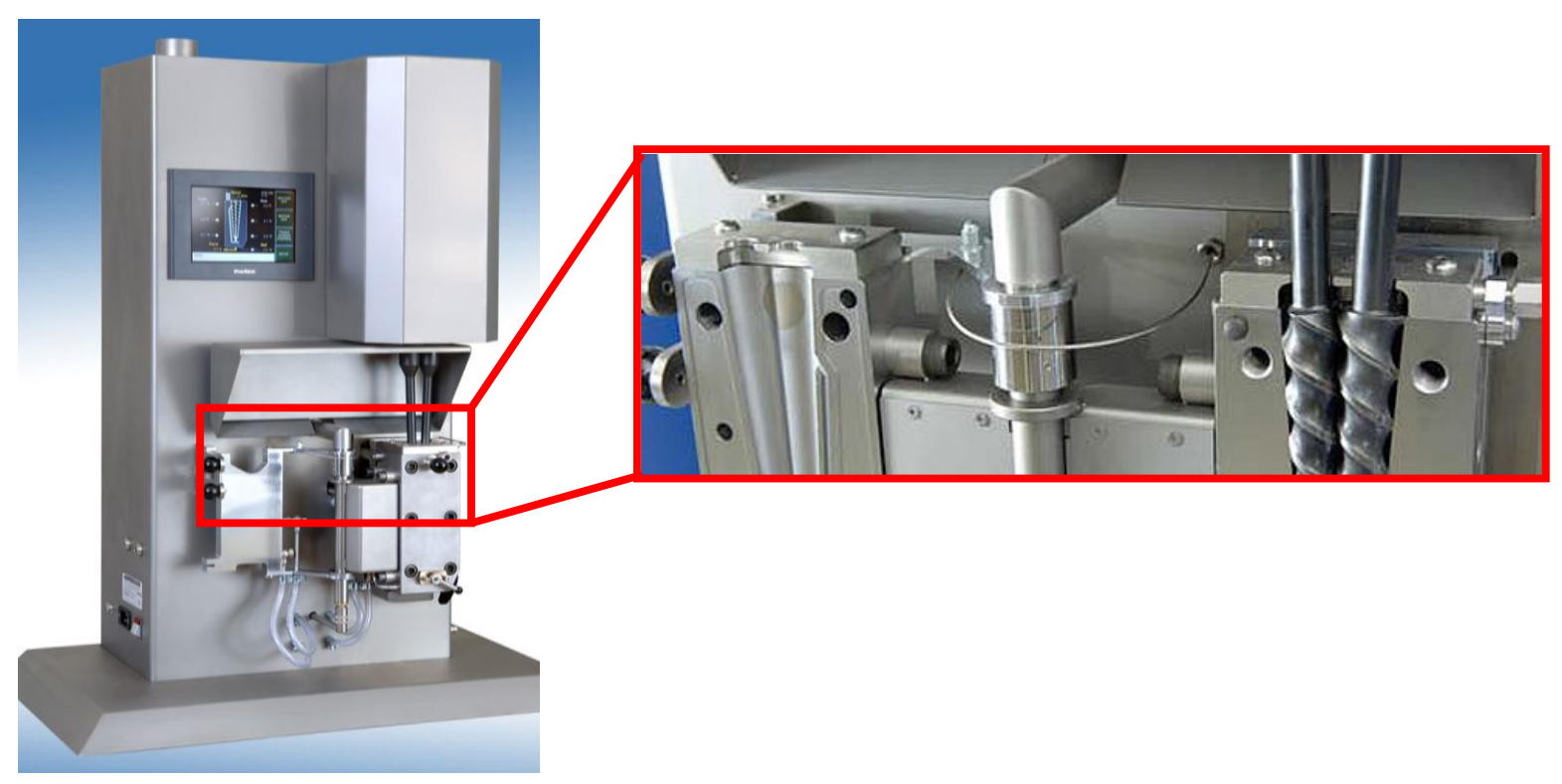

Figura 8. Miniextrusora da DSM Xplore. 
Tabela 4. Formulação das amostras estudadas.

\begin{tabular}{c|ccc}
\hline \multicolumn{1}{c}{ Amostra } & $\begin{array}{c}\text { NFC (\% em } \\
\text { massa) }\end{array}$ & $\begin{array}{c}\text { Pré- } \\
\text { processamento }\end{array}$ & Extrusão/Injeção \\
\hline PPA66Rec & 0 & $x$ & $x$ \\
\hline BPA66Rec & 0 & $x$ & $x$ \\
\hline NPA66Rec-1F & 1 & $x$ & $x$ \\
\hline NPA66Rec-2F & 2 & & $x$ \\
\hline PPA66 & 0 & $x$ & $x$ \\
\hline BPA66 & 0 & $x$ & $x$ \\
\hline NPA66-1F & 1 & $x$ & $x$ \\
\hline NPA66-2F & 2 & & $x$ \\
\hline
\end{tabular}

Tabela 5. Parâmetros do processamento de extrusão considerados para as amostras.

\begin{tabular}{cccc}
\hline $\begin{array}{c}\text { Velocidade da } \\
\text { rosca (RPM) }\end{array}$ & Temperatura das zonas de aquecimento $\left({ }^{\circ} \mathrm{C}\right)$ \\
\hline 100 & 280 & 280 & 280 \\
\hline
\end{tabular}

Para moldagem por injeção utilizou-se uma injetora da DSM modelo Xplore (Figura 9), com capacidade para $15 \mathrm{~g}$ de material, pressão máxima de $16 \mathrm{bar}$ e utilizando um molde para ensaio mecânico de tração segundo a norma ASTM D1708, os parâmetros de injeção para cada amostra são apresentados na tabela 6 .

Tabela 6. Parâmetros do processamento de moldagem por injeção, considerados para as amostras.

\begin{tabular}{cccccc}
\hline $\begin{array}{c}\text { Temperatura } \\
\text { do molde }\left({ }^{\circ} \mathbf{C}\right)\end{array}$ & $\begin{array}{c}\text { Temperatura } \\
\text { de Injeção }\left({ }^{\circ} \mathbf{C}\right)\end{array}$ & $\begin{array}{c}\text { Pressão de } \\
\text { Injeção (bar) }\end{array}$ & $\begin{array}{c}\text { Tempo de } \\
\text { Injeção (s) }\end{array}$ & $\begin{array}{c}\text { Tempo de } \\
\text { Recalque (s) }\end{array}$ & $\begin{array}{c}\text { Tempo de } \\
\text { Resfriamento } \\
\text { do molde (s) }\end{array}$ \\
\hline 40 & 280 & 4 & 5 & 2 & 60 \\
\hline
\end{tabular}




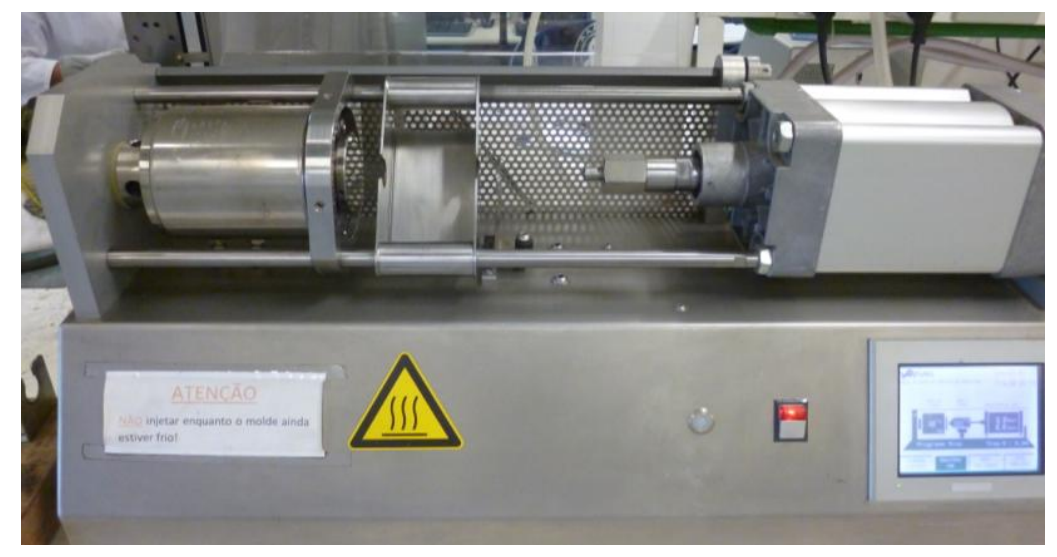

Figura 9. Injetora DSM Xplore.

\subsection{Caracterização das amostras processadas via extrusão e moldagem por injeção.}

\subsubsection{Análise Termogravimétrica (TG)}

As análises termogravimétricas das amostras processadas foram realizadas no equipamento da marca PerkinElmer modelo Pyris 1TG. Utilizaram-se amostras com massa de aproximadamente 7,0 mg, colocadas em porta-amostra de platina. Realizaram-se corridas no intervalo $25^{\circ} \mathrm{C}$ a $750^{\circ} \mathrm{C}$, com razão de aquecimento de $10^{\circ} \mathrm{C} / \mathrm{min}$, em atmosfera de $\mathrm{N}_{2}$ com fluxo de $20 \mathrm{ml} / \mathrm{min}$.

\subsubsection{Calorimetria Exploratória Diferencial (DSC)}

As análises de DSC das amostras foram realizadas no equipamento da marca PerkinEImer modelo DSC 8000. Foi utilizada amostra com massa de aproximadamente $7,0 \mathrm{mg}$, colocadas em portas-amostra de alumínio. Foram realizadas corridas no intervalo de $25^{\circ} \mathrm{C}$ a $350^{\circ} \mathrm{C}$, com razão de aquecimento e resfriamento de $10^{\circ} \mathrm{C} / \mathrm{min}$, em atmosfera de nitrogênio com fluxo de $20 \mathrm{~mL} / \mathrm{min}$.

\subsubsection{Ensaio Mecânico de Tração}

As propriedades mecânicas das amostras obtidas foram avaliadas através de um ensaio mecânico de tração. Os corpos de prova obtidos por moldagem via injeção segundo a ASTM D1708 foram acondicionados em ambiente com umidade 
relativa de $45 \pm 2 \%$ por $48 \mathrm{~h}$. Os ensaios foram realizados em uma máquina universal de ensaios mecânicos EMIC DL3000 segundo a norma ASTM D638. Os ensaios foram realizados com velocidade de $5 \mathrm{~mm} / \mathrm{min}$ e com célula de carga de $500 \mathrm{kgf}$ com o objetivo de determinar o módulo elástico $(E)$, resistência à tração $\left(\sigma_{\max }\right)$ e deformação na ruptura $(\varepsilon)$ dos corpos de prova.

\subsubsection{Microscopia Eletrônica de Varredura (MEV)}

Foi utilizado um Microscópio Eletrônico de Varredura da marca FEl, modelo Magellan 400L, com aceleração de elétrons de $2 \mathrm{kV}$. As amostras dos corpos de prova, após a fratura criogênica foram colocadas em porta amostras de alumínio e revestidas com uma fina camada de ouro ( $3 \mathrm{~nm}$ ), utilizando o equipamento Balzers Sputter Coater SCD 004 e Union CED 020. 


\section{RESULTADOS E DISCUSSÃO}

\subsection{Caracterização das nanofibras de celulose (NFC)}

\subsubsection{Espectroscopia na região do infravermelho (IV)}

O espectro na região de infravermelho da NFC está representado na figura 10. O espectro é característico de material celulósico, conforme se pode confirmar na tabela 7.

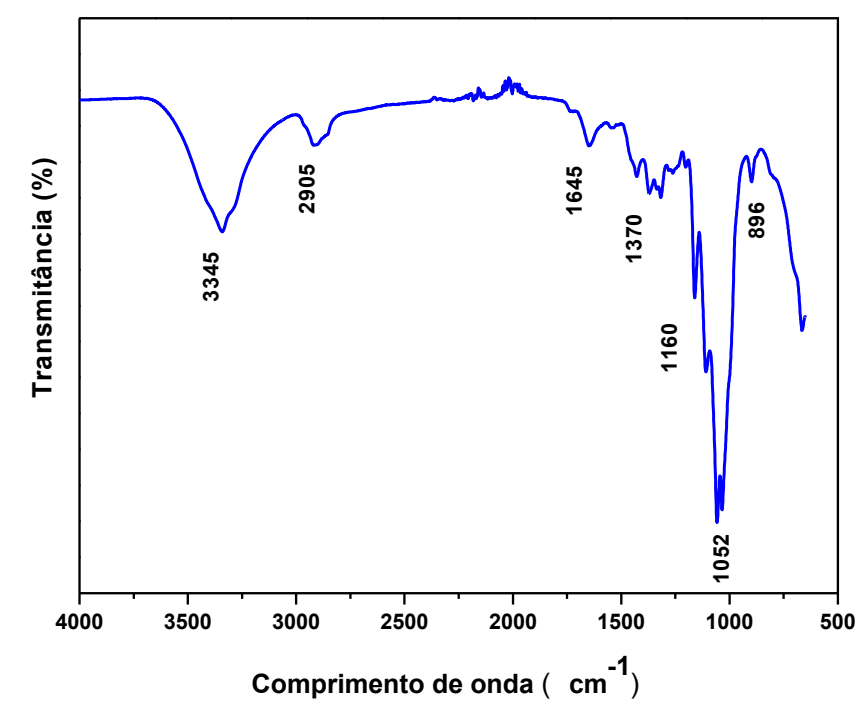

Figura 10. Espectro na região de infravermelho da NFC.

Tabela 7. Principais bandas observadas no espectro na região do infravermelho da NFC e seus respectivos modos vibracionais [SILVERSTEIN, 2007; ALEMDAR; SAIN, 2008a; MORELLI et al., 2012].

\begin{tabular}{cc}
\hline Comprimento de onda $\left(\mathbf{c m}^{-1}\right)$ & Atribuições \\
\hline $3350-3330$ & $\begin{array}{r}\text { Estiramento ou deformação axial de O-H (ligações } \\
\text { hidrogênio intra e intermoleculares). }\end{array}$ \\
\hline $2930-2900$ & Estiramento da ligação C-H de hidrocarbonetos saturados. \\
\hline 1645 & Estiramento das ligações C-C do anel aromático. \\
\hline 1370 & Deformação angular simétrica e assimétrica da ligação C- \\
H de grupos metila.
\end{tabular}




\subsubsection{Difração de Raios $X$}

A figura 11 mostra o difratograma obtido na análise de raios $X$ da NFC, através do qual foi possível calcular a cristalinidade da mesma, como descrito no procedimento experimental (item 3.2.2). Avaliando-se o perfil do difratograma notase o pico característico e bem definido da estrutura da celulose em torno $22,5(2 \theta)$ e dois picos secundários em 12 e $16(2 \theta)$, referentes aos seus planos cristalográficos (KLEMM et al., 2005; MORELLI et al., 2012; PANTHAPULAKKAL; SAIN, 2012). O grau de cristalinidade encontrado foi de $73 \%$, valor similar a outros reportados na literatura (ALEMDAR; SAIN, 2008a; ALEMDAR; SAIN, 2008b; PANTHAPULAKKAL; SAIN, 2012). O alto grau de cristalinidade se deve ao processo de obtenção das NFC, que remove boa parte das regiões não cristalinas presentes na mesma.

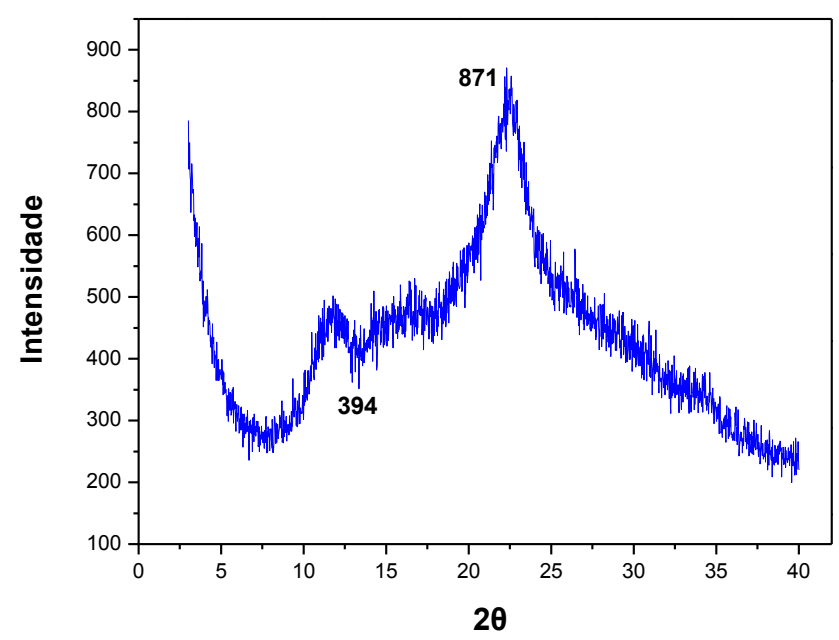

Figura 11. Difratograma de raios $X$ da NFC.

\subsubsection{Análise Termogravimétrica (TG)}

A termogravimetria permite avaliar a estabilidade térmica dos materiais, que também corresponde a uma propriedade muito importante para definir a faixa de aplicação de um determinado material.

As curvas de análise térmica (TG e dTG) para a NFC é apresentada na figura 12. A primeira queda da curva em $100^{\circ} \mathrm{C}$, indicando a primeira perda de massa, corresponde à perda de água da amostra. A curva manteve-se praticamente constante até aproximadamente $290^{\circ} \mathrm{C}$ e a perda de massa a partir da temperatura ambiente até esse ponto foi em torno de 10\%. A decomposição da nanofibra inicia- 
se em torno de $295^{\circ} \mathrm{C}\left(\mathrm{T}_{\mathrm{i}}\right)$, correspondendo à decomposição da celulose, e segue até praticamente massa constante em torno de $430^{\circ} \mathrm{C}\left(\mathrm{T}_{\mathrm{f}}\right)$. $\mathrm{O}$ teor de resíduos foi aproximadamente $6,5 \%$. A curva de dTG mostra a perda máxima de massa da NFC em $390^{\circ} \mathrm{C}$ ( $\left.T_{\text {deg.máx. }}\right)$. Esta melhor estabilidade térmica encontrada em comparação com outras fibras naturais é devido também ao processo de obtenção das NFC, que elimina uma grande quantidade da lignina e hemicelulose. Os resultados encontrados são consistentes com os relatados na literatura (ALEMDAR; SAIN, 2008a; ALEMDAR; SAIN, 2008b; PANTHAPULAKKAL; SAIN, 2012).

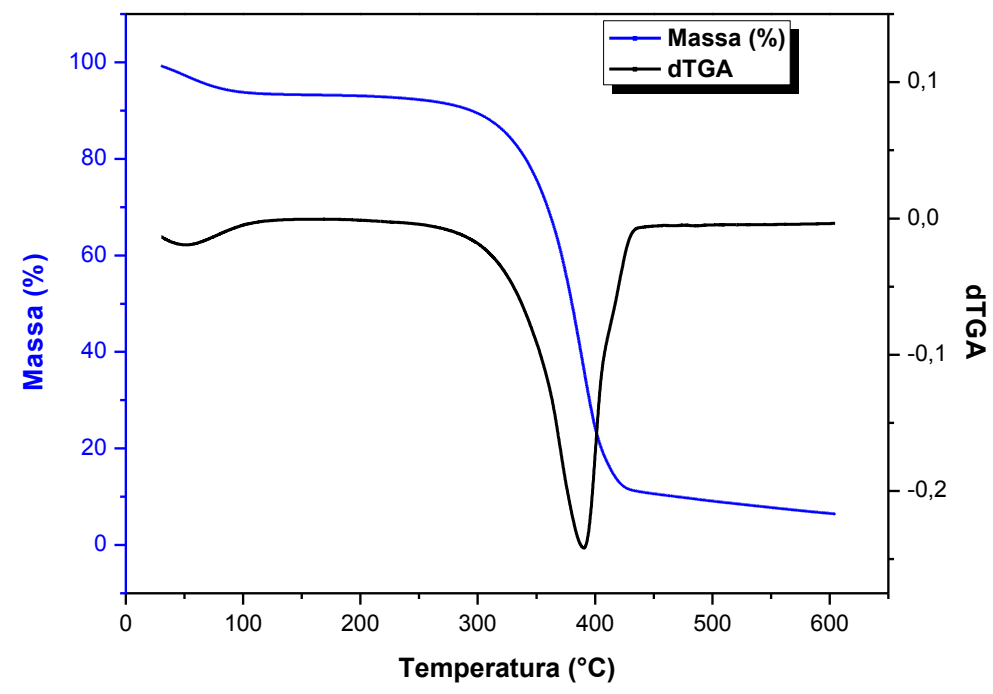

Figura 12. Curvas de TG e dTG da NFC (atmosfera de $\mathrm{N}_{2}$ ).

\subsubsection{Microscopia Eletrônica de Transmissão (MET)}

A figura 13 mostra a imagem de microscopia eletrônica de transmissão da NFC obtida no Centro de Biocompósitos e Processamento de Biomateriais, Canadá. A nanofibra recebida possui valores médios de diâmetro de 10-25 nm e comprimento de vários nanômetros (800 - $1100 \mathrm{~nm}$ ), o que leva a uma razão de aspecto (L/D) de 110-30. 


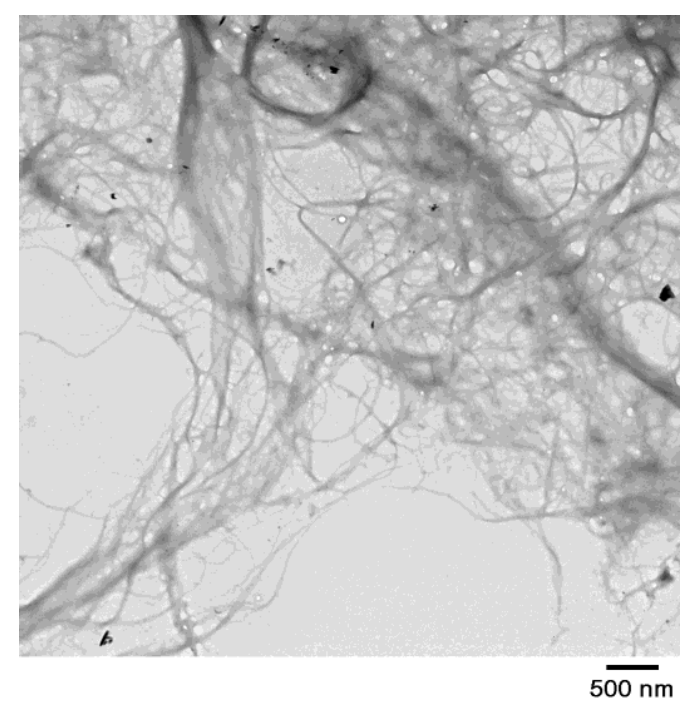

Figura 13. Microscopia eletrônica de transmissão da NFC [gentilmente cedida pelo grupo do Prof. Sain].

\subsection{Caracterização das Poliamidas}

\subsubsection{Análise Termogravimétrica (TG)}

As curvas de análise térmica (TG e dTG) para os polímeros puros de PA66Rec e PA66 são apresentadas na figura 14 e 15, respectivamente.

Considerando a curva na figura 14, da temperatura ambiente até aproximadamente $420^{\circ} \mathrm{C}$ a perda de massa foi de apenas $2 \%$, em média, correspondendo à perda de umidade que pode ainda estar presente no polímero. A decomposição da PA66-Rec inicia-se em torno de $440^{\circ} \mathrm{C}$, indo praticamente com massa constante até aproximadamente $550^{\circ} \mathrm{C}$. O teor de resíduos em $600^{\circ} \mathrm{C}$ foi aproximadamente 2,5\%. Este pode estar associado ao óleo de usinagem usado no processo de produção dos fios têxteis, ao $\mathrm{TiO}_{2}$ (cerca de 0,6\%) presente no polímero após reciclagem e a demais resíduos oriundos do processo de síntese. O pico na curva dTG, que se encontra em $517^{\circ} \mathrm{C}$, corresponde à perda máxima de massa da PA66Rec. 


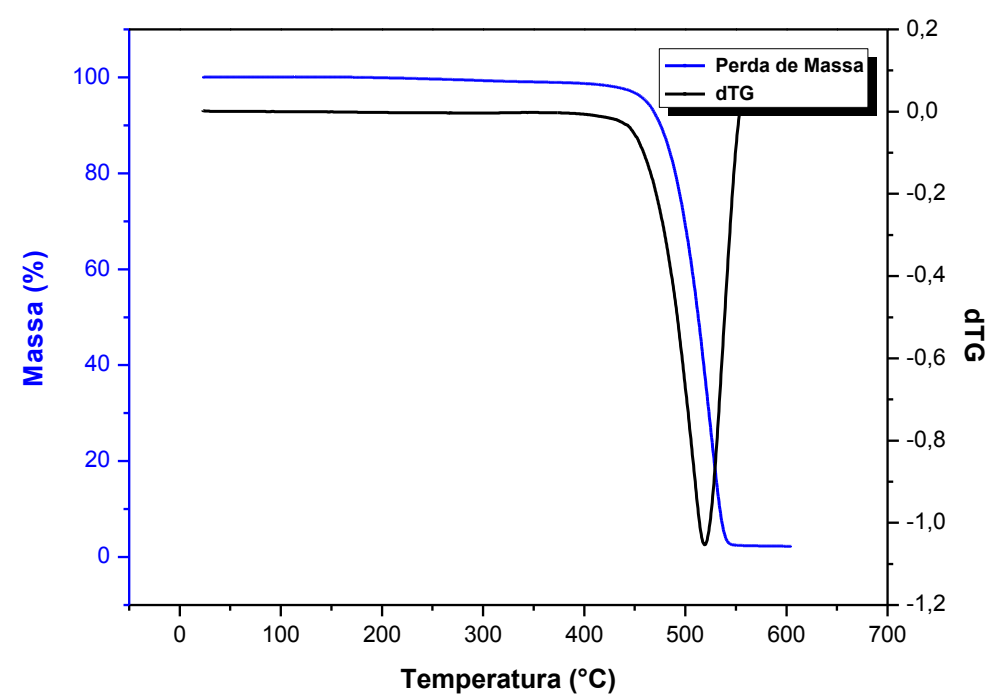

Figura 14. Curvas de TG e dTG da PA66Rec (atmosfera de $\mathbf{N}_{2}$ ).

Para a PA66 (Figura 15) da temperatura ambiente até aproximadamente $370^{\circ} \mathrm{C}$ a perda de massa também foi de apenas $2 \%$, em média, correspondendo à perda de umidade. A decomposição para essa poliamida inicia-se em torno de $380^{\circ} \mathrm{C}$, indo praticamente com massa constante até aproximadamente $700^{\circ} \mathrm{C}$. O teor de resíduos em $600^{\circ} \mathrm{C}$ foi aproximadamente $0,4 \%$. A perda de massa máxima se encontra em $468^{\circ} \mathrm{C}$ na curva dTG para a PA66. Os resultados encontrados são consistentes com os relatados na literatura (SALEHI-MOBARAKEH et al., 2012).

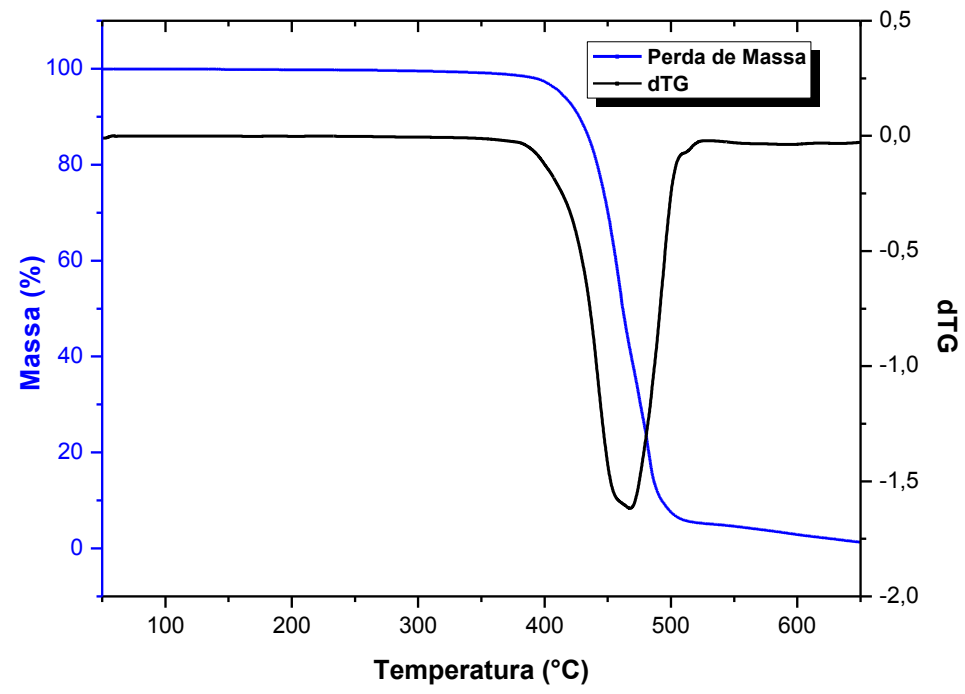

Figura 15. Curvas de TG e dTG da PA66 (atmosfera de $\mathrm{N}_{2}$ ). 


\subsubsection{Calorimetria Exploratória Diferencial (DSC)}

A calorimetria exploratória diferencial foi empregada para identificar a temperatura de fusão $\left(T_{m}\right)$, temperatura de cristalização $\left(T_{c}\right)$, calcular as entalpias de fusão $\left(\Delta \mathrm{H}_{m}\right)$ e de cristalização $\left(\Delta \mathrm{H}_{\mathrm{c}}\right)$, bem como o grau de cristalinidade $\left(\mathrm{X}_{\mathrm{C}}\right)$ dos polímeros puros. Todas as propriedades foram calculadas com o auxílio do software Pyris Manager. A figura 16 mostra as curvas de DSC para a PA66Rec e para a PA66. Na tabela 8 encontram-se os resultados obtidos a partir das mesmas.

O grau de cristalinidade foi calculado de acordo com a equação 2 , utilizando 0 valor de entalpia de fusão do polímero hipoteticamente $100 \%$ cristalino $\left(\Delta \mathrm{H}_{\mathrm{m}}{ }^{0}\right)$. $\mathrm{O}$ valor considerado e comumente utilizado para uma PA66 é de 195,9 J/g (HÖGLUND et al., 2012; SALEHI-MOBARAKEH et al., 2012; ZHANG et al., 2006).

$$
\mathbf{X}_{\mathrm{c}}=\left(\left[\Delta \mathrm{H}_{\mathrm{m}}\right] /\left[\Delta \mathrm{H}_{\mathrm{m}}{ }^{0}\right]\right) \mathbf{x 1 0 0} \quad \text { Equação (2) }
$$

Os picos endotérmicos em torno de $260^{\circ} \mathrm{C}$ correspondem à fusão dos polímeros e os picos exotérmicos em torno de $220^{\circ} \mathrm{C}$ correspondem à cristalização dos mesmos. Esses valores, bem como o grau de cristalinidade estão coerentes com os valores fornecidos pelo fabricante (Tabela 3), para a PA66, e próximos dos valores encontrados na literatura (BESCO et al, 2011; BOUSSIA; VOUYIOUKA; PAPASPYRIDES, 2012; LI et al., 2007; SALEHI-MOBARAKEH et al., 2012).

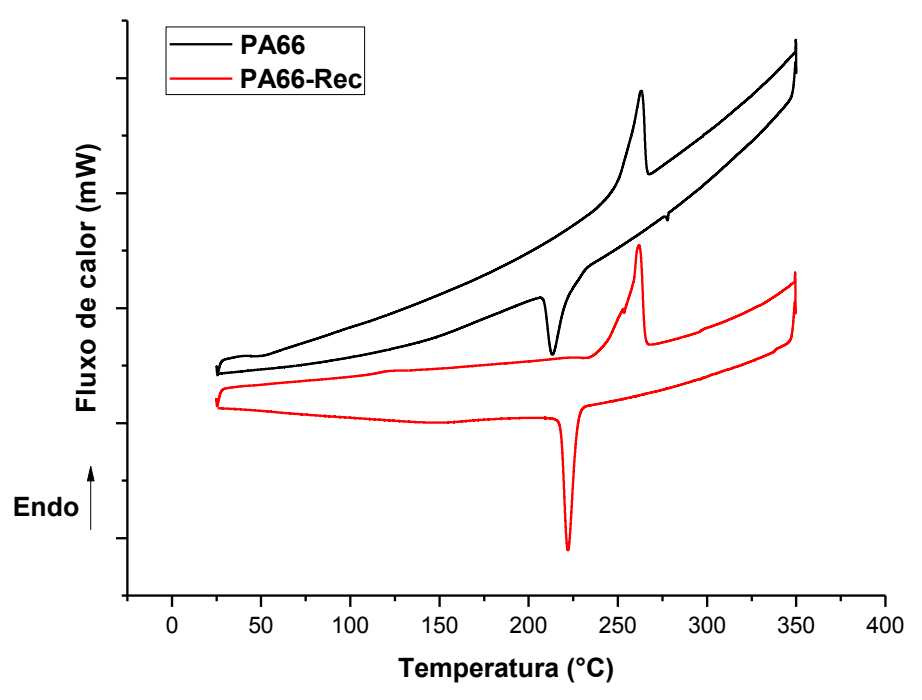

Figura 16. Curva de DSC da PA66 e da PA66Rec. 
Tabela 8. Propriedades térmicas obtidas a partir do DSC da PA66 e da PA66-Rec.

\begin{tabular}{cccccc}
\hline Polímero & $\mathrm{T}_{\mathrm{m}}\left({ }^{\circ} \mathrm{C}\right)$ & $\mathrm{T}_{\mathrm{c}}\left({ }^{\circ} \mathrm{C}\right)$ & $\Delta \boldsymbol{H}_{\mathrm{m}}(\mathrm{J} / \mathrm{g})$ & $\Delta \boldsymbol{H}_{\mathrm{c}}(\mathrm{J} / \mathrm{g})$ & $\mathrm{X}_{\mathrm{c}}(\%)$ \\
\hline PA66Rec & 262 & 222 & 74 & -56 & 38 \\
\hline PA66 & 263 & 214 & 66 & -50 & 34 \\
\hline
\end{tabular}

\subsection{Obtenção e caracterização das amostras estudadas}

A necessidade de fazer a alimentação concomitante com os pellets durante a extrusão para amostras que passaram pelo pré-processamento foi identificada na primeira amostra processada (BPA66), não sendo possível a obtenção da mesma. Solucionado o problema, foi possível obter os demais corpos de prova. Todos os corpos de prova obtidos foram homogêneos e de coloração diferente com relação aos pellets (Figura 17). $\mathrm{O} \mathrm{TiO}_{2}$ presente na PA66Rec age como um branqueador, influenciando na coloração dos corpos de prova obtidos com essa poliamida. Em geral, no caso das amostras sem NFC, o escurecimento das mesmas é possivelmente devido à degradação pirolítica das poliamidas. Já no caso das amostras com NFC, pode ser indicação da decomposição térmica da NFC.

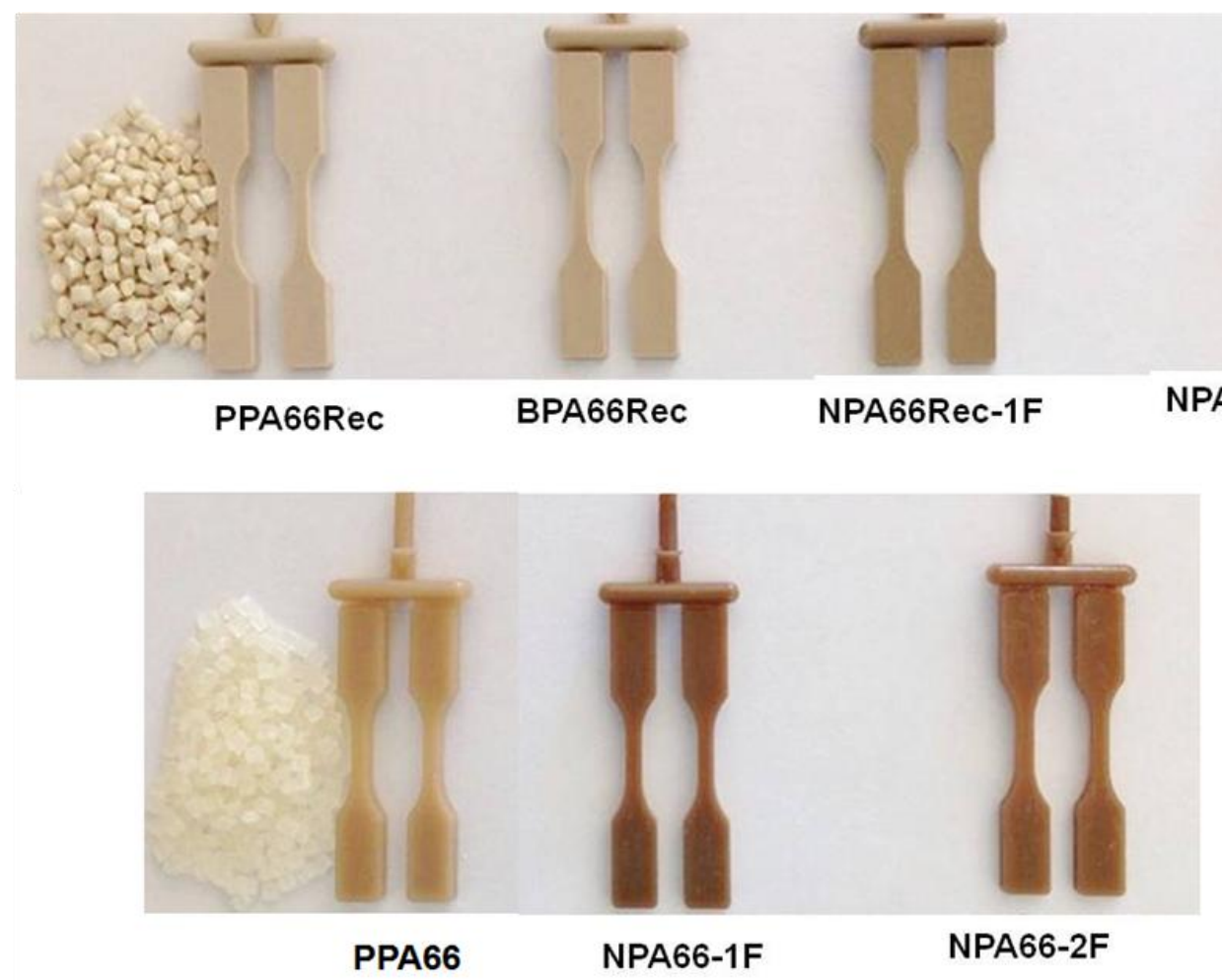

Figura 17. Corpos de prova das amostras obtidos após o processamento. 


\subsubsection{Análise Termogravimétrica (TG)}

As análises termogravimétricas foram realizadas nos nanocompósitos obtidos a partir da extrusão e moldagem por injeção. Nas figuras $18 \mathrm{a}$ e $18 \mathrm{~b}$ são apresentadas as curvas de TG e dTG, respectivamente, dos corpos de prova obtidos com a PA66Rec. Os dados obtidos a partir da análise, com o auxílio do software Pyris Manager, são apresentados na tabela 9.

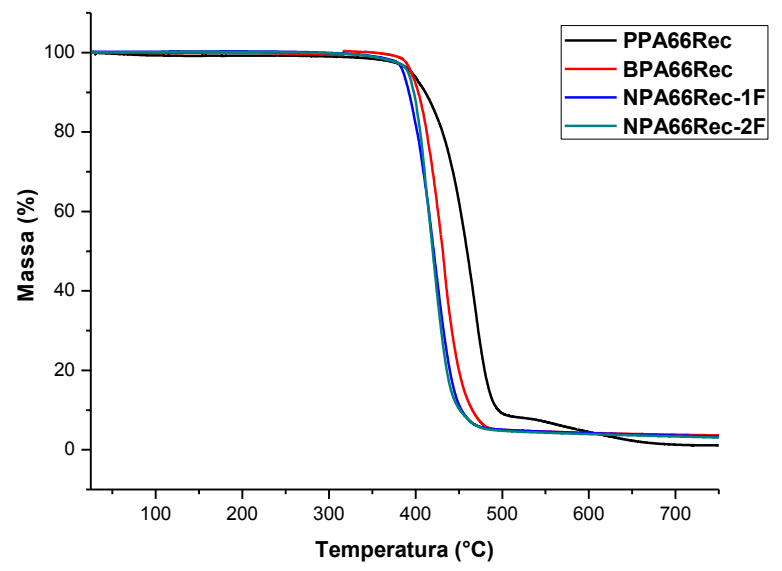

(a)

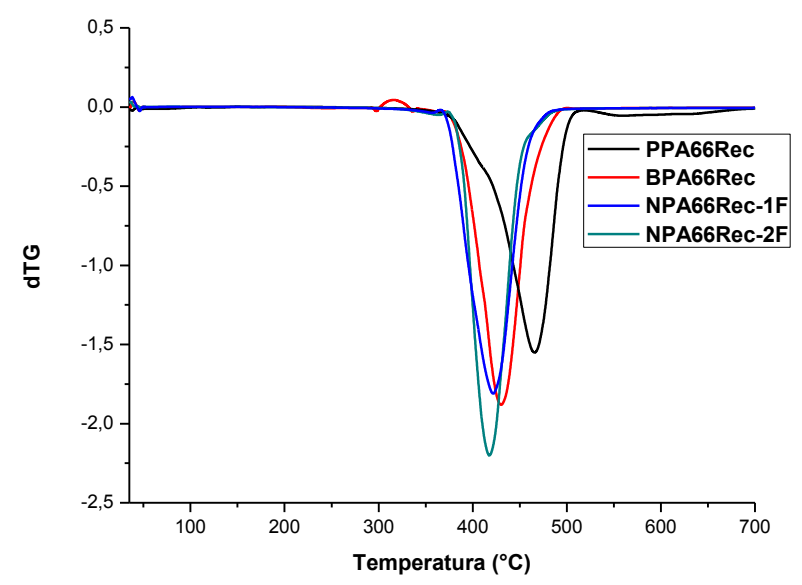

(b)

Figura 18. Curvas de (a) TG e (b) dTG para as amostras com PA66Rec (atmosfera de $\mathrm{N}_{2}$ ).

Tabela 9. Parâmetros da curva TG/dTG das as amostras com PA66Rec.

\begin{tabular}{ccccccc}
\hline Amostra & $\mathbf{T}_{\mathbf{i}}\left({ }^{\circ} \mathbf{C}\right)$ & $\mathbf{T}_{\mathbf{f}}\left({ }^{\circ} \mathbf{C}\right)$ & $\begin{array}{c}\text { Resíduos } \\
(\%)\end{array}$ & $\begin{array}{c}\text { Voláteis } \\
(\%)\end{array}$ & $\begin{array}{c}\text { Massa } \\
(\%)\end{array}$ & $\begin{array}{c}\mathbf{T}_{\text {deg. máx. }} \\
\left({ }^{\circ} \mathbf{C}\right)\end{array}$ \\
\hline PPA66Rec & 360 & 680 & 1,1 & 0,8 & 96,9 & 465 \\
\hline BPA66Rec & 360 & 500 & 4,0 & 0,4 & 95,6 & 430 \\
\hline NPA66Rec-1F & 345 & 500 & 3,9 & 0,2 & 95,9 & 420 \\
\hline NPA66Rec-2F & 350 & 500 & 3,6 & 0,2 & 96,2 & 417 \\
\hline
\end{tabular}

Observa-se (Figura 18 e Tabela 9) que até $320^{\circ} \mathrm{C}$ todas as amostras apresentam estabilidade térmica semelhante e perda de massa de apenas $0,5 \%$, em média. O pré-processamento diminuiu ligeiramente a estabilidade térmica da PA66Rec, porém não influenciou a temperatura de decomposição inicial, apenas a 
temperatura final. Já a incorporação das NFC influenciou a Ti também, fazendo com que os nanocompósitos apresentassem estabilidade térmica menor, se comparados às amostras de polímero puro, isso porque as NFC se decompõem em temperatura inferior $\left(T_{i}=295^{\circ} \mathrm{C}\right.$, Figura 12) a da PA66Rec pura $\left(T_{i}=440^{\circ} \mathrm{C}\right.$, Figura 14). $\mathrm{A}$ decomposição dos nanocompósitos com NFC iniciou-se em torno de $345^{\circ} \mathrm{C}\left(\mathrm{T}_{\mathrm{i}}\right)$ e das amostras sem NFC em $360^{\circ} \mathrm{C}\left(\mathrm{T}_{\mathrm{i}}\right)$, indicando a influência do processamento na estabilidade térmica dos materiais. Os picos na curva dTG (Figura 18b) correspondem à perda máxima de massa das amostras de PA66Rec, encontrandose entre $415^{\circ} \mathrm{C}$ e $470^{\circ} \mathrm{C}$.

Nas figuras 19a e 19b são apresentadas as curvas de TG e dTG, respectivamente, dos corpos de prova obtidos com a PA66. Os dados obtidos a partir da análise são apresentados na tabela 10.

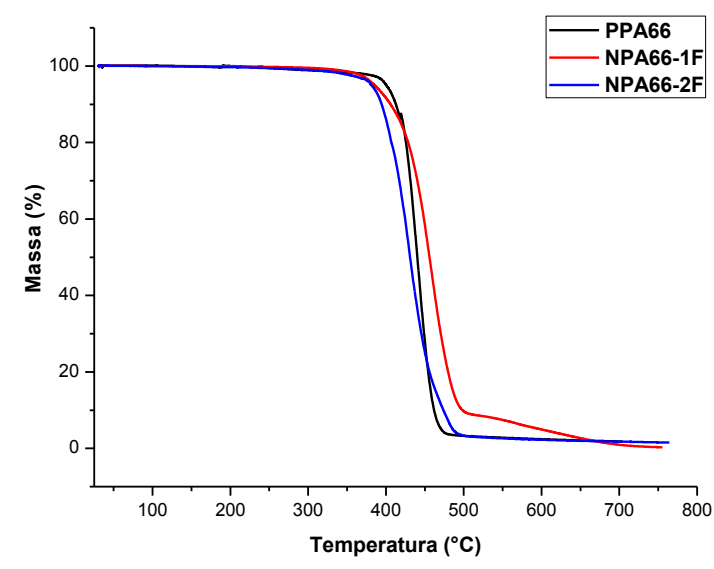

(a)

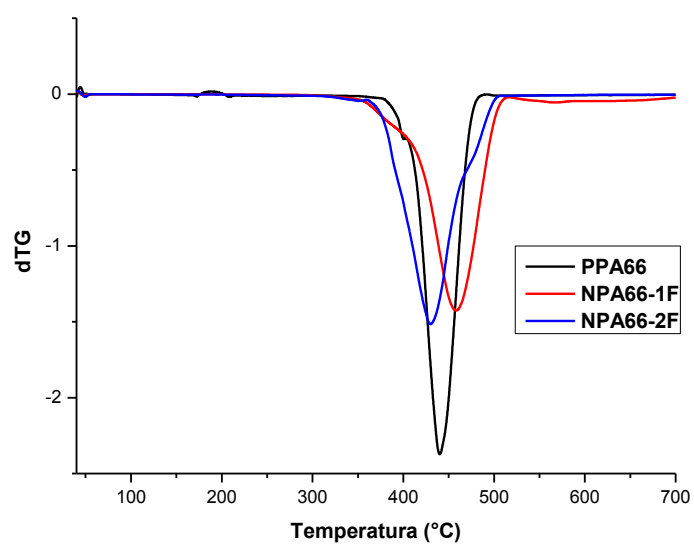

(b)

Figura 19. Curvas de (a) TG e (b) dTG para as amostras com PA66 (atmosfera de $\mathrm{N}_{2}$ ).

Tabela 10. Parâmetros da curva TG/dTG das amostras com PA66.

\begin{tabular}{ccccccc}
\hline Amostra & $\mathbf{T}_{\mathbf{i}}\left({ }^{\circ} \mathbf{C}\right)$ & $\mathbf{T}_{\mathbf{f}}\left({ }^{\circ} \mathbf{C}\right)$ & $\begin{array}{c}\text { Resíduos } \\
(\%)\end{array}$ & $\begin{array}{c}\text { Voláteis } \\
(\%)\end{array}$ & $\begin{array}{c}\text { Massa } \\
(\%)\end{array}$ & $\begin{array}{c}\mathbf{T}_{\text {deg. max. }} \\
\left({ }^{\circ} \mathbf{C}\right)\end{array}$ \\
\hline PPA66 & 370 & 510 & 2,0 & 0,9 & 97,1 & 440 \\
\hline NPA66-1F & 348 & 730 & 0,5 & 0,8 & 96,5 & 460 \\
\hline NPA66-2F & 334 & 510 & 2,0 & 0,9 & 97,1 & 430 \\
\hline
\end{tabular}


$\mathrm{Na}$ curva de TG da figura $19 \mathrm{a}$ observa-se que até $325^{\circ} \mathrm{C}$ todas as amostras apresentam estabilidade térmica semelhante e perda de massa de apenas 0,9\%, em média. Assim como para as amostras obtidas com PA66Rec, a estabilidade térmica dos nanocompósitos com NFC é menor do que a estabilidade térmica das amostras sem NFC, obtidas com PA66. A decomposição dos nanocompósitos com NFC iniciase em torno de $340^{\circ} \mathrm{C}\left(\mathrm{T}_{\mathrm{i}}\right)$ e da amostra sem NFC em $370^{\circ} \mathrm{C}\left(\mathrm{T}_{\mathrm{i}}\right)$. $\mathrm{O}$ fato da decomposição térmica da amostra de PA66 ter iniciado abaixo da decomposição térmica encontrada para o pellet (Figura 15) novamente indica a influência do processamento na estabilidade térmica dos materiais. Os picos na curva dTG (Figura 19b) correspondentes à perda máxima de massa das amostras com PA66 encontram-se entre $430^{\circ} \mathrm{C}$ e $460^{\circ} \mathrm{C}$.

\subsubsection{Calorimetria Exploratória Diferencial (DSC)}

Assim como para os polímeros puros, a calorimetria exploratória diferencial foi empregada para identificar as propriedades térmicas dos demais materiais estudados. Os resultados obtidos para as amostras com PA66Rec e PA66 são sumarizados nas tabelas 11 e 12 e as curvas do resfriamento, e do segundo aquecimento são apresentadas nas figuras 20 e 21, respectivamente. As curvas juntas, incluindo o primeiro aquecimento são apresentadas no apêndice A e B.

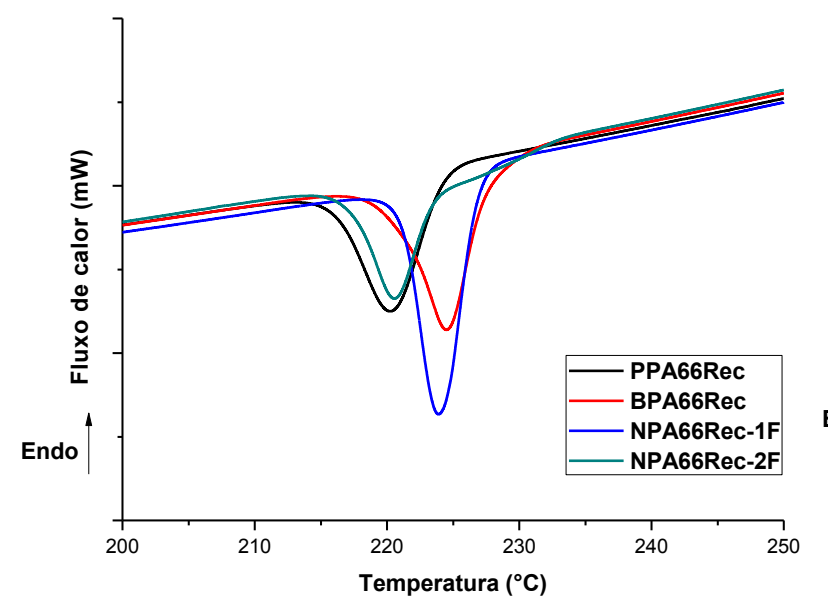

(a)

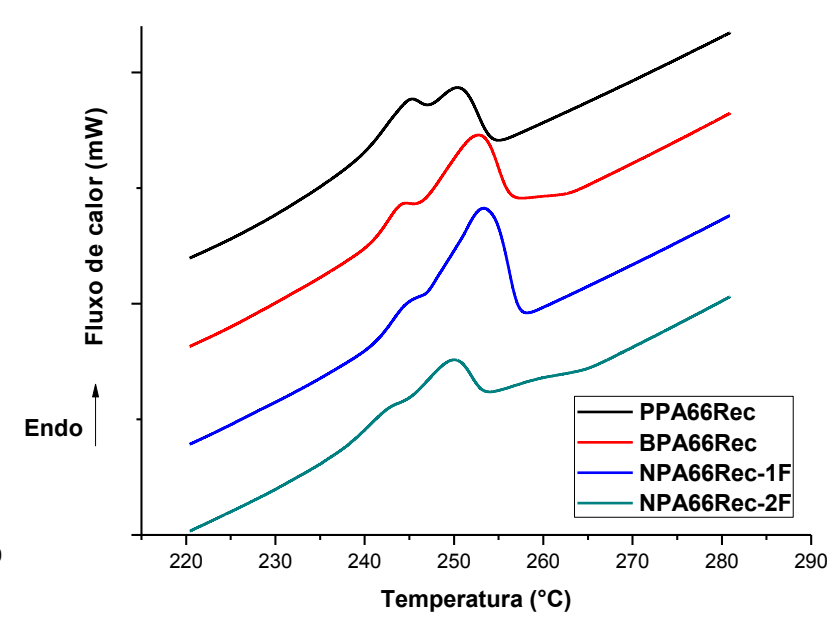

(b)

Figura 20. Curvas DSC para as amostras obtidas com PA66Rec: (a) resfriamento (b) segundo aquecimento. 
Tabela 11. Propriedades térmicas a partir do DSC das amostras obtidas com PA66Rec.

\begin{tabular}{ccccccc}
\hline Amostra & $\mathrm{T}_{\mathrm{m} 1}\left({ }^{\circ} \mathrm{C}\right)$ & $\mathrm{T}_{\mathrm{m} 2}\left({ }^{\circ} \mathrm{C}\right)$ & $\mathrm{T}_{\mathrm{c}}\left({ }^{\circ} \mathrm{C}\right)$ & $\Delta \boldsymbol{H}_{\mathrm{m}}(\mathbf{J} / \mathbf{g})$ & $\Delta \boldsymbol{H}_{\mathrm{c}}(\mathrm{J} / \mathbf{g})$ & $\mathrm{X}_{\mathrm{c}}(\%)$ \\
\hline PPA66Rec & 245 & 251 & 220 & 48 & -43 & 25 \\
\hline BPA66Rec & 244 & 253 & 225 & 46 & -45 & 24 \\
\hline NPA66Rec-1F & 245 & 254 & 224 & 51 & -48 & 26 \\
\hline NPA66Rec-2F & 242 & 250 & 221 & 38 & -45 & 19 \\
\hline
\end{tabular}

Observa-se (Figura 20 e Tabela 11) que o pré-processamento não influenciou as propriedades térmicas de fusão e cristalização da amostra BPA66Rec. Na Figura $20 \mathrm{a}$, que apresenta as curvas de resfriamento depois de apagada à história térmica com um primeiro aquecimento, é possível observar picos exotérmicos bem definidos entre $220^{\circ} \mathrm{C}$ e $225^{\circ} \mathrm{C}$. A adição de NFC não provocou grande mudança nas temperaturas de cristalização.

Nas curvas do segundo aquecimento apresentadas na figura 20b observa-se dois picos endotérmicos, um em torno de $240^{\circ} \mathrm{C}\left(\mathrm{T}_{\mathrm{m} 1}\right)$ e outro em torno de $250^{\circ} \mathrm{C}$ $\left(T_{\mathrm{m} 2}\right)$, comportamento característico para PA66 e está relacionado às diferentes condições de cristalização da amostra (BESCO et al, 2011; GUERRINI et al., 2009; LI et al., 2007; SALEHI-MOBARAKEH et al., 2012; SIMAL, 1998; ZHANG et al., 2006). Este comportamento é atribuído ao fenômeno de recristalização, no qual cristais pequenos ou com defeitos fundem em uma temperatura menor (primeiro pico endotérmico), recristalizam e, finalmente, fundem em uma temperatura maior (segundo pico endotérmico). A adição de NFC também não provocou grande mudança nas temperaturas de fusão e no grau de cristalinidade, com exceção da amostra NPA66Rec-2F, na qual houve uma redução do grau de cristalinidade, acompanhado pela redução do calor de fusão. Isso pode ser um indício de uma má incorporação das mesmas, uma vez que a incorporação efetiva da NFC, evidenciada pela boa interação $\mathrm{NFC} /$ matriz, afetaria a mobilidade e rigidez das cadeias do polímero, aumentando assim o grau de cristalinidade e a temperatura de fusão (SALEHI-MOBARAKEH et al., 2012; LU; WANG; DRZAL, 2008; ZHANG et al., 2006). 
Outro efeito esperado no caso de uma incorporação efetiva é o efeito nucleante das fibras, que acelera o crescimento dos cristais e assim aumenta a cristalização e a temperatura de cristalização. Entretanto, nas curvas de resfriamento (Figura 21a) para as amostras obtidas com PA66, na quais se observam os picos exotérmicos em torno de $220^{\circ} \mathrm{C}$ e $230^{\circ} \mathrm{C}$, a adição de NFC levou a uma redução das temperaturas de cristalização. Para nanocompósitos de PA66/nanotubos de carbono Li et al. (2007) atribuíram essa redução da temperatura de cristalização ao efeito de nucleação somado a um efeito de confinamento na difusão das cadeias poliméricas e no crescimento os cristais, retardando a cristalização. A soma desses efeitos leva a formação de cristais menores e menos perfeitos, o que pode se observar nas curvas do segundo aquecimento (Figura 21b) para as amostras com NFC, nas quais o primeiro pico endotérmico, referente a cristais menores e menos perfeitos como discutido anteriormente, torna-se mais intenso que o segundo pico endotérmico (HEDICKE et al., 2006; LI et al., 2007). Com a adição da NFC a área do primeiro pico aumentou enquanto que a área do segundo pico endotérmico diminuiu, sendo esse comportamento já relatado para nanocompósitos de PA66 reforçados com outras nanocargas, como a montimorilonita (LI et al., 2007; SALEHI-MOBARAKEH et al., 2012; ZHANG et al., 2003).

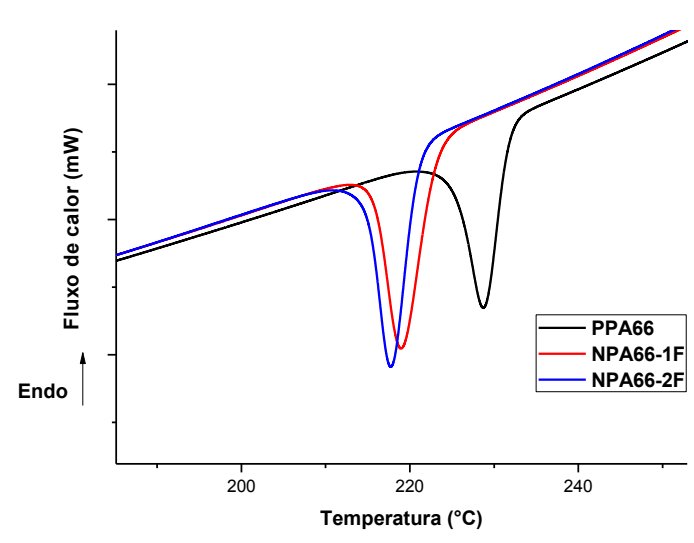

(a)

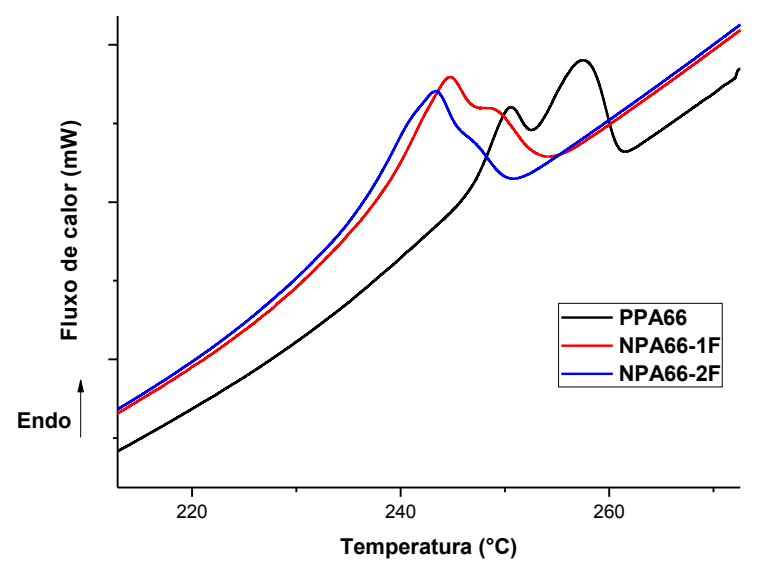

(b)

Figura 21. Curvas DSC para as amostras obtidas com a PA66: (a) resfriamento (b) segundo aquecimento. 
Tabela 12. Propriedades térmicas a partir do DSC das amostras obtidas com PA66.

\begin{tabular}{ccccccc}
\hline Amostra & $\mathrm{T}_{\mathrm{m} 1}\left({ }^{\circ} \mathrm{C}\right)$ & $\mathrm{T}_{\mathrm{m} 2}\left({ }^{\circ} \mathrm{C}\right)$ & $\mathrm{T}_{\mathrm{c}}\left({ }^{\circ} \mathrm{C}\right)$ & $\boldsymbol{\Delta} \boldsymbol{H}_{\mathrm{m}}(\mathbf{J} / \mathbf{g})$ & $\boldsymbol{\Delta} \boldsymbol{H}_{\mathrm{c}}(\mathrm{J} / \mathbf{g})$ & $\mathbf{X}_{\mathrm{c}}(\%)$ \\
\hline PPA66 & 250 & 258 & 229 & 32 & -37 & 16 \\
\hline NPA66-1F & 244 & 249 & 219 & 46 & -41 & 24 \\
\hline NPA66-2F & 243 & 250 & 218 & 42 & -38 & 22 \\
\hline
\end{tabular}

\subsubsection{Ensaio Mecânico de Tração}

Nas figuras 22 a 24 estão apresentadas as curvas tensão-deformação obtidas através dos ensaios de tração para as amostras com PA66Rec e PA66, respectivamente. Foram realizados cinco ensaios para cada amostra e com os valores obtidos foram calculadas as médias aritméticas e as estimativas de desvio padrão. Os valores médios do módulo elástico $(E)$, resistência à tração $\left(\sigma_{\max }\right)$ e deformação na ruptura $(\varepsilon)$, calculados a partir das curvas tensão-deformação estão apresentados nas figuras 23 e 25.

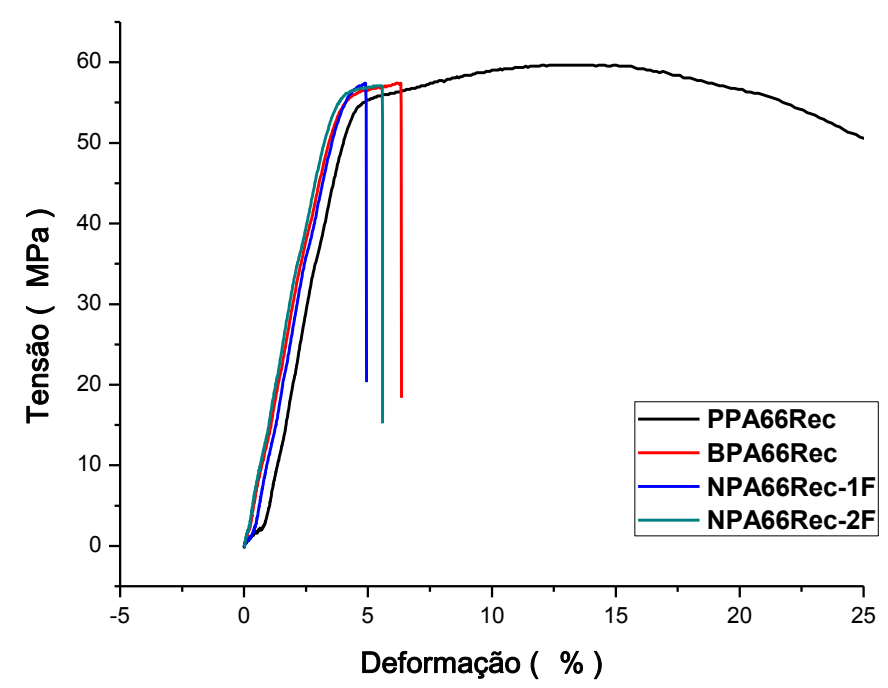

Figura 22. Curva tensão-deformação para os corpos de prova obtidos com PA66Rec. 


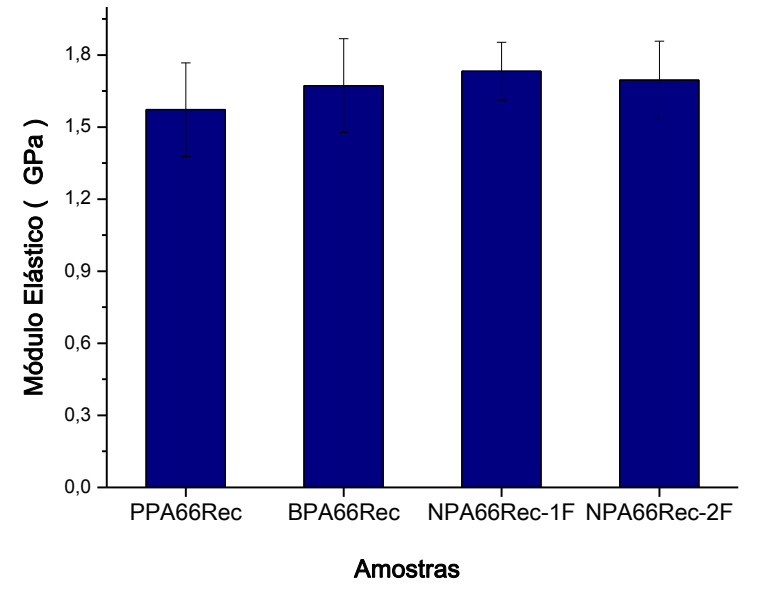

(a)

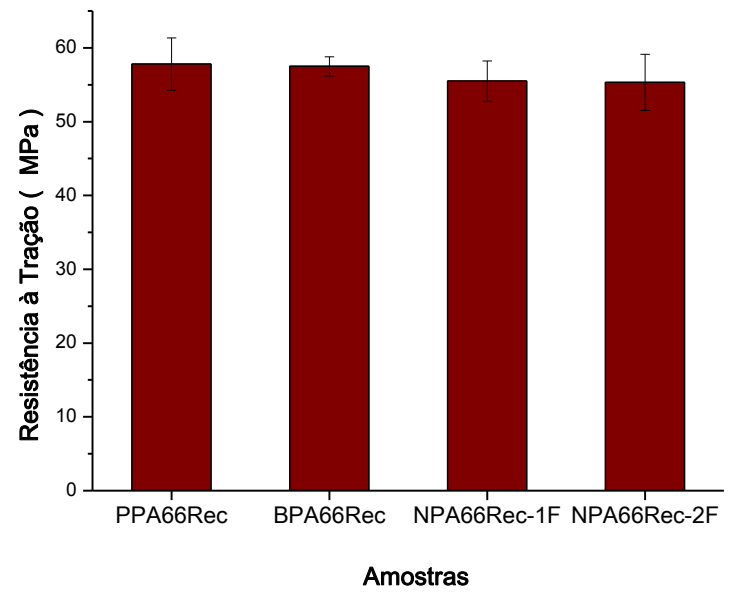

(b)

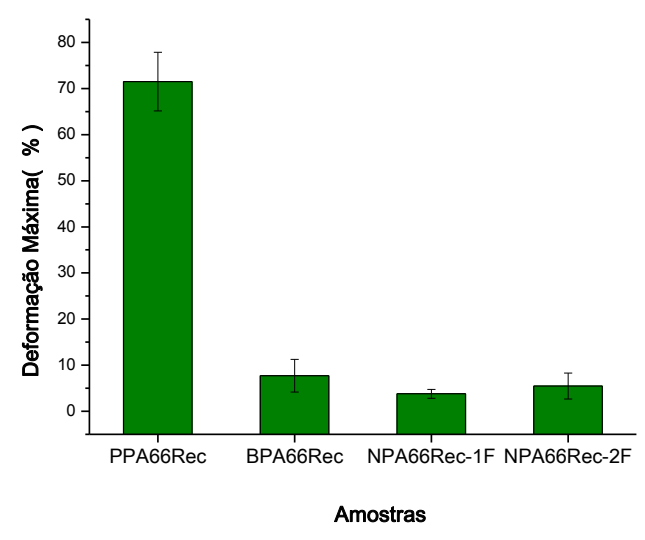

(c)

Figura 23. (a) Módulo elástico, (b) Resistência à tração e (c) Deformação máxima para os corpos de prova obtidos com a PA66Rec.

Observa-se (Figuras 22, 23a e 23b) que a etapa de pré-processamento não prejudicou o módulo elástico e a resistência a tração da PA66Rec. Considerando o erro, a adição de NFC também não influenciou o módulo elástico e a resistência a tração da PA66Rec (Tabela 13). As amostras que passaram pelo préprocessamento não tiveram grande deformação plástica e a deformação máxima diminuiu de 71,5 $\pm 6,4 \%$ (amostra PPA66Rec) para 7,7 $\pm 3,5 \%$ (amostra BPA66Rec), 3,8 $\pm 1,0 \%$ (amostra NPA66Rec-1F) e 5,5 $\pm 2,9 \%$ (amostra NPA66Rec-2F), correspondendo a uma redução de 92\%, em média (Figura 22 e 23c). Essa redução na ductibilidade com a adição de fibras em polímeros é uma tendência comumente observada para compósitos termoplásticos (IWATAKE; NOGI; YANO, 2008; JONOOBI et al., 2010; MATHEW; OKSMAN; SAIN, 2005). 
Tabela 13. Propriedades mecânicas das amostras obtidas com PA66Rec.

\begin{tabular}{cccc}
\hline Amostra & $\begin{array}{c}\text { Módulo } \\
\text { elástico (GPa) }\end{array}$ & $\begin{array}{c}\text { Resistência à } \\
\text { tração }(\mathrm{MPa})\end{array}$ & $\begin{array}{c}\text { Deformação na } \\
\text { ruptura (\%) }\end{array}$ \\
\hline PPA66Rec & $1,6 \pm 0,2$ & $59,1 \pm 3,9$ & $71,5 \pm 6,4$ \\
\hline BPA66Rec & $1,7 \pm 0,2$ & $57,5 \pm 1,3$ & $7,7 \pm 3,5$ \\
\hline NPA66Rec-1F & $1,7 \pm 0,1$ & $53,5 \pm 3,9$ & $3,8 \pm 1,0$ \\
\hline NPA66Rec-2F & $1,7 \pm 0,2$ & $55,3 \pm 3,8$ & $5,5 \pm 2,8$ \\
\hline
\end{tabular}

Para as amostras obtidas com a PA66 observou-se (Figuras 24, 25a e 25b) que o módulo elástico da mesma aumentou de 1,9 \pm 0,1 GPa (amostra PPA66) para $2,2 \pm 0,1 \mathrm{GPa}$ com adição de 1\% de NFC (amostra NPA66-1F), correspondendo a um aumento de $15 \%$. É comum para compósitos reforçados com celulose o aumento do módulo elástico, uma vez que a celulose é um material de alta cristalinidade que pode agir como entrecruzador físico, melhorando a rigidez do material (ALEMDAR; SAIN, 2008a; JONOOBI et al., 2010; LU; WANG; DRZAL, 2008; MATHEW; OKSMAN; SAIN, 2005; SOUZA et al., 2010).

Para esse polímero a adição do reforço reduziu de forma menos significativa a deformação máxima do material ( $28 \%$ em média) com relação às amostras obtidas com PA66Rec e NFC (Tabela 14). Entretanto, o próprio polímero puro processado da PA66 apresentou ductibilidade inferior ao da PA66Rec.

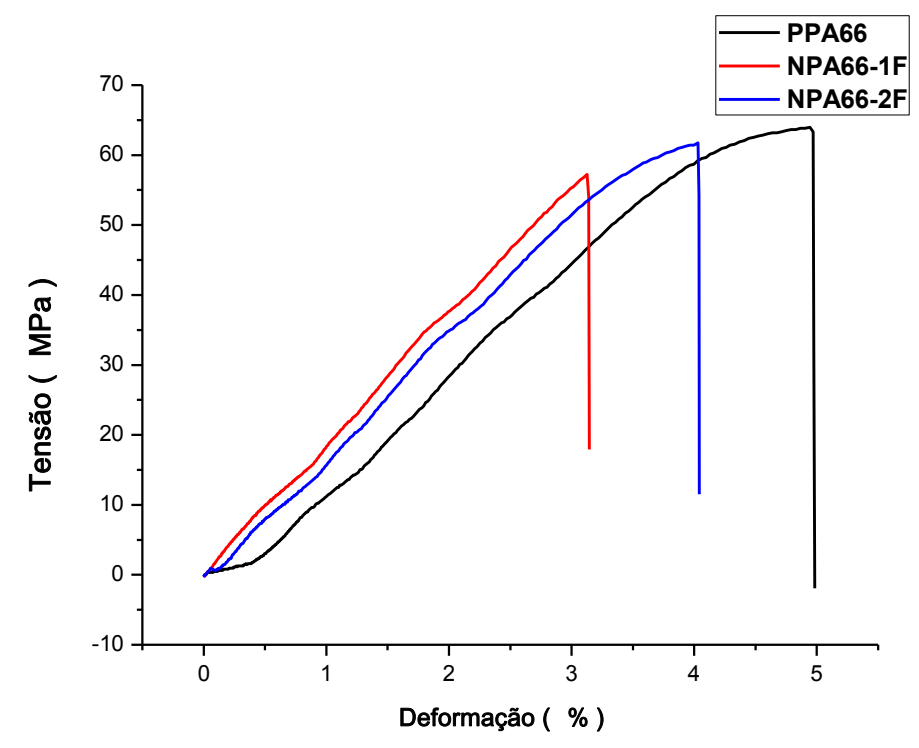

Figura 24. Curva tensão-deformação para os corpos de prova obtidos com PA66. 


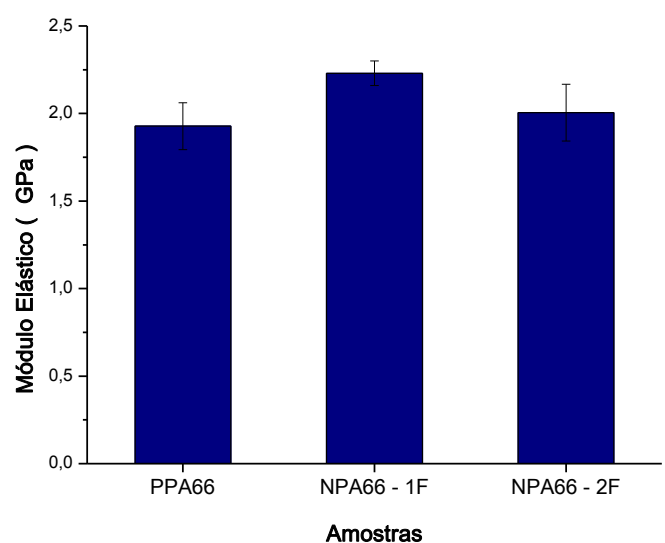

(a)

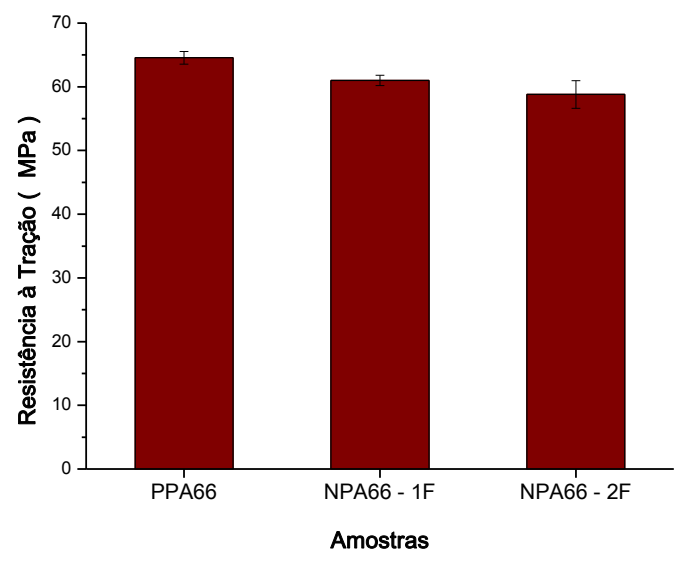

(b)

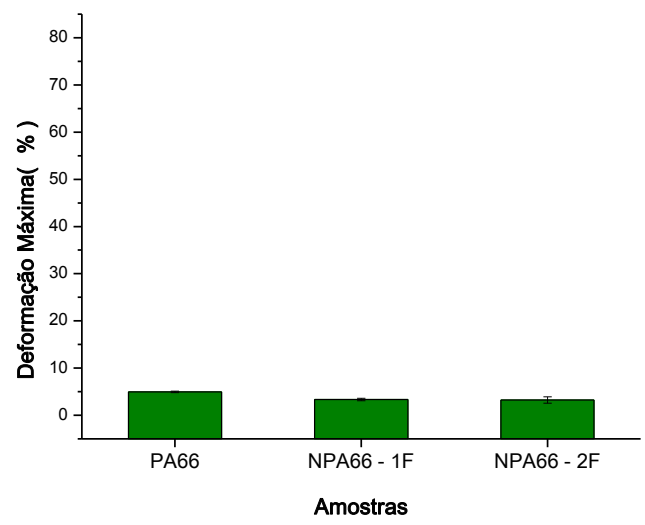

(c)

Figura 25. (a) Módulo elástico, (b) Resistência à tração e (c) Deformação máxima para os corpos de prova obtidos com a PA66.

Tabela 14. Propriedades mecânicas das amostras obtidas com PA66.

\begin{tabular}{cccc}
\hline Amostra & $\begin{array}{c}\text { Módulo } \\
\text { elástico (GPa) }\end{array}$ & $\begin{array}{c}\text { Resistência à } \\
\text { tração }(\mathrm{MPa})\end{array}$ & $\begin{array}{c}\text { Deformação na } \\
\text { ruptura (\%) }\end{array}$ \\
\hline PPA66 & $1,9 \pm 0,1$ & $64,5 \pm 1,0$ & $4,9 \pm 0,1$ \\
\hline NPA66-1F & $2,2 \pm 0,1$ & $61,0 \pm 0,8$ & $3,3 \pm 0,3$ \\
\hline NPA66-2F & $2,0 \pm 0,2$ & $54,0 \pm 5,0$ & $3,8 \pm 0,4$ \\
\hline
\end{tabular}




\subsubsection{Microscopia Eletrônica de Varredura (MEV)}

Foram analisadas as superfícies das fraturas, após a fratura criogênica dos corpos de prova obtidos por extrusão e moldagem por injeção. A figura 26a e 27a mostra as micrografias obtidas das matrizes puras após o processamento, PPA66Rec e PPA66, respectivamente. Nas figuras 26b e 26c, 27b e 27c são apresentadas as micrografias obtidas para as amostras com maior teor de NFC, NPA66Rec-2F e NP66-2F, respectivamente.

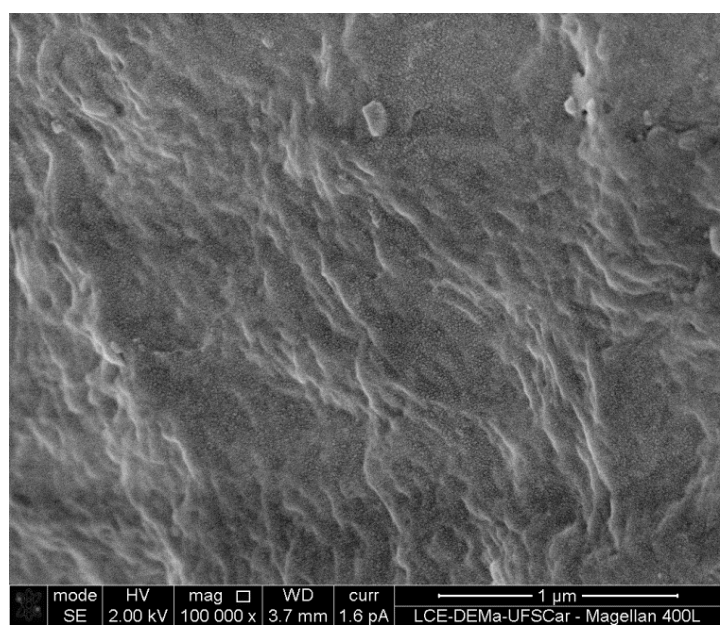

(a)

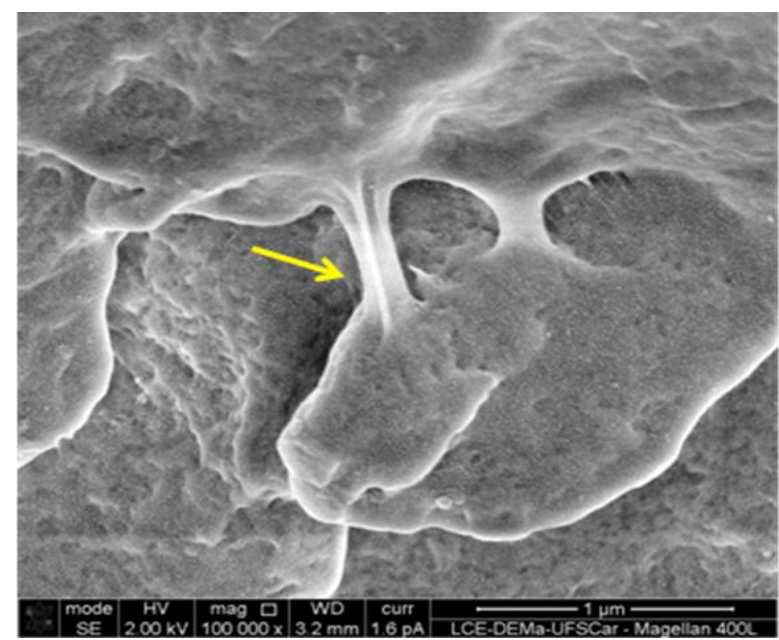

(b)

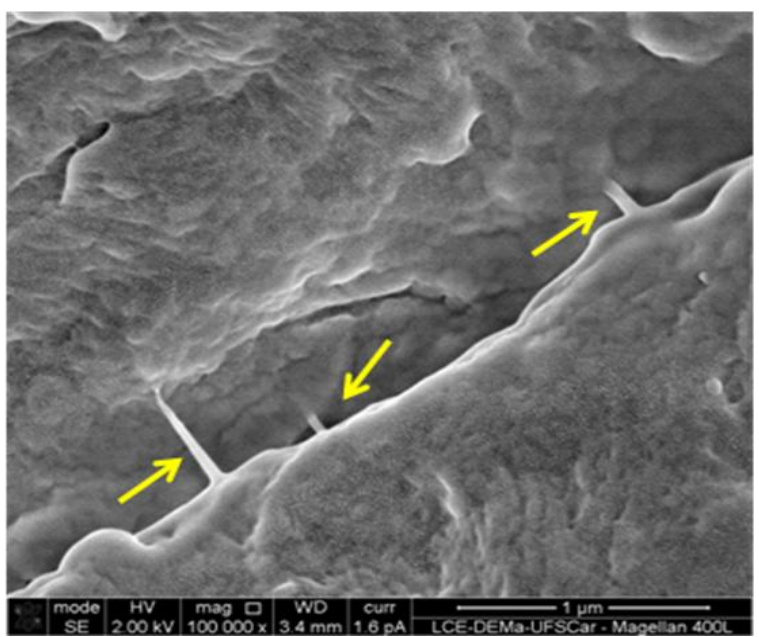

(c)

Figura 26. Micrografias das superfícies de fratura dos corpos de prova obtidos com a PA66Rec: (a) PPA66Rec, (b) e (c) NPA66Rec-2F. 


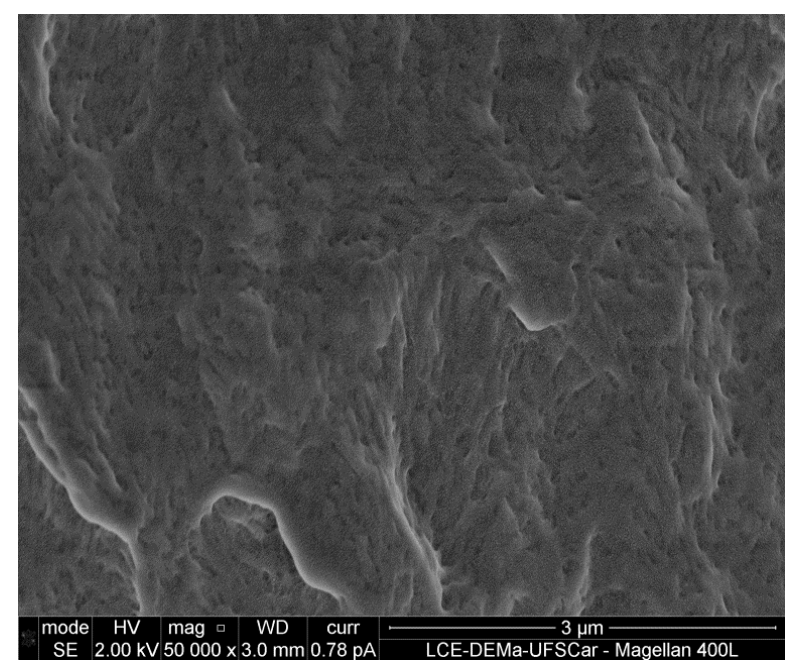

(a)

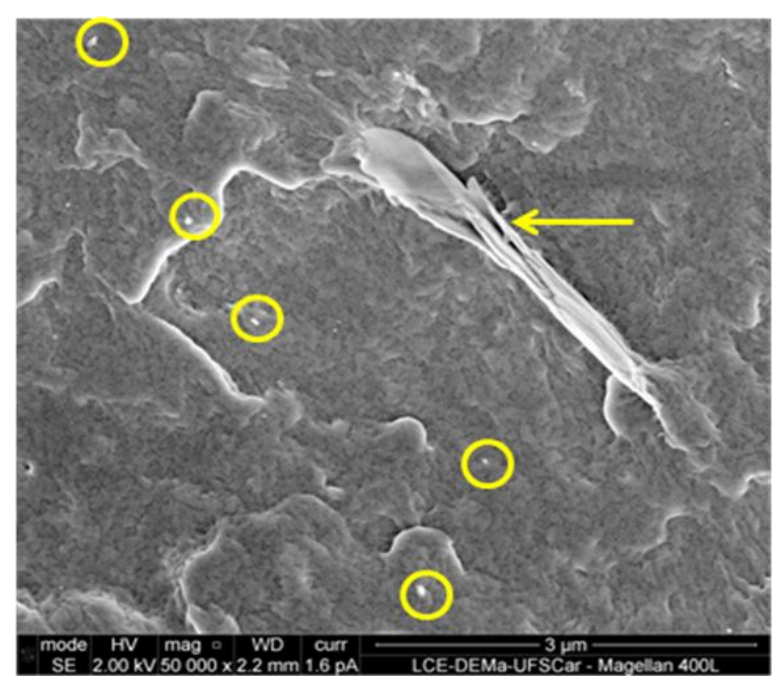

(b)

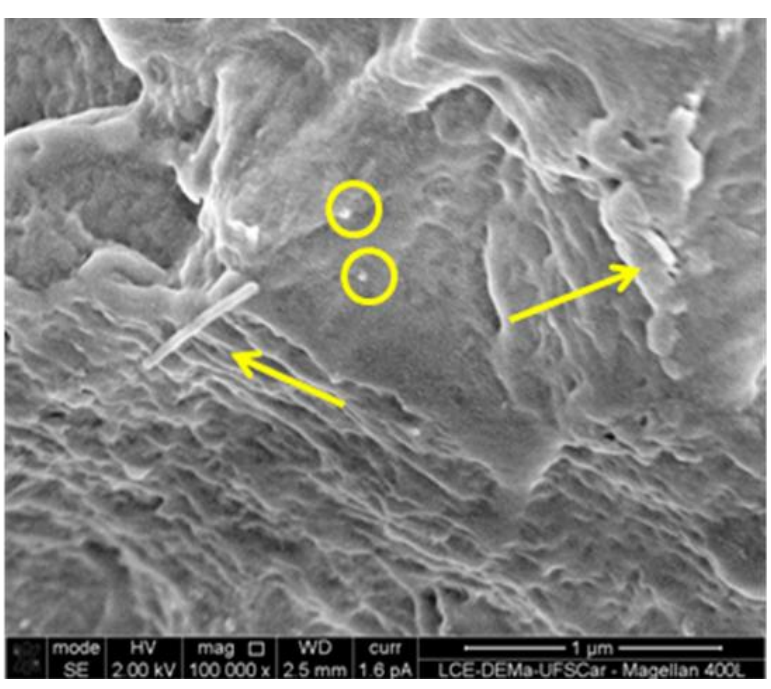

(c)

Figura 27. Micrografias das superfícies de fratura dos corpos de prova obtidos com a PA66: (a) PPA66, (b) e (c) NPA66-2F.

Diferente das amostras puras, nas demais micrografias foi possível identificar pequenos filamentos na horizontal (setas em amarelo), que possuem o diâmetro das NFC, assim como pontos (círculos em amarelo) podendo indicar as NFC na posição vertical ao plano. Observou-se que as NFC estão bem ancoradas na matriz. O préprocessamento e a extrusão foram suficientes para a dispersão das NFC nas matrizes 


\section{CONCLUSÃO}

A partir das caracterizações realizadas com a NFC foi possível observar sua boa estabilidade térmica, estando isso de acordo com alta cristalinidade também encontrada para estas. Quanto maior é a temperatura de início de decomposição, melhor é a estabilidade térmica dessas fibras em comparação com outras fibras naturais, indicando uma suscetibilidade para o processamento com termoplásticos, mesmo com polímeros de fusão elevada. As poliamidas 6,6 consideradas no trabalho (PA66Rec e PA66) apresentaram propriedades térmicas semelhantes. Entretanto a poliamida 6,6 reciclada mostrou melhor estabilidade térmica $(\mathrm{Ti}=$ $\left.440^{\circ} \mathrm{C}\right)$ se comparada à poliamida 6,6 virgem $\left(\mathrm{Ti}=380^{\circ} \mathrm{C}\right)$. Esse comportamento da PA66Rec se deve provavelmente ao processo de reciclagem química.

O pré-processamento resultou em material homogêneo, de fácil obtenção, sem alteração de coloração, porém com baixa densidade. A baixa densidade do material dificultou a etapa de alimentação na extrusora. Durante o processamento, outro grande desafio foi trabalhar no limite de temperatura de fusão das poliamidas antes que as NFC começassem a degradar. Entretanto, foi possível a obtenção de corpos de prova homogêneos, com uma coloração mais escura para os que continham NFC, já indicando a influência das mesmas na estabilidade térmica dos materiais finais. Os resultados de TG confirmaram a menor estabilidade térmica das amostras com NFC em relação as amostras sem NFC (PPA66Rec, BPA66Rec e PPA66). Para estas amostras sem NFC, a estabilidade térmica também foi menor em comparação com os pellets, mostrando a influência do pré-processamento e do próprio processamento.

Os resultados de DSC das amostras obtidas com a PA66Rec indicaram que 0 pré-processamento e a adição de NFC não modificaram significativamente as temperaturas de fusão e cristalização, bem como o grau de cristalinidade, com exceção da amostra NPA66Rec-2F. Para essa amostra, na qual a quantidade de nanofibra dobrou em relação a NPA66Rec- $1 F$, o grau de cristalinidade diminuiu de 26 para 19\%, indicando a principio uma má incorporação das NFC na matriz. Entretanto, os resultados de ensaio mecânico para essas amostras revelaram que, além do pré-processamento não ter prejudicado o módulo elástico e a resistência à tração, a adição de NFC em ambas as amostras (NPA66Rec-1F e NPA66Rec-2F) 
levou a um aumento de $10 \%$ do módulo elástico. As imagens de MEV para essas amostras mostraram a boa incorporação das NFC na matriz, refletindo assim nos resultados de ensaio mecânico.

Para as amostras obtidas com a PA66 observou-se a partir dos resultados de DSC que a adição de NFC reduziu a temperatura de cristalização e levou a um aumento do grau de cristalinidade de 16 para 23\%, em média. Esse aumento no grau de cristalinidade pode justificar o aumento do módulo elástico de $15 \%$ para as amostras com NFC, encontrado no ensaio mecânico de tração. As imagens de MEV para essas amostras também confirmaram a boa incorporação das NFC na matriz. A redução da deformação máxima observada para as amostras com NFC das duas poliamidas é comum de materiais mais rígidos. Houve essa redução mesmo para a amostra sem NFC (BPA66Rec), indicando novamente a influência do préprocessamento nas propriedades finais do material.

A partir das imagens de MEV obtidas foi possível identificar as NFC bem ancoradas nas matrizes de poliamida. Além da boa dispersão das mesmas, indicando a eficiência da etapa de pré-processamento. Com os resultados apresentados, podemos concluir que tanto o pré-processamento como a extrusão utilizados para dispersar e a incorporar as NFC, apesar de não melhorarem significantemente as propriedades mecânicas dos materiais finais, não prejudicou o módulo elástico e a resistência máxima à tração, podendo indicar uma alternativa de uso para poliamida 6,6 reciclada, dependendo da aplicação final do material. 


\section{SUGESTÕES PARA FUTUROS TRABALHOS}

Como sugestão para trabalhos futuros:

- Caracterizar por completo a amostra BPA66 processada.

- Estudar a influência da adição de maiores porcentagens de NFC nas propriedades dos nanocompósitos estudados.

- Avaliar o comportamento reológico dos materiais antes e após os processamentos realizados.

- Pensando na aplicação final desses materiais no setor automotivo, avaliar as propriedades de resistência ao impacto e de barreira à gases, à vapor de água e solventes combustíveis dos materiais finais. 


\section{REFERÊNCIAS BIBLIOGRÁFICAS}

ABIPLAST - ASSOCIAÇÃO BRASILEIRA DA INDÚSTRIA DO PLÁSTICO (2012). Disponível em: <http://file.abiplast.org.br/download/perfil_2011.pdf >. Acesso em: 08 Maio. 2012.

ALEMDAR, A.; SAIN, M. Biocomposites from wheat straw nanofibers: Morphology, thermal and mechanical properties. Composites Science and Technology, v. 68, p. 557-565, 2008a.

ALEMDAR, A.; SAIN, M. Isolation and characterization of nanofibers from agricultural residues - Wheat straw and soy hulls. Bioresource Technology, v. 99, p. 16641671, 2008b.

ALI, I.; ELLEITHY, R. Toughness of HDPE/CaCO3 Microcomposites Prepared from Masterbatch by Melt Blend Method. Journal of Applied Polymer Science, v.122, p. 3303-3315, 2011.

AMERICAN SOCIETY FOR TESTING AND MATERIALS. ASTM D638: Standard Test Method for Tensile Properties of Plastics. Philadelphia, 1991.

AMERICAN SOCIETY FOR TESTING AND MATERIALS. ASTM D1708: Standard Test Method for Tensile Properties of Plastics by Use of Microtensile Specimens. Philadelphia, 2010.

ARRAKHIZ, F. Z. et al. Mechanical and thermal properties of polypropylene reinforced with Alfa fiber under different chemical treatment. Materials and Design, v.35, p.318-322, 2012.

BAFILE, R. (2013). Metal é retirado da equação no novo painel de controle do VW Golf. Disponível em: <http://www.basf.com.br/default.asp?id=7494>. Acesso em: 30 Abr. 2013.

BEATRICE, C. A. G. et al. Nanocomposites of Polyamide 6/residual Monomer with Organic-modified Montmorillonite and their Nanofibers Produced by Electrospinning, Materials Research, v. 15, n. 4, p. 611-621, 2012. 
BLOG DO PLÁSTICO (2013). Informação atualizada sobre a indústria do plástico: Arquivos da categoria Poliamidas. Disponível em:

http://blogdoplastico.wordpress.com/category/resinas/poliamidas/. Acesso em: 10 Dez. 2013.

BOUSSIA, A. C.; VOUYIOUKA, S. N.; PAPASPYRIDES, C. D. Applying the Traditional Solution Melt Polymerization for the in situ Intercalation of Polyamide 6.6Clay Nanocomposites. Macromolecular Materials and Engineering, v. 297, p. 6874, 2012.

CALLISTER JR., W. D. Ciência e Engenharia de Materiais: uma introdução. Tradução Sérgio Murilo Stamile Soares. Ed. 8. Rio de Janeiro: LTC, 2012.

CANEVAROLO JR., S. V. Técnicas de caracterização de polímeros. São Paulo: Ardiber, 2003.

CANEVAROLO JR., S. V. Ciência dos Polimeros: Um texto básico para tecnólogos e engenheiros. São Paulo: Artliber, 2002.

CHANDA, M.; ROY, S. K. Industrial Polymers, Specialty Polymers, and Their Applications. Boca Raton: Taylor \& Francis Group, 2009.

DESHMANE, C.; YUANA, Q.; MISRA, R. D. K. On the fracture characteristics of impact tested high density polyethylene-calcium carbonate nanocomposites. Materials Science and Engineering A, v. 452-453, p. 592-601, 2007.

DORIGATO, A.; FAMBRI, L. Thermo-Mechanical Behavior of Polyamide 12-Polyamide 66 Recycled Fiber Composites. Polymer Composites, p. 786-795, 2011.

DURÁN, N.; MATTOSO, L. H. C.; MORAIS, P. C. Nanotecnologia: introdução, preparação e caracterização de nanomateriais e exemplos de aplicação. São Paulo: Artliber, 2006.

FENGEL, D.; WEGENER, G. Wood: Chemistry, Ultrastructure, Reactions. New York: Walter de Gruyter, 1989.

FERNANDES, R.; SANTO, A. M. E. (2009). Comportamento das propriedades físicas da poliamida 6.6 (nylon 6.6) após a reciclagem. Disponível em: 
<http://www.inicepg.univap.br/cd/INIC_2009/anais/arquivos/RE_0174_1240_03.pdf>. Acesso em: 23 Maio. 2013.

GUERRINI, L. M. et al. Electrospinning and Characterization of Polyamide 66 Nanofibers With Different Molecular Weights. Materials Research, v. 12, n. 2, p. 181-190, 2009.

HABIBI, Y. et al. Processing and characterization of reinforced polyethylene composites made with lignocellulosic fibers from Egyptian agro-industrial residues. Composites Science and Technology, v. 68, p. 1877-1885, 2008.

HEDICKE, K. et al. Crystallisation behaviour of Polyamide- 6 and Polyamide-66 nanocomposites. Composites Science and Technology, v. 66, p. 571-575, 2006.

HÖGLUND, A. et al. Odour perception e A rapid and easy method to detect early degradation of polymers. Polymer Degradation and Stability, v. 97, p. 481-487, 2012.

HUBER, T.; MÜSSIG, J. Fibre matrix adhesion of natural fibres cotton, flax and hemp in polymeric matrices analyzed with the single fibre fragmentation test. Composite Interfaces, v. 15, n. 2-3, p. 335-349, 2008.

IWATAKE, A.; NOGI, M.; YANO, H. Cellulose nanofiber-reinforced polylactic acid. Composites Science and Technology, v. 68, p. 2103-2106, 2008.

JAW AID, M.; KHALIL, H. P. S. A. Cellulosic/synthetic fibre reinforced polymer hybrid composites: A review. Carbohydrate Polymers, v.86, p. 1-18, 2011.

JOHN, M. J.; THOMAS, S. Biofibres and biocomposites: Review. Carbohydrate Polymers, v. 71, p. 343-364, 2008.

JONOOBI, M. et al. Mechanical properties of cellulose nanofiber (CNF) reinforced polylactic acid (PLA) prepared by twin screw extrusion. Composites Science and Technology, v.70, p. 1742-1747, 2010.

KARNANI, R.; KRISHNAN, M.; NARAYAN, R. Biofiber-Reinforced Polypropylene Composites. Polymer Engineering and Science, v.37, n. 2, p. 476-483, 1997. 
KEMAL, I. et al. Toughening of unmodified polyvinylchloride through the addition of nanoparticulate calcium carbonate. Polymer, v. 50, p. 4066-4079, 2009.

KEMAL, I. et al. Toughening of Unmodified Polyvinylchloride Through the Addition of Nanoparticulate Calcium Carbonate and Titanate Coupling Agent. Journal of Applied Polymer Science, v. 127, n. 3, p. 2339-2353, 2013.

KHALIL, H. P. S. A.; BHAT, A. H.; YUSRA, A. F. I. Green composites from sustainable cellulose nanofibrils: A review. Carbohydrate Polymers, v.87, p. 963979, 2012.

KIZILTAS, A. et al. Dynamic mechanical behavior and thermal properties of microcrystalline cellulose (MCC)-filled nylon 6 composites. Thermochimica Acta, v.519, p. 38-43, 2011.

KLEMM, D. et al. Cellulose: Fascinating biopolymer and sustainable raw material. Angewandte Chemie International Edition, v.44, p.3358-3393, 2005.

KLEMM, D. et al. Nanocelluloses: A New Family of Nature-Based Materials. Angewandte Chemie International Edition, v.50, p.5438-5466, 2011.

LI, L. et al. Structure and crystallization behavior of Nylon 66/multi-walled carbon nanotube nanocomposites at low carbon nanotube contents. Polymer, v. 48, p. 3452-3460, 2007.

LU, J.; WANG, T.; DRZAL, L. T. Preparation and properties of microfibrillated cellulose polyvinyl alcohol composite materials. Composites: Part A, v. 39, p. 738746, 2008.

MANTIA, F.P.L. et al. Rheological and Mechanical Behavior of LDPE/Calcium Carbonate Nanocomposites and Microcomposites. Journal of Applied Polymer Science, v. 127, n. 4, p. 2544-2552, 2013.

MATHEW, A. P.; OKSMAN, K.; SAIN, M. Mechanical properties of biodegradable composites from poly lactic acid (PLA) and microcrystalline cellulose (MCC). Journal of Applied Polymer Science, v. 97, p. 2014-2025, 2005.

MANRICH, S. Processamento de Termoplásticos. Ed. 2. São Paulo: Artliber, 2013. 
MINISTÉRIO DA FAZENDA (2012). IPI Balanço. Disponível em: <http://www.fazenda.gov.br/audio/2012/julho/a310712b.asp>. Acesso em: 22 Maio. 2013.

MORAES, R. (2012). País ganhará nova fábrica de compostos de poliamida. Disponível em:<http://www.plastico.com.br/reportagem.php?rrid=847>. Acesso em: 18 Abr. 2013.

MORELLI C. L. et al. Extraction and Characterization of Cellulose Nanowhiskers from Balsa Wood. Macromolecular Symposia., v. 319, p. 191-195, 2012.

NICOLAI, F. N. P.; BOTARO, V. R.; LINS, V. F.C. Effect of saline degradation on the mechanical properties of vinyl ester matrix composites reinforced with glass and natural fibers. Journal of Applied Polymer Science, v. 108, p. 2494-2502, 2008.

OKSMAN K. et al. Manufacturing process of cellulose whiskers/polylactic acid nanocomposites. Composites Science and Technology, v. 66, p. 2776-2784, 2006.

PANTHAPULAKKAL, S.; SAIN, M. Preparation and Characterization of Cellulose Nanofibril Films fromWood Fibre and Their Thermoplastic Polycarbonate Composites. International Journal of Polymer Science, v. 2012, p. 1-6, 2012.

RETO, M. A. S. (2012a). Compósitos: Programas do governo ajudam a elevar a demanda do setor, também impulsionada pelo avanço da energia eólica, dos agronegócios e outros mercados. Disponível em:

<http://www.plastico.com.br/plastico/compositos/compositos/>. Acesso em: 14 Maio. 2013.

RETO, M. A. S. (2012b). Plásticos Especiais: Montadoras movem novos desenvolvimentos na indústria de resina. Disponível em:

$<$ http://www.plastico.com.br/plastico/plastico/plasticos-especiais-montadorasmovem-novos-desenvolvimentos-na-industria-de-resina/>. Acesso em: 14 Maio. 2013.

REVISTA GLOBO RURAL (2011). Produtos naturais pegam carona na indústria de automóveis. Disponível em:

$<$ http://revistagloborural.globo.com/Revista/Common/0,,EMI239026-18281,00PRODUTOS+NATURAIS+PEGAM+CARONA+NA+INDUSTRIA+DE+AUTOMOVEIS .html>. Acesso em: 27 Nov. 2012. 
RODIONOVA, G.; LENES, M. Surface chemical modification of microfibrillated cellulose: improvement of barrier properties for packaging applications. Cellulose, v.18, p. 127-134, 2011.

RHODIA SOLVAY GROUP (2012). Rhodia, Valeo e PSA Peugeot Citroen confirmam benefícios ambientais de resina de poliamida reciclada para autopeças. Disponível em: <http://blogdoplastico.wordpress.com/2012/08/06/rhodia-valeo-e-psa-peugeotcitroen-confirmam-beneficios-ambientais-de-resina-de-poliamida-reciclada-paraautopecas/>. Acesso em: 18 Abr. 2013.

ROSATO, D. V. An Overview of Composites, Handbook of Composites. New York: Van Nostrand Reinhold Company, 1982.

SALEHI-MOBARAKEH, $\mathrm{H}$. et al. Modifying Montmorillonite Clay via Silane Grafting and Interfacial Polycondensation for Melt Compounding of Nylon-66 Nanocomposite. Journal of Applied Polymer Science, v. 124, p. 1501-1510, 2012.

SAMIR, M. A. S. A.; ALLOIN, F.; DUFRESNE, A. Review of Recent Research into Cellulosic Whiskers, Their Properties and Their Application in Nanocomposite Field. Biomacromolecules, v. 6, p. 612-626, 2005.

SANTOS, C. R. et al. Preparação e Caracterização de Nanofibras de Nanocompósitos de Poliamida 6,6 e Argila Montmorilonita. Polímeros, v. 21, n. 5, p. 398-408, 2011.

SILVERSTEIN, R. M.; WEBSTER, F. X.; KIEMLE, D. J. Identificação espectrométrica de Compostos Orgânicos. Ed. 7. Rio de Janeiro: LTC, 2007. p. 84-99.

SIQUEIRA, G.; BRAS, J.; DUFRESNE, A. Cellulose Whiskers versus Microfibrils: Influence of the Nature of the Nanoparticle and its Surface Functionalization on the Thermal and Mechanical Properties of Nanocomposites. Biomacromolecules, v. 10, p. 425-432, 2009.

SIMAL, A. B.; MARTIN, A. R. Structure of Heat-Treated Nylon 6 and 6.6 Fibers. II. Recrystallization Mechanism. Journal of Applied Polymer Science, v. 68, p. 453474, 1998.

SIMIELLI, E. R.; SANTOS, P. A. dos. Plásticos de Engenharia - Principais Tipos e Sua Moldagem por Injeção. Ed. 1. São Paulo: Artliber, 2010. 
SPOLJARIC, S.; GENOVESE, A.; SHANKS. R.A.. Polypropylene-microcrystalline cellulose composites with enhanced compatibility and properties. Composites: Part A, v. 40, p. 791-799, 2009.

SOUZA, S.F. et al. Nanocellulose from Curaua Fibers and their Nanocomposites. Molecular Crystals and Liquid Crystals, v. 522, p. 342-352, 2010.

SUKRI, S. M. et al. Green composites based on recycled polyamide-6/recycled polypropylene kenaf composites: mechanical, thermal and morphological properties. Journal of Polymer Engineering, v. 32, p. 291-299, 2012.

SURYANEGARA, L.; NAKAGAITO, A. N.; YANO, H. The effect of crystallization of PLA on the thermal and mechanical properties of microfibrillated cellulose-reinforced PLA composites. Composites Science and Technology, v. 69, p. 187-1192, 2009.

VALÊNCIO, N. (2012). Montadoras de veículos de produções menores, como caminhões e utilitários, começam a empregar mais o plástico em suas peças e componentes. Disponível em:

<http://www.plastico.com.br/reportagem.php?rid=890>. Acesso em: 30 Abr. 2013.

YANG, H. S.; GARDNER, D. J.; NADER, J. W. Characteristic impact resistance model analysis of cellulose nanofibril-filled polypropylene composites. Composites: Part A, v. 42, p. 2028-2035, 2011.

ZHANG, QX. et al. Multiple Melting and Crystallization of Nylon-66/Montmorillonite Nanocomposites. Journal of Polymer Science: Part B: Polymer Physics, v. 41, p. 2861-2869, 2003.

ZHANG, X. et al. Thermal and crystallization studies of nano-hydroxyapatite reinforced polyamide 66 biocomposites. Polymer Degradation and Stability, v. 91, p. 1202-1207, 2006. 


\section{APÊNDICE A - CURVAS DSC PARA AS AMOSTRAS OBTIDAS COM PA66Rec}

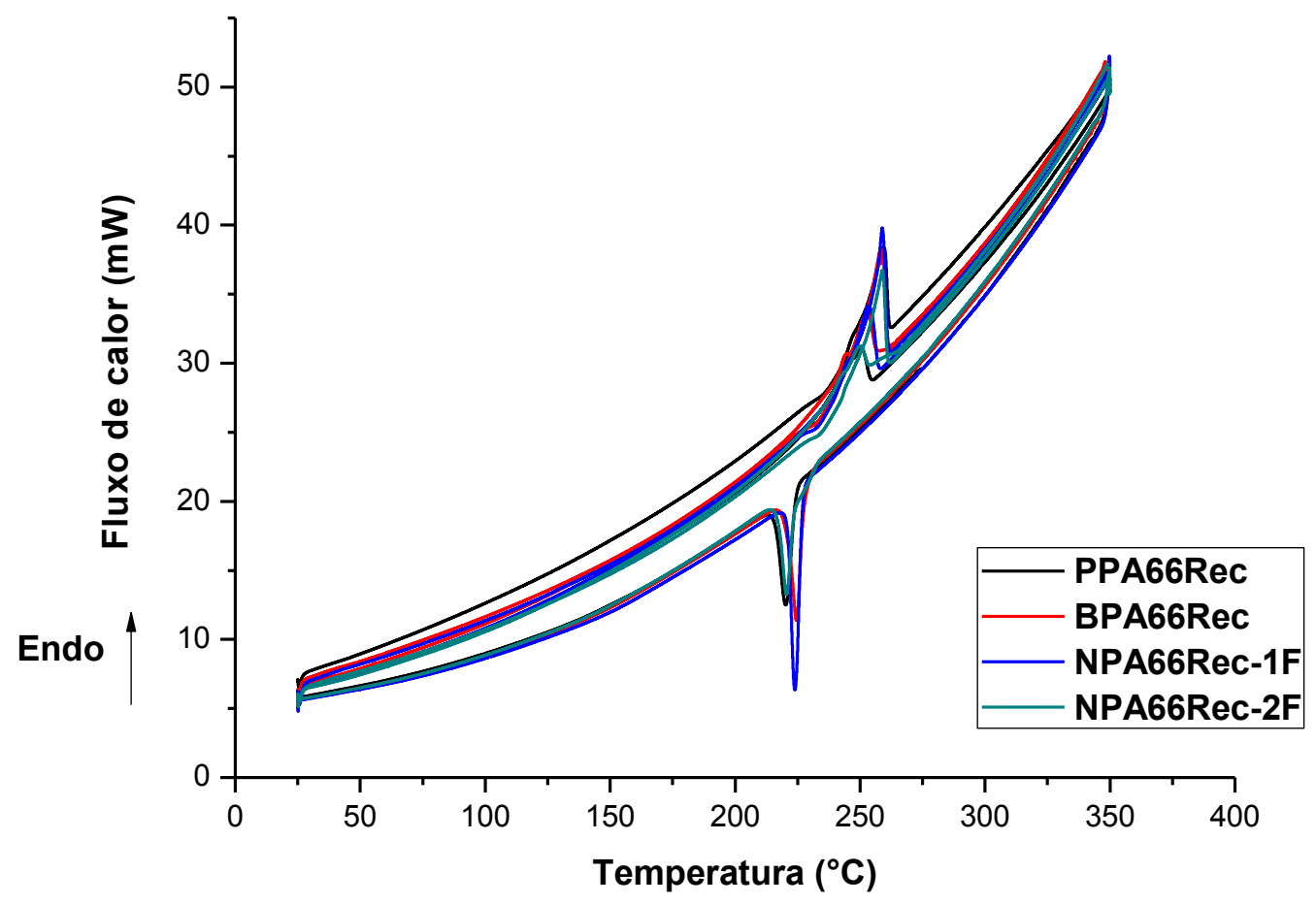

Figura 1A. Curvas DSC para as amostras obtidas com PA66Rec.

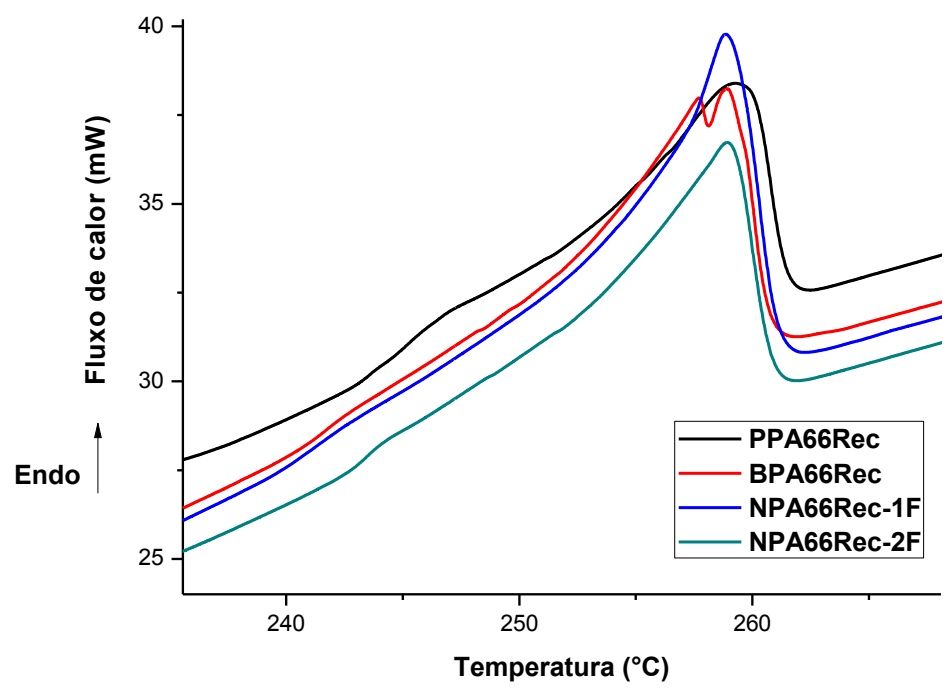

Figura 2A. Curva do primeiro aquecimento do DSC das amostras obtidas com PA66Rec. 


\section{APÊNDICE B - CURVAS DSC PARA AS AMOSTRAS OBTIDAS COM PA66}

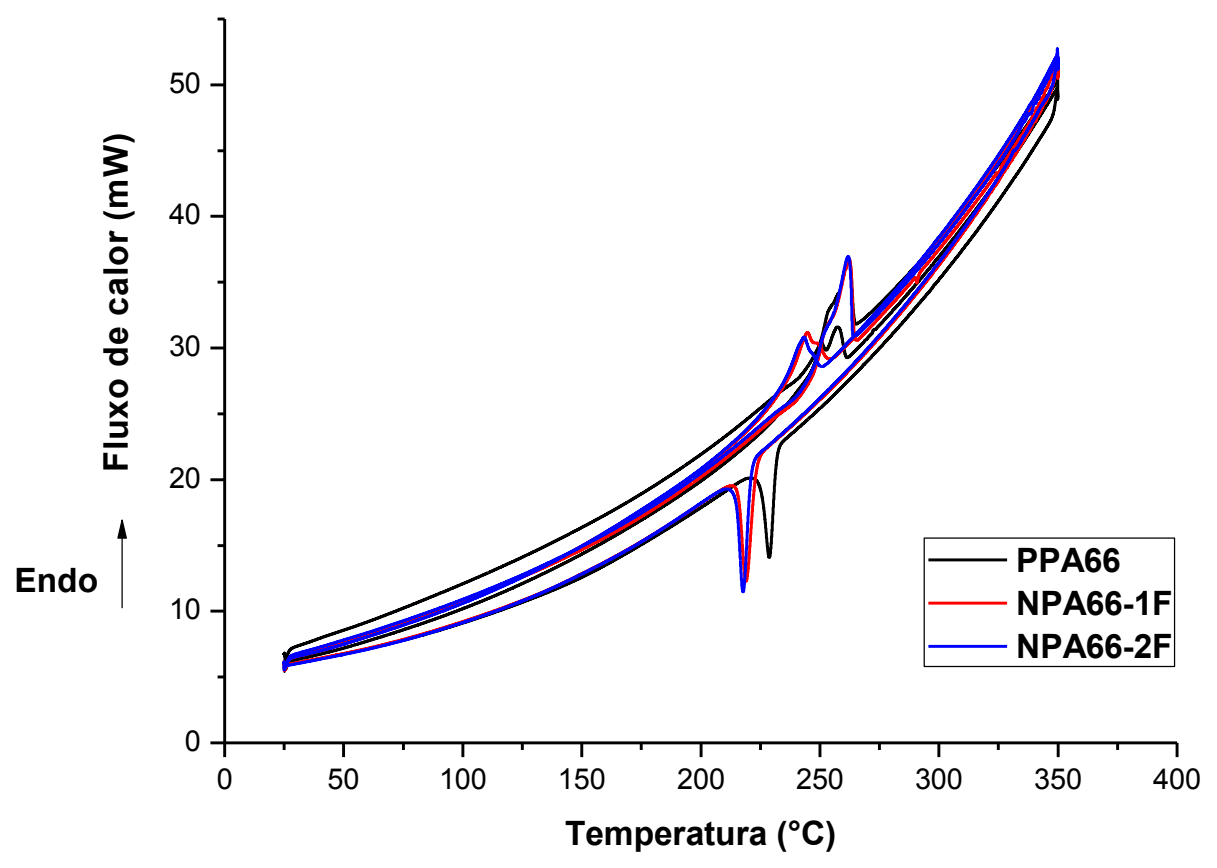

Figura 1B. Curvas DSC para as amostras obtidas com PA66.

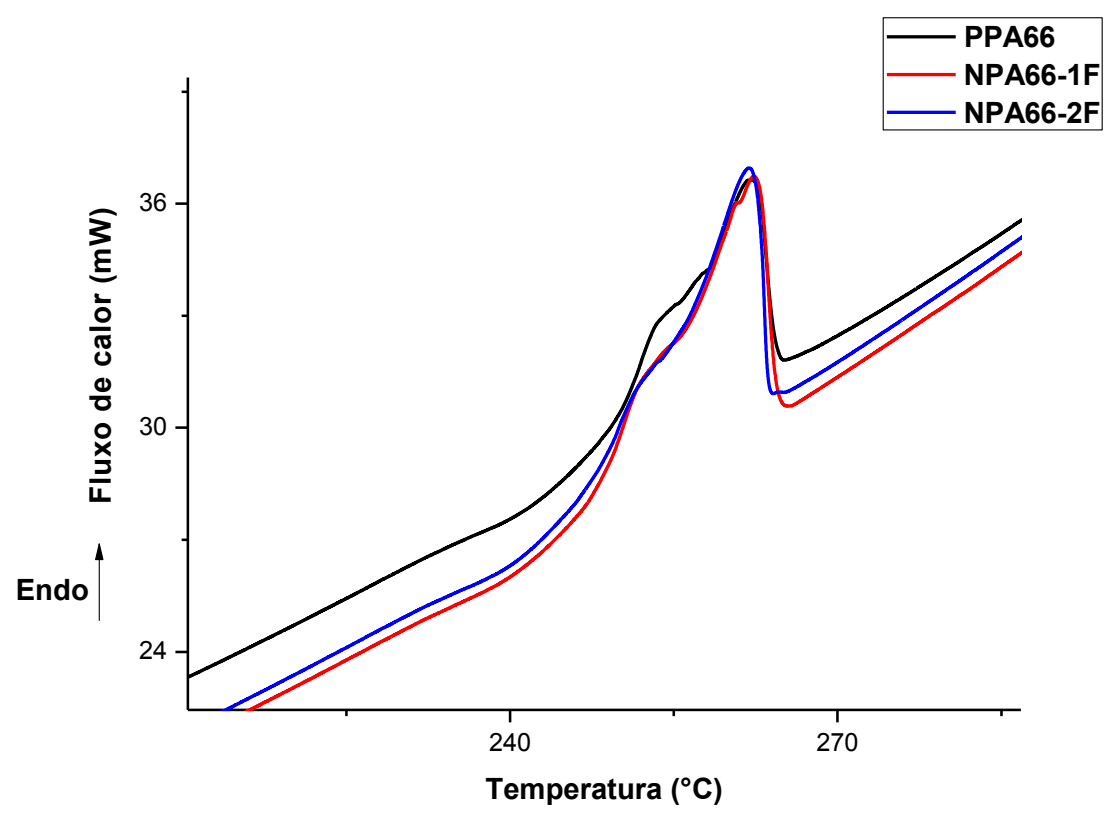

Figura 2B. Curva do primeiro aquecimento do DSC das amostras obtidas com PA66Rec. 